\title{
A STUDY TO ASSESS THE APPLICATION OF SHADOW PRICING TECHNIQUES TO NATIONAL ENERGY RESOURCE PLANNING YEAR I FINAL REPORT
}

June 1976

Submitted to:

THE NATIONAL SCIENCE FOUNDATION

RANN PROGRAM

Under NSF Agreement SIA74-02555-01

(formerly AG-501)

ECONOMIC ANALYSIS DIVISION DEPARTMENT OF APPLIED SCIENCE BROOKHAVEN NATIONAL LABORATORY UPTON, NEW YORK 11973
W. AVERELL HARRIMAN COLLEGE

FOR URBAN AND POLICY SCIENCES STATE UNIVERSITY OF NEW YORK AT STONY BROOK STONY BROOK, NEW YORK 11798 


\section{DISCLAIMER}

This report was prepared as an account of work sponsored by an agency of the United States Government. Neither the United States Government nor any agency Thereof, nor any of their employees, makes any warranty, express or implied, or assumes any legal liability or responsibility for the accuracy, completeness, or usefulness of any information, apparatus, product, or process disclosed, or represents that its use would not infringe privately owned rights. Reference herein to any specific commercial product, process, or service by trade name, trademark, manufacturer, or otherwise does not necessarily constitute or imply its endorsement, recommendation, or favoring by the United States Government or any agency thereof. The views and opinions of authors expressed herein do not necessarily state or reflect those of the United States Government or any agency thereof. 


\section{DISCLAIMER}

Portions of this document may be illegible in electronic image products. Images are produced from the best available original document. 
BNL 50537

[General, Miscellaneous, and

Progress Reports (Nonnuclear) - TID-4500]

\section{A STUDY TO ASSESS THE APPLICATION OF SHADOW PRICING TECHNIQUES \\ TO NATIONAL ENERGY RESOURCE PLANNING \\ YEAR I FINAL REPORT}

by

Harold Abilock

Larry Bodin Joseph Indusi
William Marcuse

Robert Nathans

Yasuko Sanborn

Raymond Tessmer

June 1976

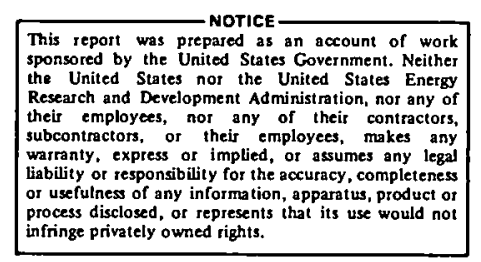

Submitted to:

THE NATIONAL SCIENCE FOUNDATION

RANN PROGRAM

Under NSF Agreement SIA74-02555-01

(formerly AG-501)

ECONOMIC ANALYSIS DIVISION

DEPARTMENT OF APPLIED SCIENCE

BROOKHAVEN NATIONAL LABORATORY

UPTON, NEW YORK 11973
W. AVERELL HARRIMAN COLLEGE

FOR URBAN AND POLICY SCIENCES

STATE UNIVERSITY OF NEW YORK AT STONY BROOK STONY BROOK, NEW YORK 11798 


\section{ADDITIONAL.}

CONTRIBUTORS:

ENERGY DATA AND MODELS GROUP

TECHNOLOGY ASSESSMENT GROUP

\section{DEPARTMENT OF APPLIED SCIENCE BROOKHAVEN NATIONAL LABORATORY}

This report was sponsored by the National Science Foundation. Views and conclusions expressed herein should not be interpreted as the official opinion of the sponsoring agency. 


\section{Abstract}

A Dynamic Energy System Optimization Model is described which can analyze optimal allocation of exhaustible energy resources over time. It is a multi-period representation of the nation's energy supply and utilization system which . incorporates cost and time elements associated with new capital facilities, the discount rate, internal selection of new energy technologies, and internal determination of primary energy resource allocation over time.

Two demonstration applications of a single period energy model are also presented. The first estimates benefit cost ratios for federal $R$ \& $D$ investment in high Btu coal gasification technology. The second evaluates the economic impact of a sulphur dioxide emission constraint in certain end uses. 


\section{Executive Summary}

A new analytic tool - the Dynamic Energy System Optimization Model - has been developed to investigate optimal allocation of exhaustible energy resources over time. This multi-period representation of the nation's energy supply and utilization system has the following distinct advantages over Brookhaven's single period model:

- Explicit treatment of cost and time elements involved in the construction of new capital facilities;

- Introduction of the discount rate as a policy parameter;

- Internal determination of when and to what extent new energy technologies can be economically introduced;

- Internal determination of optimal resource allocation patterns over time.

This tool greatly enhances one's ability to assess timebased constraints on fossil fuel supplies, construction of new capital facilities, and introduction of new, capital-intensive synthetic fuel technology. It should prove extremely useful in the evaluation of alternative energy R\&D policies and policies concerned with conservation of scarce, exhaustible energy resources.

Because this analytic model is still under development, two demonstration applications have been made with a more limited, single period energy model. They provide examples of what might be done when the multi-period model development is complete.

The first application estimates benefit-cost ratios for federal R\&D investment in hiyl Dtu coal gasification technology.

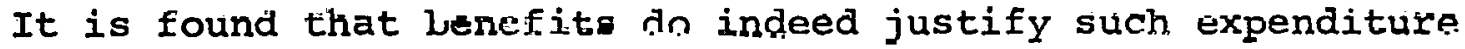
under current price expectations. However, they ale jensitive to the amount of natural gas produced domestically or imported in the future. The interconnection between R\&D policy to develop coal gasification and federal policieg on natural gas production, importation and pricing thus becomes apparent.

The second application evaluates the economic impact of a sulphur dioxide emission constraint in certain end uses. An upper bound on the economic cost of this constraint is estimated by the use of shadow pricing techniques. This can be used to help determine if new pollution abatement equipment will be installed or if firms will shift to "cleaner" synthetic fuels.

Having demonstrated the usefulness of a multi-period energy optimization model and shadow pricing techniques for evaluation of energy system constraints, the importance of continuing the development of the dynamic model and in applying it to federal energy policy becomes apparent. 
CONTENTS

Page

I. Introduction. . . . . . . . . . . . . . . . 1

II. Summary of Results. . . . . . . . . . . . . . . 3

III. Demonstration of the Use of Shadow Prices

for R\&D Selection and Evaluation . . . . . . . . . 9

IV. User Instructions for Evaluation of Federal

Energy R\&D Programs. . . . . . . . . . . . . 31

V. Demonstration of the Use of Shadow Prices

for Evaluating the Impact of Environmental

Controls . . . . . . . . . . . . . . 37

VI. Development of the Dynamic Linear Programming

Model. . . . . . . . . . . . . . . 54

Appendix A - Analytical Methodology for Evaluating

R\&D in New Energy Technologies . . . . . . . . . 117

Appendix B - Description of the Dynamic Energy System

Optimization Model (DESOM) . . . . . . . . . . . 125

References. . . . . . . . . . . . . . . 148 


\section{LIST OF FIGURES}

Fiqure No.

Title

Page

1

Expected Benefits From High BTU Coal Gasification. . . . . . . . . . . . 23 Sensitivity of Benefit/Cost Ratio... . . . 27 Sensitivity of Benefit/Cost Ratio to Future Oil Price. . . . . . . . . . . 30

Increase in System Cost vs. Reduction

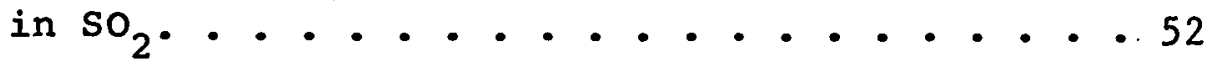
Current Market Supply and Demand for a Resource. . . . . . . . . . . . . 55

optimal Market Supply and Demand for a Scarce Rejource. . . . . . . . . . . . 56 Energy Resource Consumption . . . . . . . 68 Energy Resource Consumption . . . . . . . . 70 Electricity Production by Fuel Used . . . . 73 Electricity Generating Capacity . . . . . . 80 Annual Fuel Use to Meet Auto and Water. Heat Demands . . . . . . . . . . . . . . . 87

Márket clearing Price vs. Projected Market Price for Coal. . . . . . . . . . . . 95

Market clearing Price vs. Projeoted Market Price for Oil . . . . . . . . . . . . 97 Market Cleariny Price $\gamma^{s}$. projected Market Triuo for Natural Gas . . . . . . . . . . 98ષ Market clearing Price vs. Projected Price for Uranium . . . . . . . . . . . . . 100 Imputed Market clearing Prices for Plutonium and $\mathrm{U}-233$. . . . . . . . . . . . . . . 101 Supply Technolugieo in short supply - Shadow Prices (Upper Curve) vs. Cost (Lower Curve) ...104 Desirable Supply Technologies - Shadow Prices (Upper Curve) vs. Cost (Lower Curve). . . . .106 Marginal Supply Technologies - Shadow Price vs. Cost. . . . . . . . . . . . . . . 108 Unattractive Supply Technologies (Shadow Price vs. Cost) .110 


\section{LIST OF FIGURES (con't $t$ )}

Figure No.

Title

Page

A-1

Energy System Benefit from a New

Technology. . . . . . . . . 121

B-1

Reference Energy System, Year 2000. . . . 143

B-2

BESOM Supply/Demand Categories. . . . . . 144

B-3

Coal sector . . . . . . . . . 145

B-4

oil sector. . . . . . . . . . 145

B-5

Renewable Energy Sector . . . . . . . 146

B-6

Natural Gas Sector. . . . . . . . 146

B-7

Electrical Storage Sector . . . . . 147

B-8

Nuclear Sector.

-. 147 


\section{IIST OF TABLES}

Table No.

Title

Page

1

2

3

4

5

6

7

8

10

11

12

13

14

15

16

17

18

19

20

Proposed Federal Research Expenditure on

High BTU Coal Gasification (millions). . . . 14

Expected Energy Savings from High BTU Coal

Gasification (bililions). . . . . . . . . 22

Sensitivity of Benefits to Future Natural

Gas Supply . . . . . . . . . . • . 25

Sensitivity of Benefits to Future Oil Prices . 29

Expected R\&D Results - Energy Conversion

Process Data . . . . . . . . . . 33

Additional Data. . . . . . . . . . . 34

Expected R\&D Results - End Use Device Data . . 35

Antioipated F'ederal Expenditures for R\&D

Result \#

1985 Base Case Results. . . . . . . . . . 4h

Case I - Reduction in $\mathrm{SO}_{2}$ for Fuels Meeting

Process Heat Demand . . . . . . . . . . 48

Case II - Reduction in $\mathrm{SO}_{2}$ for Fuels Meeting

Process Heat Demand with $\mathrm{SO}_{2}$ Emissions Con-

stant for $\mathrm{All}$ other Demands ${ }^{2}$. . . . . . 50

Resources Consumed for Case 7 of Table 11. . . 51

Primary Pufl. Supply Constraints $\left(10^{15}\right.$ DTU) . . 64

Supply Conversion Device Constraints

(Appropriate units/yr) . . . . . . . . 65

Total Resource Consumption . . . . . . 69

Resource Use... . . . . . . . . . . . 71

Elactrisity production $\left(10^{9} \mathrm{KWHr}\right) . . . . .74$

Annual Production and Use of Nuclear Fuels

(Tonnes Fissile) . . . . . . . . . 75

Installed Electricity Generating Capacity

(Nominal l000MW(e) plants) . . . . . 78

Installed Production Capacity for selected

Non Electrical Supply Technology (No. of.

nominal plants). ............ 79 


\section{IIST OF TABLES (con't)}

Table No.

Title

Page

21

Capital Investment Requirements (Billions of 1970 dollars per year) • • • . 82

22

Fuel Mix to Meet Energy Demands

$10^{15} \mathrm{BTU} / \mathrm{Yr}$. . . . . . . . . . . 86

23

Shadow Prices on Growth . . . . . . . . 113

24

Shadow Prices of Demands $\$ / 10^{6}$ BTUs . . . . 116

25

Implicit Prices for Energy Purchases. . . . 116 


\section{Introduction}

With increasing scarcity of fossil fuels the national energy supply, distribution, and demand system will experience a reallocation of resources in order to meet future consumer demand. Cheaper resources will be substituted for increasingly scarce and costly ones, capital investment will shift to new technology, and consumer demand patterns will respond to relative price changes.

Improved estimates of probable change will greatly assist long range planning, policy analysis, and decision making. Questions to be faced include allocation of federal research and development funds among potential energy technolgies, minimization of environmental degradation, decreased dependence on foreign energy supplies, and effects of various energy pricing policies.

Scarce resources will conslrain present or future usage and encourage introduction of new technologies. Alternatively, capital limitations may constrain plant expansion. These constraints can be evaluated with the aid of an optimization model. Each constraint in an optimization model generates a shadow price if the constraint is indeed binding on an optimal solution. A shadow price, in effect, indicates 
the benefit or cost* associated with a given unit change of that constraint. In the case of an energy resource, it is indicative of the incremental premium or "economic rent" that can be extracted because the resource is scarce. Under fairly specific conditions it can be shown that markets allocate resources efficiently. Unfortunately, a full set of markets is not available for most goods. Markets are concentrated in tho piesent, so snly a very small fraction of energy resources are actually allocated over time by markets. The main missing element in markets, according to William Nordhaus (1, pp. 560-561), is the setting of the correct scarcity rent or shadow price on different resources. This crucial calculation is most important for nonrenewable resources such as oil, gas, and uranium. The purpose of this study is, therefore, to establish techniques for estimating shadow prices within a dynamis - time framowork and for. utilizing this information in energy planning and policy analysis.

*If the hinding constraint is on available supply, an additional unit of supply would dectease total cost, and one could interpret this as a benefit. It tho constraint indicates demand for a good, an additional unit of demand would increase total cost, and one could interpret this change as a cost. 


\section{Summary of Results}

Project work described in this report encompasses three items. The first demonstrates application of shadow pricing techniques for evaluation of R\&D investment in a new energy technology -- high BTU coal gasification. The second demonstrates the use of shadow prices for evaluating the impact of an environmental constraint. The third comprises mathematical model development -- generalization of the Brookhaven Energy System Optimization Model to multiple time periods. These items, respectively, correspond to task 1.3, to task 1.2, and to tasks 2, 3, and 4 as described in the Research Proposal submitted to the National Science Foundation (2). The remaining tasks described in the original Research Proposal are scheduled for completion under second year activity as described in (3).

On the basis of methodologies developed and in anticipation of the successful conclusion of model development under second year NSF activity, considerable interest has developed by several federal agencies and industrial groups in having the BrookliavenSUNY group apply these techniques to a number of policy related questions. In particular, the Division of Controlled Thermonuclear Research of ERDA has committed funds for assessment of the quantitative benefits from various levels of R\&D activities in this 
area. The Electric Power Research Institute has also recently approved funding for a two-year period to deal with a variety of tasks related to the electrical utility industry. Further possible applications of this methodology are being pursued with other Divisions in ERDA, the Department of the Interior, and $E P \dot{A}$.

Item 1 - R\&D Investment in Coal Gasification

In the first completed task; federal R\&D expenditure to develop technology for converting coal to pipeline quality gas is evaluated by use of a cost/benefit analysis. Benefits are measured in terms of total energy system cost reduction resulting from the new technology. Coal gas is evaluated in competition with other new technologies such as the combined cycle power plant, nuclear reactors and oil shale as well as with existing fossil fuel technologies. The major analytical tool employed is the Brookhaven Eneryy System Optimization Model, and this is described in detail in (9).

Under the most probable estimates for future supplies and costs of competing resources and technologies, it is found that benefits do indeed justify federal RED expendituro on rnal gas. technology. Expected coal gas capacity is $1.1 \times 10^{12} \mathrm{ft} / \mathrm{year}$ (13 plants) in 1985 and $3.9 \times 10^{12} \mathrm{ft}^{3} /$ year $(47$ plants) in the year 2000 . 
However, benefits are extremely sensitive to the amount of natural gas which will be available for domestic use in future

years. An increase of between 10 and $20 \%$ in natural gas availability over the most probable estimates reduces the benefit/ cost ratio to the breakeven point, beyond which federal expenditures can not be justified.

High shadow prices for natural gas in future years are estimated by the constrained optimization model. This indicates strong market forces to expand domestic production, to expand imports of liquified natural gas, and to deregulate interstate gas prices. If a federal commitment to coal gas technology is made it will be imperative to coordinate this policy with federal policy on natural gas production, importation and pricing. To support both coal gasification technology and a maximum increase in natural gas supply would be counterproductive.

Future oil prices also effect the benefit/cost ratio for coal gas. If the price of imported oil, in real terms, remains close to its present value benefits due to cnal gao will increase. Additional pipeline gas can economically be substituted for higher priced oil in more uses, and the coal gas benefit/cost ratio will not be as sensitive to natural gas availability. 


\section{Item 2 - Evaluation of an Environmental Constraint}

This task demonstrates the utility of shadow pricing techniques in reflecting the economic impact of environmental constraints. The demonstration case considered here was imposition of a restriction on the amount of sulfur dioxide released by plants producing their own process heat for various industrial and commercial processes.

It is firot shown that imposition of a sulfur dioxide emission constraint càuses a shift to "cleaner" fuel use by plants producing their own process heat. However, use of less desirable fuels, in terms of air pollution, increases in other parts of the energy system.

An additional constraint is then added which still requires cleaner fuel use for process heat production, but with no increase in air pollution from the rest of the energy system. Reduction of sulfur dioxide emissions is achieved by the use of coal gas and slightly more oil as opposed to direct use of coal in bôllerṣ. The increase in energy cost due to reduction of sulfur dioxide emission establishes an upper bound on the cconomic rost of this constraint. If pollution abatement equipment is available which can rcduce emissions at lower cost, it will be cheaper to continue using more dirty fuels than synthetie gab, and the sost of the environmental constraint will be less than that which has been calculated. 
Item 3 - Development of a Multiple Time Period Energy Model

A dynamic version of the Energy System Optimization Model has been formulated and the first demonstration runs completed. In addition to being able to provide information on the present worth of future availability of scarce energy resources, this model has the following distinct advantages over the single period model. It allows:

1) the explicit treatment of cost and time elements involved in the construction of new capital facilities;

2) the explicit introduction of a discount rate as a policy parameter;

3) the internal determination of when and to what extent new energy technologies can economically be introduced; and

4) the use of total resource availability as a constraint and internal determination of optimal consumption pattcms over time.

As a result, future applications of this model will permit the estimation of present and future shadow prices of constrained resources with appropriate discounting at one point in time for comparative purposes. 
Necessary data inputs have been developed for optimization over four time periods extending from 1985 to the year 2000. The beginning and end period solutions of the model have been calibrated to two base cases in an earlier BNL study (4) which were established from solutions of the single period Brookhaven Energy System Optimization Model.

The model generates four different kinds of shadow prices. One of these is uniquely related to onergy resources, one uniquely related to energy capacity; one related to both energy capacity and energy resources, and one related to energy demands. These shadow prices represent the decrease in total energy system cost if one more unit of a constrained, scarce supply is available or if one less unit of demand for energy has to be met. 
III. Demonstration of the Use of Shadow Prices for R\&D

\section{Selection and Evaluation}

A. Introduction

Prior to the Energy Crisis of 1973-74 many people believed fossil and nuclear fuel resources to be inexhaustible in the foreseeable future. Recent events question this hypothesis, and there is growing concern about meeting the nation's energy needs throughout this century. Nuclear energy is pushed as the solution by its proponents, advocates speaking for coal say it is the better answer, and still others insist that renewable energy resources such as solar and fusion are the long term solutions.

Alternative energy technologies to natural gas and oil are, for the most part, in the developmental stage. A major research and development effort is required to bring reliable production plants on stream and to minimize environmental degradation. Because of the large financial and time commitments involved, federal support, both in monetary and policy commitment, is necessary. The immediate question then becomes which future technologies should be supported by the federal government and to what extent?

It is obvious that any single new technology cannot be 
evaluated in absence of competing technologies including existing fossil and nuclear fuel conversion processes and potential new technologies such as oil shale and solar energy. A unique capability exists at Brookhaven National Laboratory for making such a comparison, the Brookhaven Energy System Optimization Model (BESOM). This is a linear programming representation of the national energy supply, conversion and distribution system that minimizes total cost. It specifically determines when and to what extent a new technology can competitively enter into the energy system, the cost savings that result, and sensitivity of these savings to assumptions ahnut. future supply and price of competing resources and technologies. It is only with a comprehensive model of the nation's energy system such as BESOM that crediblo results can be obtained.

Benefits accruing to a new technology, in this case high BTU coal gasification, are estimated by solving the model for the optimal energy system configuration in future years both with and without coal gasificatiur capacity. ralculated savings (benefit.s) are then discounted back to the present and compared with federal $R \& D$ expenditures (cost) needed to achieve that 
coal gas capacity. ${ }^{1}$ The resulting benefit/cost ratio is a measure of whether or not this R\&D program can be justified.

Succeeding sections describe data sources and assumptions and the sensitivity of the estimated benefit/cost ratio to future supply of natural gas, future oil prices, and the discount rate. Analytical methodology is described in Appendix A.

Although the results of this specific application and the associated policy implications are of interest, this study was performed to demonstrate methodology rather than piovide information to assist an R\&D decision maker. The inputs to the study were not discussed with the agency having responsibility for coal gasification R\&D nor were the estimates of technical risk generated by that agency. For an actual application, cost, schedule and technical risk would have to be supplied by the decision maker as would ranges on these inputs if sensitivity analyses are considered necessary.

Now that this tool has been demonstrated, studies similar to this one can be performed for specific R\&D projects under

1. This analysis evaluates expected results from a single R\&D policy decision. Generalized methodology for evaluating multiple decisions with more than one possible outcome has been developed by Dr.Edward Berman of MITRE Corporation, consultant to BNL on this project. In this case a decision tree is formulated which shows the time phasing of decisions and all possible results or outcomes for each decision. Outoomes are stated in terms of technical efficiency, capacity, cost of production, and/or additional required R\&D costs along with the probability of achieving each outcome. 
the direction of project managers. Under such circumstances the data will be the best available and the technical estimates of optimistic and pessimistic outcomes will be based on the best available knowledge. A useful piece of work as an extension of this project would be to identify a specific user and apply the methodology to a key decision faced by that user.

\section{B. Objective}

The specific objective of this task is to establish a workable framework for evaluating a single R\&D activity. Quantitative estimates of the benefits resulting from successful R\&D programs will greatly assist decisions regarding research fund allocation.

The first question to be answered is how to evaluate expected $R \& D$ benefits with the Brookhaven Energy System Optimization Model (BEsom). Appondix A describes the methodology which has been developed.

The second question is how to incorporate parameters which cannot be estimated for the future with certainty. For example, if the future price of a resource is critical to a project's expected benofit and future prices are uncertain, this factor should be incorporated in the evaluation structure. similar uncertainties exist with respect to technical efficiencies and 
system costs.

In order to increase computational efficiency when investigating uncertainty a secondary objective was adopted. This was to solve BESOM with a more versatile algorithm on the stony Brook University computer.

within such a framework for dealing with research risk and other uncertainties one will be able to evaluate alternative R\&D funding strategies for various mixes of technological development.

c. Research Cost

Federal funding for energy research and development has been proposed for fiscal years $1975-79(5, p .6)$. Funds directly attributable to high BTU coal gasification are identified and listed in Table 1. These funds, discounted to 1970, establish research cost, the term used in this report to denote federal R\&D investment in coal gasification technology. In 1970 dollars they total $\$ 514,300,000$.

The following assumptions regarding research cost have been made:

1. Expenditure of federal funds is required to insure development of adequate pollution controls and pro- 
Table 1

PROPOSED FEDERAL RESEARCH EXPENDITURE ON HIGH BTU COAL GASIFICATION (millions)

FY 75 FY 76 FY 77 FY 78 FY 79 Total

Task $3 \lambda$ gasifjçation Process $\begin{array}{llllll}35.0 \quad 75.0 & 92.0 & 81.0 & 57.0 & 340.0\end{array}$

Task 3B Pioneer Plant Program $\begin{array}{llllll}33.3 & 33.3 & 18.3 & 16.7 & 18.7 & 118.3\end{array}$

Task 3C Environmentäl Contrọl Technology $\begin{array}{llllll}23.3 & 16.7 & 14.0 & 15.0 & 17.7 & 86.7\end{array}$

Task 3D supporting R\&D $6.7 \quad 7.3 \quad 8.0 \quad 9.0 \quad 9.0 \quad 40.0$ Total (1973 dollars) $\begin{array}{llllll}98.3 & 132.3 & 132.3 & 121.7 & 100.4 & 585.0\end{array}$ Total (1970 dollars) ${ }^{2}$ 514.3 Present Value (discounted-1970 @4\%) 391.7

Present Value (discounted-1970 @6\%) 343.3

Present Value (discounted-1970 @8\%) 302.0 Present Value (discounted-1970 @10\%) 266.2

2, A GNP deflator of .879 ig uspa, per (6). 
cesses which can use caking as well as non-caking coals. without federal commitment, timely installation of sufficient coal gas capacity will not occur and environmental degradation will not be minimized.

2. Private industry investment can be assured through the use of guaranteed prices or loans as incentives. Companies will finance their own portion of the R\&D out of current operations.

3. 1975-79 expenditure proposals are stated in 1973 dollars.

4. One third of the expenditures listed in $(5, p .29)$ for the pioneer plant program, environmental control technology and supporting R\&D can be assigned to coal gasification. These expenditures will be common to the low and high BTU gasification programs and to the coal liquefaction program.

\section{Expecited Results from R\&D}

Precise estimates of the production cost of synthetic natural gas are difficult to make. The exact technology which will be most economical and methodo to minimize environmental pollution have yet to be determined. Pröduction costs in this analysis are 
therefore based on an established technology--the Lurgi fixed-bed process. Although commercial plants do not currently exist in the U.S., several construction proposals have been filed with the Federal Power Commission. Production cost estimates (7, p.102) for gasification of Western $\operatorname{coal}^{3}$ have been adjusted upward to reflect the latest capital cost estimates by El Paso Natural Gas (7,pp.101-2) and they range from $\$ 1.12-1.34 / \mathrm{million}$ BTU in 1970 dollars. 4

Earlier estimates of production costs are now known to have been grossly understated, and there is no way to be certain that present estimates, although much higher, may not still be too low. On the other hand, some of the newer gasification processes now in the pilot plant stage might result in lower costs. In addition, they would overcome a requirement restricting installation of the Lurgi process--the necessity for a non-caking, sized fieed wal.

The Brookhaven Optimization Model utilizes cost data on the basis of 1970 dollars. Therefore, no correction is needed

3. $21 \% / \mathrm{mill}$ ion $\mathrm{BTU}, 19 \mathrm{million} \mathrm{BTU} / \mathrm{ton}, \$ 4 / \mathrm{ton}(1 \mathrm{n}$ constant 1970 dollars). This is the average coal cost cotimater in $(8, p .168)$.

4. A GNP deflator of .879 is used to convert 1973 costs to 1970 costs. A $15 \%$ rate of return on investment is assumed, not utility-type financing which would lower cost estimates somewhat. coal conversion efficiency of $65 \%$ and plant opcrating factor of 0.9 are assumed. 
for the El Paso Natural Gas synthetic gas cost estimates of $\$ 1.12 / \mathrm{million}$ BTU for the lower cost estimate (Case I) and $\$ 1.34 / \mathrm{million}$ BTU for the higher cost estimate (Case 2). Simulation of the year 2000 is made with 1970 costs of $\$ 1.24 / \mathrm{million}$ BTU for the low estimate and $\$ 1.46 / \mathrm{million}$ BTU for the high estimate, assuming less accessible and, therefore, more costly coal. Percentage increase in coal cost is consistant with that used in Brookhaven's electrification study (4). Capital construction, operating, and distribution costs for coal gas are assumed constant in terms of 1970 dollars for the years 1985 and 2000.

Specification of $R \& D$ results also requires estimates of feasible coal gas capacity. The National Petroleum Council, upon investigation of coal reserves and future utilization, has made such estimates (8,pp.167-8). Assuming maximum governmental incentive to private industry, a total of 30 plants is feasible for 1985 with a combined capacity of $2.56 \times 10^{15}$ BTU/year. For the year 2000 it is presumed that Weotern voal reserves available for synthetic fuel plants can be fully utilized, resulting in 47 gas plants with a capacity of $4.01 \times 10^{15}$ BTU/year (8, p.164). Even though limited water supply may reduce western coal availability, there is a good chance that research will establish 
processes capable of using Eastern coals. The federal R\&D program thus gives a better guarantee that capacities assumed in this analysis are feasible. If this evaluation were done with the agency responsible for coal gas $R \& D$ these inputs would reflect their best judgement.

Expected results of $R \& D$ are thus stated in terms of feasible capacity limits and production costs expected in future years. Two possible outcomes are assulied. Froduction onsts differ for each alternative, but feasible capacity limits are the same.

Two assumptions are implied by the specification of $\bar{R} \& D$ results:

1. That coal gas capacity is independent of the level of federal R\&D expenditure; and

2. Coal gas capacity is independent of shadow prices. 
E. Research Benefit

Optimization model results for case \#l, the low estimate of coal gas cost, indicate total energy system savings of $\$ 170$ million in 1985 and $\$ 5.15$ billion in the year $20000^{5}$ In 1985 about $90 \%$ of available capacity is utilized $\left(2.2 \times 10^{12}\right.$ $f t^{3} /$ year, or 27 plants). No shadow price is generated because coal gas capacity is not a binding constraint. In 2000 all of the available capacity is used $\left(3.88 \times 10^{12} \mathrm{ft}^{3} /\right.$ year, or 47 plants), and a shadow price of $\$ .96 / 10^{6}$ Btu is generated. By way of comparison, the shadow price of natural gas is $\$ .70 / 10^{6}$ Btu in 1985 and $\$ 1.69 / 10^{6}$ Btu in 2000 .

Optimization model results. for case \#2, the high estimate of coal gas cost, indicate total savings of $\$ 4.37$ billion in the year 2000, but no saving in 1985. All of the capacity would be used in 2000, but none of it in 1985 at the high cost of production. By way of comparison, the shadow price of natural gas is $\$ .78 / 10^{6}$ Btu in 1985 and $\$ 1.69 / 10^{6}$ Btu in 2000 .

Given equal probabilities of achieving case \#l and case \#2 results, expected energy system savings are $\$ 84$ milion in 1985 and $\$ 4.76$ billion in 2000. These savings are the measure of research benefit in two future years. The expected number of 5. Note: All prices and savings are measured in terms of 1970 dollars. 
plants, in this instance the average of the number of plants predicted with low and high production costs, is 13 plants of $250 \times 10^{6} \mathrm{ft}^{3} /$ day capacityceach in 1985 and 47 plants in 2000. Thirteen operational plants in 1985 does not appear unreasonable since plans for constructing at least three plants have been annoùnced to date.

In all runs except one the amount of oil used for space heating decreases when coal gas capacity is added to the energy system. Either natural gas or coal gas displaces this oil. Coal gas is interchangeable with natural gas in three final demand categories--miscellaneous thermal, petrochemicals, and space heat. 6 In essence, savings in total energy cost result from the replacement of imported oil by cheaper coal gas.

Research benefit, or reduction of total energy system cost, has been determined for two future years through BESOM runs. Extrapolation of these resultc for other years up to $20 n n$ is therefore required. 7,8 An exponential distribution of annual research benefits over time has been assumed for this purpose.

6. This means that the specified supplies of coal gas and natural gas ian be arbitrarily allocated among these three uses without changing total energy system cost.

7. This problem will be alleviated when the dynamic LP model becomes opcrational. Annual research benefit for every year will be calculated by the optimal solution to this multiperiod model.

8. Benefits beyond the year 2000 have not been included because of increasing uncertainty as to how well the optimization model portrays reality. 
This implies that energy cost savings grow slowly around the year 1985 and very rapidly at the end of the century. Because the shadow price of coal gas is mugh higher in 2000 and much more attractive, economically, this assumption appears realistic.

Expected annual benefits, under the assumption of an exponential distribution, are depicted in Table. 2. Benefits prior to 1980 are not listed since the first commercial plants will not be operational much before that time. Benefits have been discounted at four discount rates in order to calculate their 1970 present value.

Benefit/cost ratios have been calculated using present values of research expenditure (Table 1) and present values of research benefit (Table 2). The benefit/cost ratio, plotted in Figure 1 against discount rate, indicates that very substantial benefits are expected from high Btu coal gasification research, even if one assumes a discount rate of 10\%. Under the assumptions incorporated in the analysis for natural gas and oil availability and price in future years, benefits of coal gas as measured in terms of savings to the nation's energy customers justify this federal R\&D investment. 
Table 2

EXPECTED ENERGY SAVINGS FROM

HIGH BTU COAL GASIFICATION '(BILLIONS)

\begin{tabular}{|c|c|c|c|c|c|}
\hline Yoax & $\begin{array}{l}\text { Anrual } \\
\text { Snvings }\end{array}$ & $\begin{array}{c}\text { Prosent } \\
\text { Value @ } 4 \%\end{array}$ & $\begin{array}{c}\text { Present } \\
\text { Value @6\% }\end{array}$ & $\begin{array}{c}\text { Present } \\
\text { Value @8\% }\end{array}$ & $\begin{array}{c}\text { Present } \\
\text { Value } 910 \% \\
\end{array}$ \\
\hline 1980 & .022 & .015 & .012 & .0110 & .008 \\
\hline 81 & .029 & .019 & .015 & .012 & .010 \\
\hline 82 & .038 & .024 & .019 & .015 & .012 \\
\hline 83 & .050 & .030 & .023 & .018 & .014 \\
\hline 84 & .065 & .038 & .028 & .022 & .017 \\
\hline 85 & .084 & .047 & .035 & .026 & .020 \\
\hline 86 & .110 & .059 & .043 & .032 & .024 \\
\hline 87 & .145 & .074 & .054 & .039 & .029 \\
\hline 88 & .190 & .094 & .067 & .047 & .034 \\
\hline 89 & .250 & .119 & .083 & .058 & .041 \\
\hline 90 & .320 & .146 & .100 & .069 & .048 \\
\hline 91 & .420 & .184 & .123 & .082 & .055 \\
\hline 92 & .540 & .227 & .148 & .098 & .065 \\
\hline 93 & .710 & .287 & .184 & .119 & .077 \\
\hline 94 & .950 & .369 & .233 & .148 & .094 \\
\hline 95 & 1.230 & .461 & .287 & .179 & .114 \\
\hline 96 & 1.600 & .575 & .349 & .214 & .132 \\
\hline 97 & 2.150 & .742 & .441 & .264 & .159 \\
\hline 98 & 2.750 & .913 & .533 & .313 & .186 \\
\hline 99 & 3.600 & 1.151 & .660 & .382 & .223 \\
\hline 2000 & 4.760 & 1.468 & .829 & .473 & .273 \\
\hline \multirow{2}{*}{\multicolumn{6}{|c|}{$\begin{array}{l}\text { Expected } \\
\text { Research }\end{array}$}} \\
\hline & it: & 7.042 & 4.266 & 2.620 & 1.635 \\
\hline
\end{tabular}




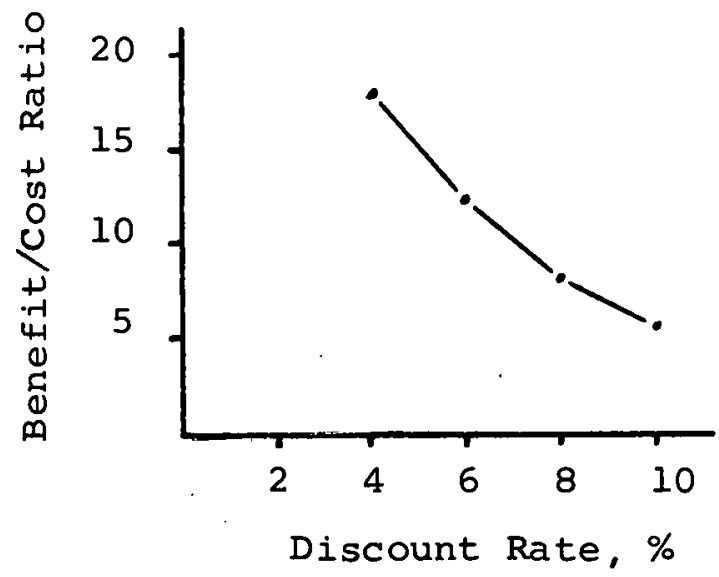

Figure 1. Expected benefits from high BTU coal gasification.

F. Sensitivity of Benefits to Future Price and Availability of Natural Gas

Because coal gas and natural gas are direct substitutes it is important to investigate the sensitivity of expected benefits to future availability and price of natural gas. In the analysis presented in the previous section natural gas wellhead prices of $\$ .443 / 1000 \mathrm{ft}^{3}$ in 1985 and $\$ .90 / 1000 \mathrm{ft}^{3}$ in 2000 are assumed. Recent intrastate and interstate pricc increases indicate that these estimates may be low. Runs have therefore been made, successively increasing the wellhead price of natural gas. Total system cost with coal gas capacity was compared with total system cost without any coal gas for each increase in the price of natural gas. 
Although one expects more coal gas to be utilized as the price of natural gas rises, resulting in increased benefits, this is not the case. Even with a wellhead price up to $\$ 1.40 / 1000 \mathrm{ft}^{3}$ slack coal gas capacity in 1985 is not utilized. (Benefits do not change since total system costs with and without this new technology increase by equal amounts as the price of natural gas rises.) The reason for this is that oil can meet direct heating and petrochemical demands more cheaply than can coal gas. With a high natural gas cost, oil displaces the gas regardless of coal gas availability. Sensitivity of research benefits to natural gas availability must also be investigated since its supply is not expected to completely satisfy demand. Table 3 ists iesearch benefits for a $3 \%$ and $8 \%$ increase in natural gas supply. With a 3\% increase in 1985 some coal gas is used in case \#l (lower snal gas cost) and none in case \#2 (higher coal gas cost). With an 8\% increase in 1985 no coal gas is used in either case. Parameterization runs for the year 2000 indicate no change in research benefits as natural gas supply is increased since all coal gas capacity is still utilized. 
Table 3

Sensitivity of Benefits to

Future Natural Gas Supply

Year

Present Value of Annual Savings, Discounted to 1970 (a) $10 \%$ (billions)

$3 \%$ Increase $^{9} \quad 8 \%$ Increase $^{10}$

1980

1981

1982

1983

1984

1985

1986

1987

1988

1989

1990

1991

1992

1993

1994

1995

1996

1997

1998

1999

2000

.006

.008

.010

.012

.014

.017

.021

.025

.030

.036

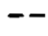

.045

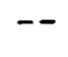

.052

--

.060

--

.075

00

.005

.006

.009

.012

.016

.022

.090

.029

.111

.040

.132

.055

.156

.075

.189

.104

.229

.138

.275

.192

.275

Total Research

Benefit

$\$ 1.593$

$\$ .981$

9. Natural Gas Supply of $29.2 \times 10^{15}$ Btu in 1985 , $35.0 \times 10^{15}$ Btu in 2000 .

10. Nalural Gas Supply of $30.6 \times 10^{15} \mathrm{Btu}$ in 1985 , $36.7 \times 1015$ Btu in 2000 . 
Corresponding benefit/cost ratios are plotted in

Figure 2 for a discount rate of $10 \%$. This ratio drops

from 6.2 to about 3.7 with only an $8 \%$ increase in natural

gas supply. ${ }^{11}$ with an increase of 10 to $20 \%$ the benefit/

cost ratio might drop below 1.0, the breakeven point for

justification of coal gas R\&D. Since the shadow price of

natural gas is so high, even a tripling of the wellhead

price of natural gas will not improve the benefit/cost

ratio as availability increases.

The extreme sensitivity of coal gasification benefits to

future natural gas supply should be recognized when establish-

ing national policy for natural gas exploration and development.

Two recent studies indicate that domestic production of natural

gas cou ld approach $33 \times 10^{15}$ Btu's annually by $1985 .^{12}$ Increased

11. Calculation of benefit/cost ratios with greater than $8 \%$ increases in natural. gas supply cannot be made at this time. Since no cual gas would be uscd in 1485, the static linear programuing model rnidd only estimate benefits for one tisture point in time--the year 2000. Extrapolatlun of annual hnnefits between 1985 and 2000 would introduce great deals of uncertainty in the results.

12. The NPC's Committee on U.S. Energy Outlook estimates maximum U.S. production of $32.9 \times 10^{15}$ Btu's in 1985 (8, p. 62). The Natural Gas Task Force estimates maximum U. S. production of non-associated gas at $24.6 \times 10^{15}$ Btu's in 1985 (Projent Independence Blueprint Report of the Natural Gas Task Force (draft)). Aasuming the same ratio of assoclated to nonassociated production as in 1973, total 1985 produation would be $33.4 \times 10^{15}$ Btu's. 
importation of foreign LNG is a second factor that could erase the competitive advantage of synthetic gas and benefits accruing to Federal R\&D expenditure on coal gasification.

A practical follow up study is investigation of the trade offs associated with increased domestic production of natural gas and coal gas versus decreased importation of foreign oil. In addition to differences in total energy cost one would be able to determine necessary price support levels.

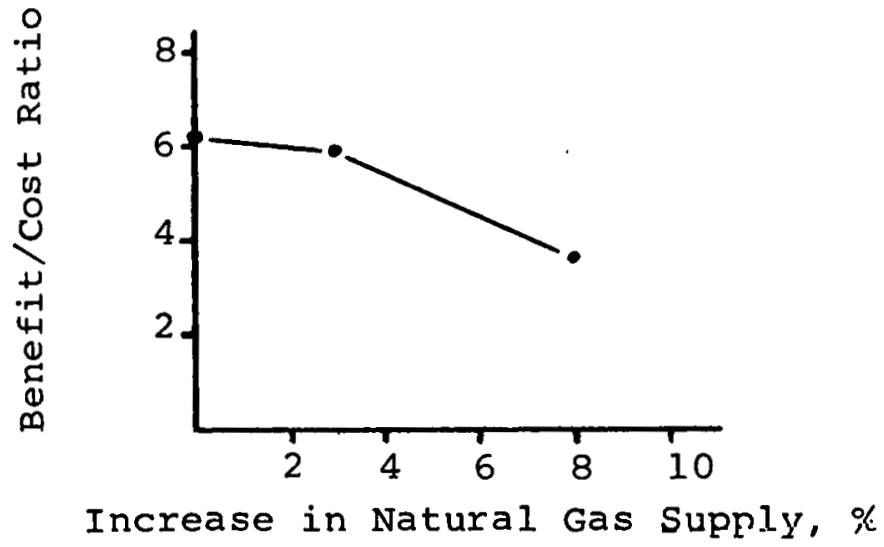

Figure 2. Sensitivity of Benefit/Cost Ratio to Future Natural Gas Supply a 10\% Discount Rate. 
G. Sensitivity of Benefits to the Future Price of Oil

The analysis presented in section $\mathrm{E}$ assumed crude oil

price at the wellhead of $\$ 6.17 /$ barrel in 1985 and $\$ 13.50 /$ barrel

in 2000 as well as unlimited availability of foreign oil. In

light of recent price increases these estimates appear to be

low. A sensitivity analysis has ther efore been made with

respect to future oil prices utilizing a mathematical programming

system algorithm (MPS) at the State University of New York at Stony Brook. This linear programming algorithm solves BESOM for successively higher costs or constraint values within the model. Results of these runs for oil base price increases of $20 \%, 40 \%$, and $100 \%$ are presented in Table 4 , assuming a $10 \%$ discount rate.

rorresponding benefit/cost ratios are depicted in Figure 3 . As the price of oil increases, coal gas benefits increase in two ways: Direct savings result because coal gas is now even llúre economical than oil, and indirect savings result because möre coal gas capacity is brought on stream. With an oil price of about $40 \%$, for instance, all of the available coal gas capacity (30 plants) is utilized in 1985 , even at the higher cost of coal gas production. 
Table 4

SENSITIVITY OF BENEFITS TO FUTURE OIL PRICES

Year

Present Value of Annual Savings, Discounted to 1970 @10\% (billions)

\begin{tabular}{rc} 
& $20 \%$ Increase \\
1980 & .092 \\
81 & .098 \\
82 & .105 \\
83 & .113 \\
84 & .121 \\
85 & .131 \\
86 & .140 \\
87 & .152 \\
88 & .161 \\
89 & .177 \\
90 & .190 \\
91 & .199 \\
92 & .215 \\
93 & .228 \\
94 & .249 \\
95 & .272 \\
96 & .288 \\
97 & .312 \\
98 & .338 \\
99 & .360 \\
2000 & .394 \\
\hline
\end{tabular}

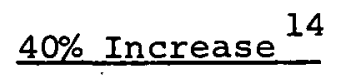

.246

.256

.261

.267

.276

.284

.294

.305

.309

.320

.327

.331

.340

.348

.370

.383

.387

.405

.422

$-.444$
.382

$100 \%$ Increase ${ }^{15}$

.293

.301

.312

.318

.329

.339

.348

.366

.378

.392

.401

.411

.418

.430

.449

.471

.477

.489

.500

.527

.554

Total

Research

Benefit

4.335

6.957

8.503

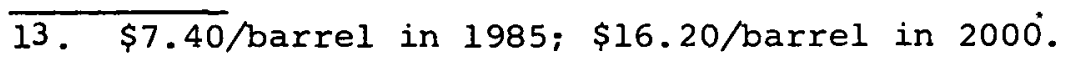

14 . $\$ 8.63 / \mathrm{barrel}$ in $1985 ; \$ 18.90 / \mathrm{barrel}$ in 2000 .

15. $\$ 12.34 /$ barrel in 1985; $\$ 27.00 /$ barrel in 2000 . 
(a) 10\% Discount Rate

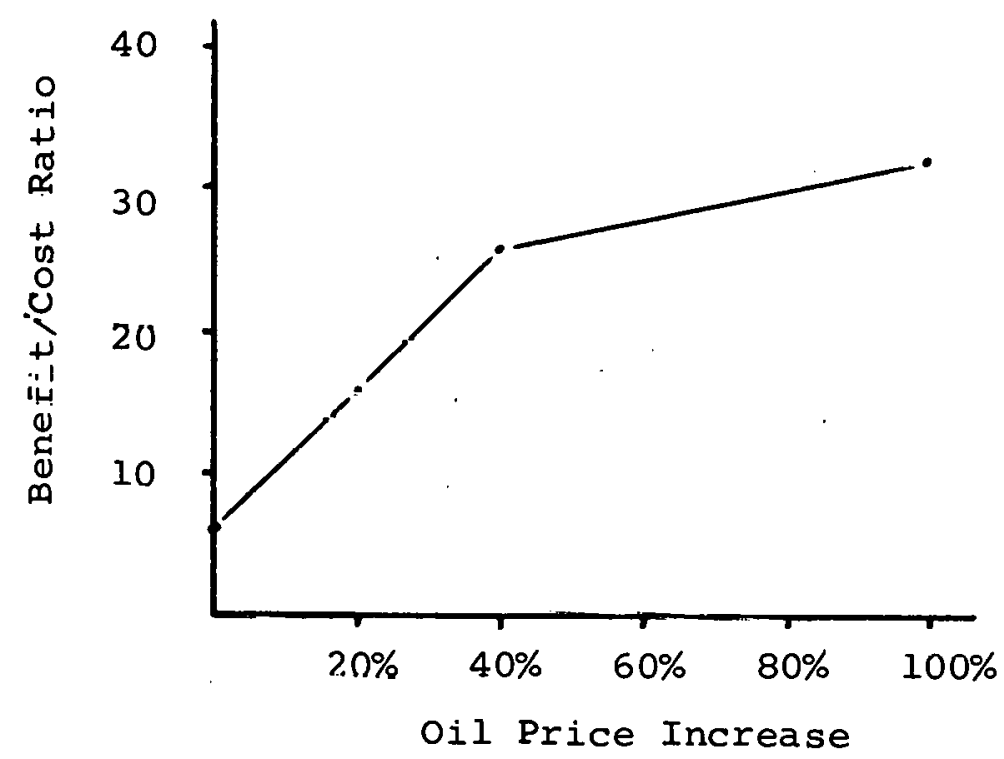

Figure 3. Sensitivity of benefit/cost ratio to future oil price. 
IV. User Instructions for Evaluation of Federal Energy R\&D Programs

Federal energy research and development programs can be evaluated in the context of the entire national energy system with the Brookhaven Energy System Model. With data inputs describing technological results of the R\&D program and any desired assumptions about alternative energy resources, optimization model solutions can 'generate expected benefit of the program. Benefit, as measured by reduction in total energy system cost, can then be compared to projected federal R\&D cost as a measure of program worth. Necessary data items are tabulated in Tables 5 through 8.

If the program is to result in a new or improved energy conversion process for fuel or electricity production, such as high BTU coal gas or shale oil retorting, Table 5 lists needed data items. This data describes in a simple form technological characteristics of the energy conversion process, costs of production, the time framework for process introduction, and pollution emissions per unit of output. Provision is made for upper and lower production cost estimates. If it is desirable to state other datd items in terms of range rather than point estimates, analysis can easily be made on this basis. A more complex pattern of development results can also be analyzed in which end results depend upon successful completion of intermediate R\&D outcomes. 
Supportive data items that can be specified for alternative energy resources are listed in Table 6. This data summarizes assumptions to be made about future cost and/or availability of fuels. If there is appreciable uncertainty about any of the specified data items, sensitivity of calculated benefits can be determined by parameterization runs of the model on these items.

Data needed to evaluate an end use energy device, such as . an electric car or solar liome furnace, is somewhat different from that needed to evaluate energy conversion processes. Table 7 summarizes the necessary input data, and this table should be used in conjunction with Table 6 .

Estimated federal expenditures needed to achieve each R\&D result is summarized according to the format of Table 8 . It is important to list all dollar figures in these tables in terms of constant dollars so that inflationary distortions are not introAnred into calculations.

These tables, then, summarize the basic information that is needed by a user of the optimization model to evaluate federally funded R\&D programs. Assistance in developing portions of this data is available from Brookhaven. With such information it is simple and quick for Brookhaven personnel to evaluate proposed programs. Alternatively, it is possible to transfer the computer model to the user for his own utilization if he has adequate computer facilities and analytical staff. 
EXPECTED R\&D RESULTS - ENERGY CONVERSION PROCESS DATA

1. Description of Result \#
a) Process or activity name
b) Energy input form BTU content
c) Energy output form BTU content
d) Process conversion efficiency
e) Typical plant size
f) Useful plant lifetime, yrs.
g) Plant factor

2. Pollution emission (pounds per $10^{6}$ BTU or $\mathrm{kW}$ of output) -
a) $\mathrm{SO}_{2}$
b) Particulates
c) $\mathrm{NO}_{\mathrm{x}}$
d) $\mathrm{CO}^{\mathrm{x}}$
e) $\mathrm{CO}_{2}$
f) Hydrocarbons

3. Date of commercial implementation

4. Maximum production capacity, 1985

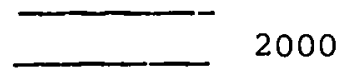

5. Cost of production (dollars per $10^{6}$ BTU or $\mathrm{kW}$ of output energy form)
1. Capital cost administrative and other annual costs
3. Assumed raw fuel cost
4. Probability* of achieving this production cost, $\%$
a) Low estimate
2. Operating, maintenance, 19852000
b) High estimate
1. Capital cost
2. Operating, maintenance, administrative and other annual costs
3. Assumed raw fuel cost
4. Probability ${ }^{*}$ of achieving this production cost, $\%$
c) Probability* of
failing to achieve
R\&D result,
$\%$

6. Other R\&D results depending on success of this conversion process

* Probabilities for $a, b$, and $c$ must add to $100 \%$. 
Table 6

ADDITIONAL DATA

1. Cost/prices in Tables 5 and/or 7 are given in terms of (year) dollars.

2. Raw fuel prices and annual supply constraints to be assumed in this analysis -

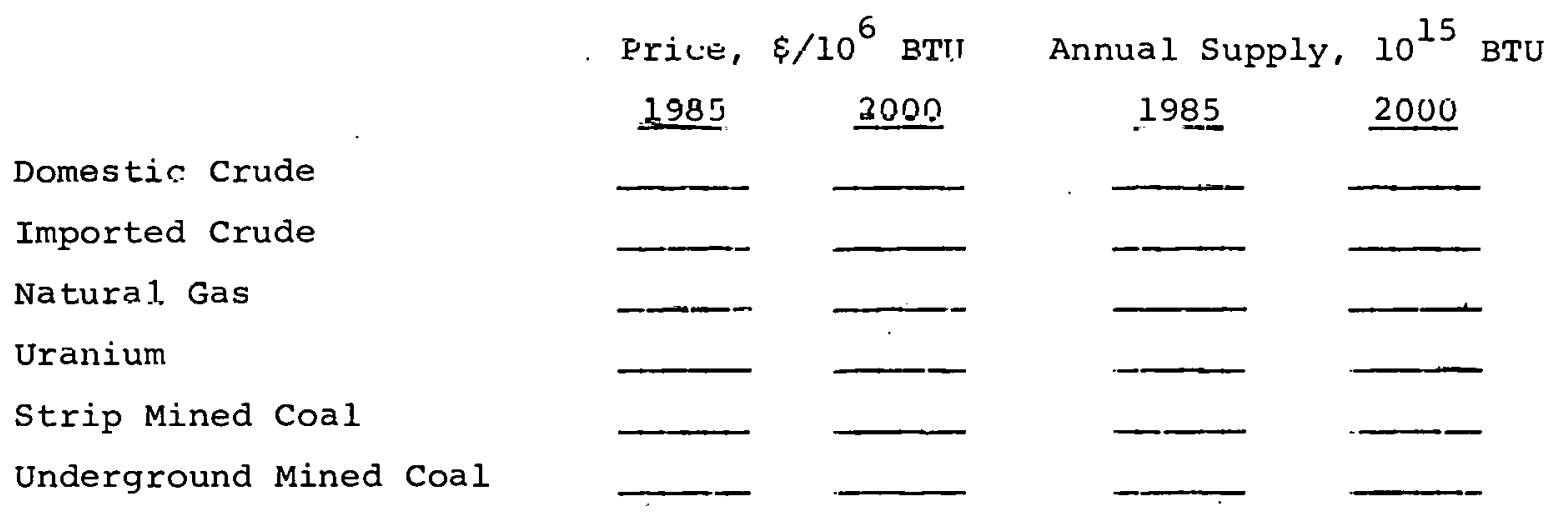

3. Fuels on which parameterization with respect to price is desired

4. Fuels on which parameterization with respect to supply availability is desired

5. Other costs, quantities; or efficiensies on which parameterization is desired 
EXPECTED RAD RESULTS - END USE DEVICE DATA

1. Description of Result \#
a) Name of end use device
b) Energy input form
- BTU content
c) End use conversion efficiency
d) Useful lifetime, years
e) Typical unit size

2. Pollution emission (pounds per $10^{6}$ BTU or $\mathrm{kW}$ input)
a) $\mathrm{SO}_{2}$
b) Particulates
c) $\mathrm{NO}_{x}$
d) $\mathrm{Co}^{\mathrm{x}}$
e) $\mathrm{CO}_{2}$
f) Hyarocarbons

3. Date of commercial implementation

4. Cost of end use device (dollars per $10^{6}$ BTU or $\mathrm{kW}$ input energy form)
a) Low estimate
1. Capital cost
2. Repair, maintenance, costs cost
4. Probability ${ }^{*}$ of achieving these costs, $\%$ and other annual
3. Assumed raw fuel
b) High estimate
1. Capital cost
2. Repair, maintenance, and other annual costs
3. Assumed raw fuel cost
4. Probability* of achieving these costs, $\%$
$1985 \quad 2000$
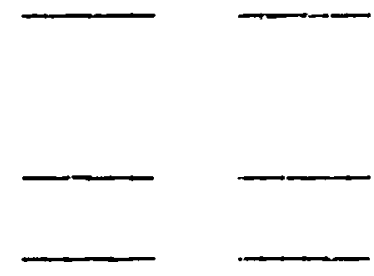
c) Prubability ${ }^{*}$ of failing to achieve R\&D result, $\%$

5. Other R\&D results depending on success of this end use device

$\overline{\text { * Probabilities for } a, b, ~ a n d ~} c$ must add to $100 \%$. 
Table 8

ANTICIPATED FEDERAL EXPENDITURES FOR R\&D RESULT \#

1.

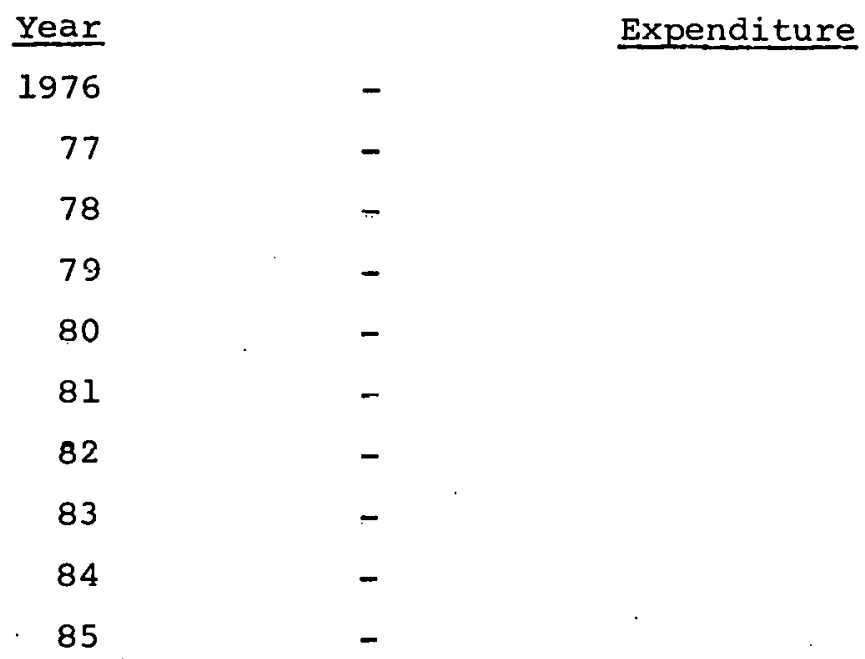

2. Expenditures are given in terms of (year) dollars.

3. Discount rate to be used in caloulation of R\&D benefita - 
V. Demonstration of the Use of Shadow Prices for Evaluating the Impact of Environmental Controls

A. Introduction

Extraction of energy resources, conversion of resources into usable energy forms, and usage of energy by final consumers can cause the emission of large quantities of air pollutants. In particular, the combustion process can be singled out as the major contributor to air pollution in the United States.

Various strategies for reducing air pollution have evolved over the years. One such strategy is to use "cleaner" fuels. To pursue this strategy, one can extract cleaner resources from the earth (low sulphur versus high sulphur crude oil) or one can remove impurities from extracted resources prior to combustion (desulphurization of crude oil at the refinery). A second strategy is to remove air pollutants from the products of combustion prior to their release in the atmosphere (electrostatic precipitators, stack gas scrubbers, etc.). A third strategy is to substitute burners and engines which result in more complete combustion uf fuels (i.e., the stratified charge engine versus current auto engines, or cyclone burners versus stokers).

Strategies to reduce air pollution often involve a group of interrelated energy extraction, conversion, and final use activities, rather than one single activity. To evaluate the electric car, 
for example, one immediately recognizes the reduction in air pollution due to the substitution of electric motors for internal combustion engines. However, fuels must still be burned in power plants to produce energy in the final useable form -- electricity. In the Northeast, one must consider the increase in air pollutants coming from central station power plants which burn residual fuel oil. In the Midwest one must consider the increase coming from bituminous coal fircd plants.

The task described in this chapter demonstrates how the Brookhaven Energy System Optimization Model (BESOM) may be used to evaluate the impact of Inpusing onvirnnmental controls on the nation's energy system. A major feature of this tool is that policies can be evaluated which affect an interrelated group of activities in the energy system. Within the limitations of the Lechnioal artivities specified in the model, any of the three serdleyico for reducing air pollutiun describen duve can he evaluated. Although the model at present is national in its representation of the energy system, this analysis establishes the usefulness of such an approach and highlights the desirability of regionalizing the model to provide an even more powerful tool for evaluation of environmunal controls. This task specifically evaluates imposition of more restrictive controls on sulphur dioxide emissions from fossil fuel burning boilers 
which produce process heat for industrial and commercial needs. Interest in further reducing $\mathrm{SO}_{2}$ emissions remains high, and discussions on this topic in regard to power plants are contained in (10).

The optimization model has the capability of evaluating emission controls on other air pollutants besides sulphur dioxide. These include carbon monoxide, hydrocarbons, carbon dioxide, nitrous oxides, and particulates. Water pollutants that can be evaluated include acids, phosphates, other dissolved solids, nondegradable organics, bases, nitrates and suspended solids. Although controls are only applied to one energy activity in this demonstration - process heat boilers - they can similarly be applied to other extraction and conversion activities or to end use energy devices.

The general approach in this demonstration is to first establish a base case for the reference year of interest -- 1985 . This base case establishes expected energy resource supplies, energy demands, energy technologies, and pollution control requirements for the reference year. Demand constraints for this case are taken from the 1985 Reference Energy system in AET 8 (11, Fig. V-3). Solution of BESOM with this base case data establishes the optimum fuel mix to meet projected energy demands for 1985. The solution 
also establishes amounts of $\mathrm{SO}_{2}$ released into the atmosphere, assuming national average emission coefficients for each energy system activity. Emissions of $\mathrm{SO}_{2}$ are partitioned into that generated by process heat boilers and that generated from all other sources.

Two perturbations of the base case are then analyzed, each repregenting imposition of more restrictive emission controls than those asoumed in the base casc. Case I constrains the diluunt of $s n_{2}$ generated by process heat boilers to successively smaller values, causing a shift in fuel usage and an 1rlieagc in total energy syslem aost. Although $\mathrm{SO}_{2}$ emissions from process heat boilers decrease, a very important secondary result is that $\mathrm{so}_{2}$ emissions from the remainder of the energy system increase due to substitution of fuels with.higher $\mathrm{SO}_{2}$ content.

Tn case II, $\mathrm{SO}_{2}$ generaled by prôness lieat boilers is constrained to smaller values as in case $I$. But at the same time, $\mathrm{SO}_{2}$ generated by all other sources is constrained to the base case level. This, in effect, simulates a cleanup in the industrial and commercial sectors without a shift of high sulphur fuels to other sectors. The results of these analyses provide useful insights for evaluating the effects of more restrictive environmental controls. 
B. Discussion of Cost and Environmental Coefficients

Each variable in BESOM, representing an energy flow from

a fuel supply to a final demand, is called an intermediate energy form (IEF). Each IEF is measured in $10^{15}$ BTU and each has a cost associated with it which is measured in $10^{9}$ dollars. An optimal solution (in the minimum total cost sense) to BESOM-determines the quantity of each intermediate energy form. Associated with each IEF are several environmental coefficients that indicate, in most cases, the pounds of a particular pollutant per BTU of energy delivered.

The model used for this demonstration is a national model which uses data that is the average of data accumulated throughout the nation. In applying the methodology given here to other problems, one may want to use a regional model. In addition, for a complete study of the effects of environmental constraints, one would consider additional control technologies; however, for this demonstration, the emphasis has been placed on interfuel substitution as the primary llleans of reducing $\mathrm{SO}_{2}$ emissions below the controlled levels of the base case.

The cost coefficient for each variable in BESOM includes capital costs of conversion plants (oil steam electric generating plants, for example) and transmission and distribution facilities, operating and maintenance costs, and fuel costs. In addition 
to these, the cost coefficients in the 1985 base case include additional costs of performing some amount of environmental cleanup in anticipation of tighter 1985 EPA standards. For example, $\$ 75.00$ per kilowatt for coal fired electric plants is added on for the cost of sulphur removal equipment (stack gas scrubbers) and for cooling towers. Detailed cost data is available from BNL report ESAG-16. (12)

In a similar manner, the coefficients in the constraint. equations for environmental pollutants have been calculated to reflect the effects of reduced emissions due to the installation of various types of equipment. A detailed discussion of environmental effects may be found in (11). In addition, we have made the following assumptions concerning sulphur emissions for some newer techmologias:

1. Coal Steam Combined Cycle - These plants will gasify coal to form a $1 \mathrm{nw}$ BTU qas for use in generating clectrirtty. Tnis gasification process will generate $\mathrm{H}_{2} \mathrm{~S}$ which will be recovered and not released to the atmosphere. The dooffirient for $\mathrm{SO}_{2}$ emissions for electricity from Coal Steam Combined Cycle is therefore zero. See page 14 of reference (13).

2. Oil Steam Combined Cycle - An assumption has been made that the prucess will use low sulphur oil (less than .6\% 
sulphur by weight). This is necessary to avoid damage to turbines used in electrical generation.

3. Synthetic Natural Gas from Oil - This technology has been blocked from the solution in the model. This has been done primarily because the rising cost of the feedstock (generally naptha) has made it unattractive to most utilities.

4. Hydrogen from Coal - Sulphur removal, as with low BTU gas, will be done after gasification by a Klaus desulphurization step. The coefficients for Hydrogen from Coal are therefore zero.

5. Methanol from Coal - Production of methanol from coal requires processes very similar to those of synthetic natural gas, from coal. After gasification, a purification process is needed to remove impurities including sulphur from the gas. The sulphur content of the methanol is essentially zero. However, some of the coal or residue from the gasification step will be burned to provide steam, electricity or other forms of energy to drive the methanation step. Coefficients for sulphur content, in viewing the process as a whole, are the same as Lhose for synthetic natural gas from coal. 
6. Synthetic Natural Gas from Coal - To calculate the sulphur released to the atmosphere for this process, a number of data items have been used. The process is assumed to be $65 \%$ efficient, and it uses coal having $0.8 \%$ sulphur by weight. See AET-8 reference (1I). There are a number of processes which may be used for production of SNG from coal. For our purposes, we have assumed that the Hygas-Electrotherma.1. Process is representative as described by Just in (14). Some amount of the original coal or residue from the initial gasification step is burned directly to provlue energy for other steps. This results in approximately $40 \%$ of the sulphur in the original coal being released to the air in the form of $\mathrm{SO}_{2}$. Theer data give a coefficient value of..40, or $.4 \times 10^{9}$ lbs. of $\mathrm{SO}_{2}$ for every $10^{15} \mathrm{BTU}$ of synthetic gac from rnal.

7. Shale Oil - The uses of shale oil are generally made after upgrading to syncrude. The sulphur oontent is . nn $5 \%$ by weiqht and is obtained from reference (15). Assuming that shale oil syncrude has the same heating value as petroleum derlved crude, we obtain an emission coefficient of $.0025 \times 10^{9} \mathrm{lbs}$. of $\mathrm{so}_{2}$ for every $10^{15}$ BTU of shale oil. 
A slight change in the cost coefficients for synthetic natural gas was made to allow the base case to agree with that described in Chapter III of this report. The cost of synthetic natural gas from coal used in this analysis is $\$ 1.31$ per $10^{6}$ BTU.

\section{c. Results and Findings}

A number of important 1985 base case results are shown in Table 9. None of the constraints concerning the emission of pollutants or other environmental effects were made binding for this base case. Recall, however, that the costs of the variables (IEF's) and the coefficients in the environmental constraint equations reflect some effort at controlling emissions. The amount of $\mathrm{SO}_{2}$ released is representative of this policy. One may note from Table 9 that additional coal and oil are available but not used. Natural gas and nuclear fuels are used to capacity. The model was next used to assess the impact of imposing stricter controls on the emission of $\mathrm{SO}_{2}$ by industries requiring process heat (case I). This was done by reduciny the right hand side constraint value of the $\mathrm{SO}_{2}$ equation for those intermediate energy forms capable of meeting this demand. The generation of $\mathrm{SO}_{2}$ by other intermediate energy forms supplying all other energy demands was not constrained. The results of this cage for various 
Table 9

1985 Base Case Results

\section{Resources}

Oil (Domestic and Imported

roal (Strip and Underground)

Natural Gas

Electricity From Light water Redulorg

synthetic Gas From Coal
Consumed

$\left(10^{15} \mathrm{BTU}\right)$

47.12

$16: 61$

28.4

12.67

0.0
Total Projected

Supply $\left(10^{15}\right.$ BTU)

$$
51.6
$$

34.0

28.4

12.67

3.43

Fuels Meeting Process Heat Demand $\left(10^{15}\right.$ BTU)

Natural Gas

coal

Sulfur Dioxide keleased $\left(10^{9}\right.$ pounds)

For Process Heat

6.35

For All other Eneryy Usec

Total System Cost - $\$ 170.46 \times 10^{9}$
12.99

5.00 
levels of $\mathrm{SO}_{2}$ emission constraints on process heat demand are shown in Table 10 as runs 1 through 7 .

In run 7 the total oil consumed was $50.4 \times 10^{15}$ BTU (compared to $47.1 \times 10^{15}$ BTU for the base case) out of a total projected supply of 51.6. The total coal consumed was $13.52 \times 10^{15}$ BTU which is less than the $16.61 \times 10^{15}$ BTU consumed in the base case. (Note that run 1 of Table 10 is identical to Table 9, the base case.) As can be seen from Table 10, the total system cost increases as the constraint on $\mathrm{SO}_{2}$ emissions becomes more stringent. Note also that there is the expected shift of "cleaner" fuel (natural gas in this case) from other uses to the environmentally controlled demand (process heat), while the less desirable fuel (direct combustion of coal) shifts to other uses. This is also reflected by the increase in $\mathrm{SO}_{2}$ emissions for all other energy demands. Even in run 7, no use of synthetic gas from coal, a cleaner fuel from the standpoint of emissions, was selected by the model.

These findings clearly indicate what may result if a cleanup of industrial areas is made at the expenec of previously clean areas.

An alternate approach is to institute stricter $\mathrm{SO}_{2}$ emission controls for process heat while constraining the emissions from all other energy uses at that value $\left(21.3 \times 10^{9}\right.$ lbs.) determined from the base case. The results of this approach, case II, are 
Table 10

Case I

Rediation in $\mathrm{SO}_{2}$ for Flels

Meeting Process Heat Demand

\begin{tabular}{|c|c|c|c|c|c|c|}
\hline 1 & $\begin{array}{c}\text { Case } \\
\# \\
\end{array}$ & $\begin{array}{l}\mathrm{SO}_{2} \text { For } \\
\text { Frocess Heat } \\
\text { (109 Pounds) }\end{array}$ & $\begin{array}{l}\mathrm{SO}_{2} \text { For } \mathrm{A.11} \\
\text { Jther Deroands } \\
\left(10^{9} \text { Pounds) }\right. \\
\end{array}$ & $\begin{array}{l}\text { Total } \\
\text { Systen } \\
\text { Cost } \\
\left(10^{9}>\right)\end{array}$ & $\begin{array}{l}\text { Nat. Gas } \\
\text { to Process } \\
\text { Feat (1015 BTU) }\end{array}$ & $\begin{array}{l}\text { Coal To } \\
\text { Process } \\
\text { Heat }\left(10^{15} \text { BTU) }\right.\end{array}$ \\
\hline so & 1 & 6.35 & 21.30 & 170.46 & 12.99 & 5.0 \\
\hline & 2 & 5.72 & 21.60 & 170.86 & 13.42 & 4.5 \\
\hline & 3 & 5.08 & 21.90 & 171.27 & 13.36 & 4.0 \\
\hline & 4 & 4.45 & 22.21 & 171.67 & 14.30 & 3.5 \\
\hline & 5 & 3.81 & 22.5 .1 & 172.07 & 14.74 & 3.0 \\
\hline & 6 & 3.18 & 22.82 & 172.47 & 15.18 & 2.5 \\
\hline & 7 & 2.54 & 23.12 & 172.88 & 15.61 & 2.0 \\
\hline
\end{tabular}


shown in Table 11. Run 7 again represents the most extreme constraint on $\mathrm{SO}_{2}$ emissions and includes the interesting result that more coal is consumed in run 7 than in the base case. This is partly due to the need for coal to create synthetic natural gas. Resource consumption for run 7 is shown in Table 12. Note also from Table 12 that only slightly more oil is used than in the base case. Figure 4 shows a plot of the increase in total system cost (cost above base case cost) as a function of $\mathrm{SO}_{2}$ emission reduction. This plot was made using the data from Table 11 for case II. The slope of this line is the shadow price of $\mathrm{SO}_{2}$ emissions; that is, the unit increase in system cost per unit reduction in $\mathrm{SO}_{2}$ emissions. This shadow price is a measure of the cost of the more restrictive environmental controls placed upon $\mathrm{SO}_{2}$ emissions.

\section{Conclusions}

We have demonstrated how BESOM may be used to assess the imposition of environmental controls. The results are what one would expect intuitively. Case I, which some may view as a poorer policy than case II because of the shift of less desirable fuels to other sectors, had a total cost of $\$ 172.88 \times 10^{9}$ for run 7 . The total cost for run 7 of case II was $\$ 173.17 \times 10^{9}$ which is an increase over case I of about $\$ 0.29 \times 10^{9}$ or about $0.2 \%$. This 
Table 11

case II

Reduction in $\mathrm{SO}_{2}$ For Fuels Metting

Process Heat Demand With $\mathrm{SO}_{2}$ Enissiors

Corstarit For All other Denanas

$\mathrm{SO}_{2}$ For All

Total

जั

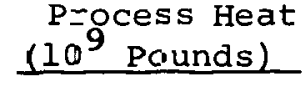

1

6.35

5.72

$5 \cdot 0.3$

4.45

3. 81

6

3.18

2.54

ather Demand

system

Cost

Nat. Gas

Coal To

(i1) 9 pounds)

$\left(10^{9} \mathrm{~s}\right)$

to Process

Process

$21.3 \quad 170.46$

12.99

5.0

$21 \cdot 3$

170.88

13.42

4.5

2.13

$171 \cdot 30$

13.86

4.0

$21 \cdot 3$

171.72

14.30

3.5

$21 \cdot 3$

$172 \cdot 16$

14.74

3.0

21.3

172.66

15.18

2.5

21.3

173.17

15.61

2.0 
Table 12

Resources Consumed For

Case 7 of Table 11

\begin{tabular}{|c|c|c|}
\hline & $\begin{array}{l}\text { Consumed } \\
\left(10^{15} \mathrm{BTU}\right) \\
\end{array}$ & $\begin{array}{c}\text { Consumed From } \\
\text { Base Case (Table 1) } \\
\text { (1015 BTU) }\end{array}$ \\
\hline 011 (Domestic and Imported) & 48.08 & 47.12 \\
\hline Coal (strip and Underground) & 16.77 & 16.61 \\
\hline Natural Gas & 28.4 & 28.4 \\
\hline $\begin{array}{l}\text { Electricity From light } \\
\text { water Reactors }\end{array}$ & 12.67 & 12.67 \\
\hline Synthetic Gas From coal & 3.43 & 0.0 \\
\hline
\end{tabular}




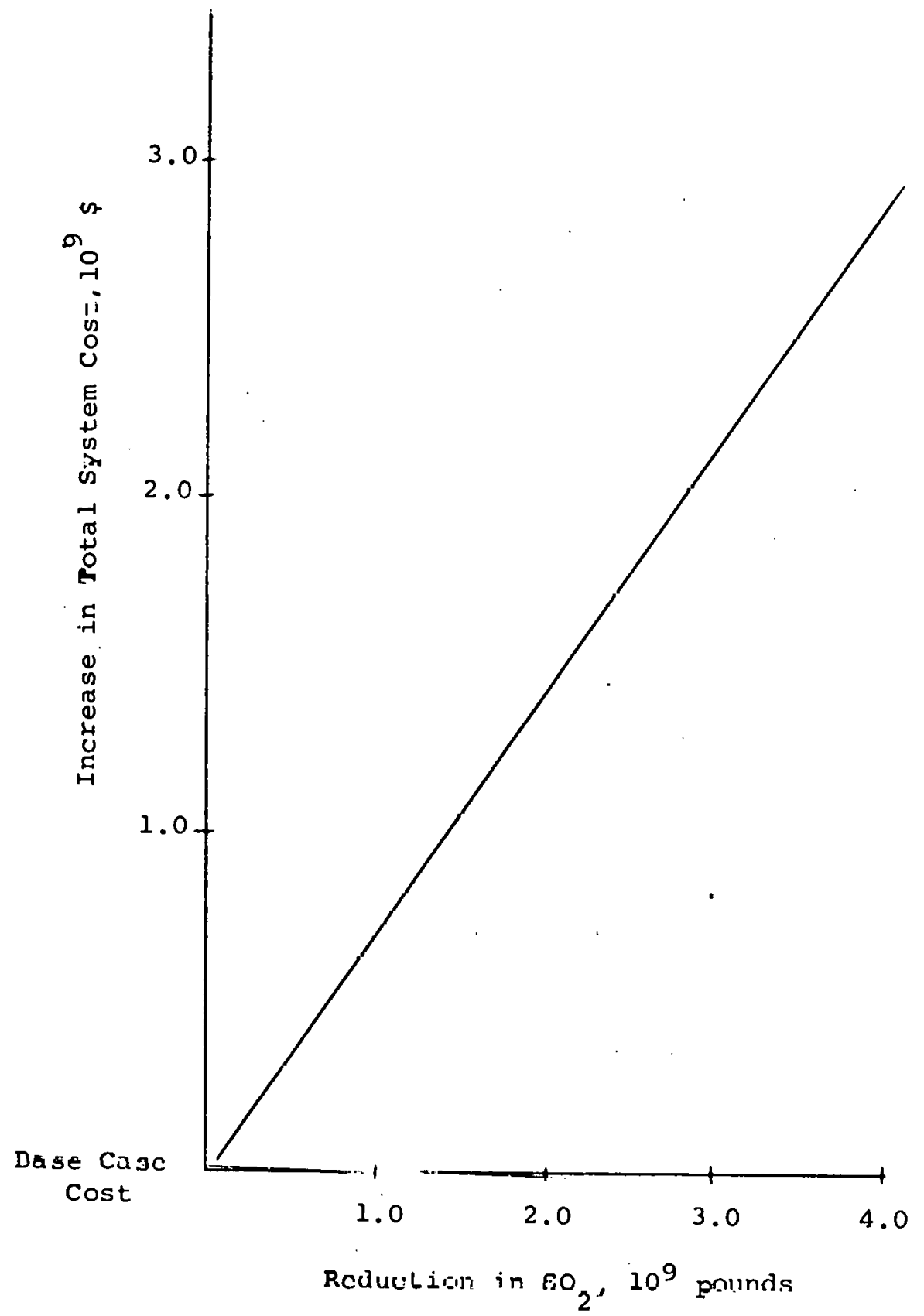

Figurc 4. Increase in system cost vs. reduction in $\mathrm{SO}_{2}$. 
increased cost reduces the total $\mathrm{SO}_{2}$ emissions from $25.66 \times 10^{9}$ pounds for run 7 of case I to $23.84 \times 10^{9}$ pounds for run 7 of case II. The cost of selecting the policy represented by case II over case I amounts to about $\$ .16$ per pound of $\mathrm{SO}_{2}$.

The methodology presented here allows one to compute the shadow price for a reduction in the amount of pollutant released. As more biological data concerning the harmful effects of this pollutant become known, one may be in a position to weigh these against the increase in cost needed to remove additional amounts of the pollutant. Hard data such as manhours lost and medical expenditures due to the effects of the pollutant on humans may be obtainable. Comparison of these costs to the shadow price determined in the manner demonstrated here will help in selecting among alternative policies for pollution control. 
VI. Development of the Dynamic Linear Programming Model

A. Introduction

One of the areas addressed in work under this research grant is the assessment of the present value of future resource scarcity. Because the constraints on amount of resource supply are time and use related, the original proposal calling for the use of the static model in a comparative mode for different time periuds has serious wedknessce. Examination of the problem by means of a dynamic (or time dependent) formulation offers more meaningful and believable results. Consequently, work has proceeded on creating a time phased linear program with an additional set of relationships depicting inter-period use of resources and the formation of capital. The morel is briefly described in Appendix $B$. Unfortunately, project funding expired before an analyia nf the shadow prices generdted by the model could be completed. Continuing, unfunded work has clarified their interpretation, and this will bo puhliṣhed when additional funding becomes available.

As noted in the introduction to this report, competitive markets seldom allocate resources elficicntly over time. There are a number of potential reasons for this, and a comprehensive revtew is presented by solow 
in (19, pp. 1-14). For illustrative purposes here, it is merely assumed that the current market supply curve for an exhaustible resource is not in its optimal location with respect to future resource availability and a "correct" social discount rate, without examining in detail the conditions under which this might occur. Suppose, for example, that the current market supply and demand curves for a resource are those shown in Figure 5. This market will be in equilibrium at quantity $\mathrm{q}_{e}$ and price $\mathrm{p}_{e}$.

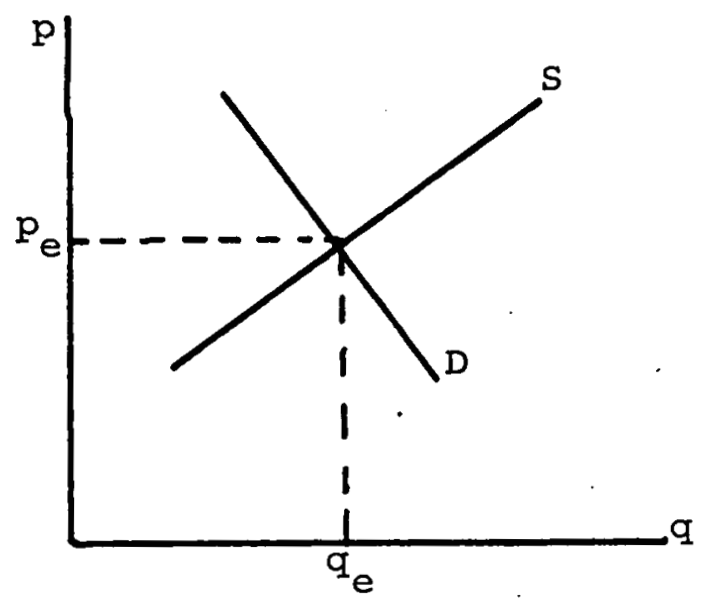

Figure 5. Rurrent market supply and demand for a resource.

If this market does not recognize and reflect future resource scarcity or if the market rata of interest lies above the "correct" social discount rate, the supply curve as shown will not result in optimum allocation 
of that resource over time. Correct use will occur only if the current time period's supply curve lies to the left of $S$, as shown by $S^{\prime}$ in Figure 6 . With a complete futures market and/or a lower market rate of interest, the supply curve shifts because of the resource's higher recognized scarcity value. This has the effect of restricting current consumption and saving more of the resourco for future use.

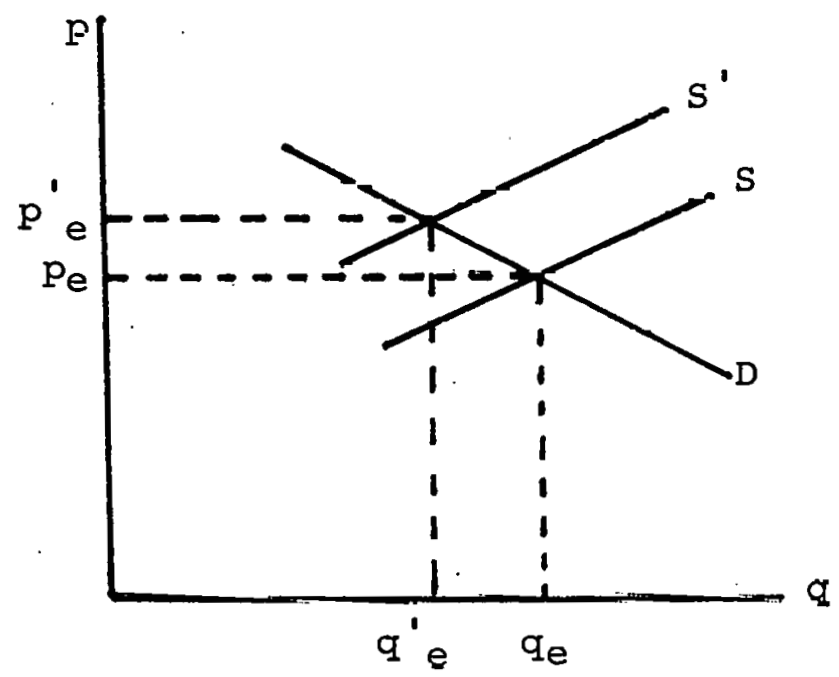

Figure 6. Optimal market supply and demand for a scarce resource.

Resource usage in a dynamic optimal sense would be $q_{e}^{\prime}$ in the present period at price $p^{\prime} e^{\cdot}$ In effect this means that current consumption should be reduced in the case of a market clearing solution through an increased price placed on the resource. 
Correct allocation of the resource over time will result in less quantity available for current consumption, and future resource scarcity will be reflected if the market clearing price is increased in the current time period by

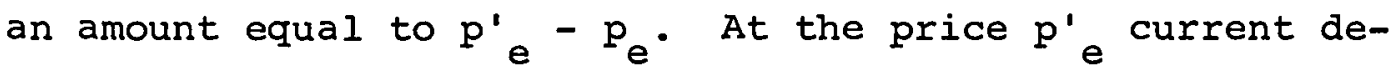
mand can be met 'at an output $q^{\prime} e^{\prime}$ and the market will optimally reflect future resource scarcity.

The goal in developing a dynamic energy system model is to determine whether or not future resource scarcity is adequately reflected in current market prices and resource usage. If not, it is probable that current consumption of a non-renewable resource is excessive relative to the value of having more of that resource available in the future. Within the constraints imposed by extrapolating present demand characteristics and foreseeable technological advance, the dynamic model makes it possible to analyze the impact of resource scarcity on the rate of usage of these nonrenewable energy resources nver time. It dues this based on a determination of the finite bounds of resource availability and total recoverable reserves. Under the assumption that no great surprises lie ahead in either advanced extraction technology or in discovery of rich new sources, estimation of shadow prices is then possible. 
Solution of the model determines optimal ${ }^{16}$ usage of the resource in each time period. If the model would like to use more than is available at the prices specified for that resource in present and future time periods, the model in effect says that those prices will not effect optimal allocation of the resource over time.

The quantity actually allocated by the model for use in a given time period will be less than the market clearing quantity, $q_{e}$, under the incorrect price assumption $\mathrm{p}_{e}$. Instead, quantity $q^{\prime}{ }_{e}$ will be allocated for use in the curront time period, as showl ill Figure 6. A shadow price for the resource in this time period will also be generated, equal

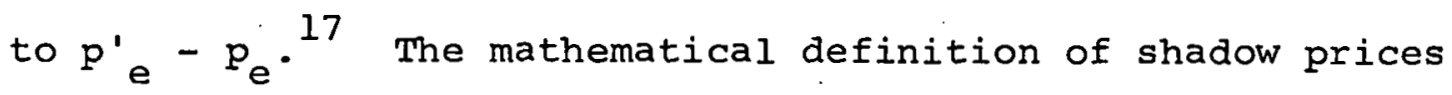
on resources as used here is the marginal decrease in total. discounted cost of energy (C) over time resulting from an inrraase in the supply of the resource (q), ur -dc/dq. The value of an inter-temporal or dynamic model thus lies in its ability to determine whether or not ultimate resource scarcity as represented by constrained variables will generate differential shadow prices $\left(p_{e}^{\prime}-p_{e}>0\right)$ that forecast over-consumption in one time period at the expense of more valuable use

16. Optimal is defined in the sense of minimum discounted system expenditure on energy over all time periods.

17. Shadow prices san be expressed as an absolute price $\left(p^{\prime} e^{\prime}\right.$ or as a differential above the assumed price $(p+e-p)$. The second convention, differential price, is used in this report. 
in future time periods if the actual market clearing price is held down to $\mathrm{p}_{e}$. Shadow prices generated by constraints other than those on resource availability are also of interest, and they are examined and interpreted in the following sections to the extent possible under available project funding.

B. Extension of Shadow Price Concepts

The usual definition of a shadow price is the dual solution value assigned to a row constraint in the linear program. It has a value of zero if. that row constraint is not binding, and it has a value equal to the shadow price if in. fact the constraint is a binding one. Unfortunately, many of the interesting solution values in this linear program are associated with columns rather than rows. For example, one would like to know the value of another unit of productive capacity in a given time period. However, productive capacity in a given time period is an activity (or, a variable) which appears in only a single column of the program. It is not an activity which is summed over a row in the LP. Similarly, one would like to know the value of another unit of a primary resource in a given time period. Since the selection of the amount of resources to be used in each time period is endogenous to the model, this is also a variable which appears in only a single column.

Careful examination of theoe columns of interest indicates that a value can be generated which is very similar to a shadow price and which in fact we give the name shadow price. It is not the first derivative of that variable with respect to cost, but it does represent the additional cost which could be added to that cost exogenously inserted into the objective function without changing the optimal solution. This value is calculated as follows. If one examines the solution to the LP and looks down a single column, one 
can identify each row in which the activity or variable of interest appears. One can then multiply the coefficient of the variable in each row by the dual solution value of that row. The sum of these products will be equal to the cost assigned to that variable in the objective function. This sum can be divided into two subsets. One subset represents henefits. This represents the value of this varidule for producing mitput in this time poriod and, if it is a new unit of capacity, the value for future time perlods. A second subset represents endogenous costs. Subtracting these from the benefite one nhtains the objective function cost. That is, the cost assigned to the variable in the objective function equals the sum of the products of the cocfficient.s and the dual values for the rows in which those coefficients appear.

These endogenous costs are those Lliat occur because of constraints that inhibit the uses of the resource: in that time period or inhibit the acquisilion of a now unit of capacity in the time period.

If the value of the endogenous benefits were added to the exogenous cost, the inet reoult would bc to redine these endogenous benefits to zero and the solution to the problem and the value of the objective function would not change. 
Hence, we can calculate the equivalent of a shadow price or at least an economic grant or an increment to cost or some other measure that represents an economic transfer that could occur in order to bring forth new resources or new capacity in that time period. This is very similar to a shadow price. It indicates, as a shadow price does, the value that could be assigned to that activity (resource or unit of capacity in a single time period) without changing the LP solution. This concept will be dealt with at some future time in an extended paper by the participants in this project.

C. Description of Demonstration Study

An operational four period model has been completed and a demonstration application made. Selected shadow price information has been generated from the demonstration application. The model is now available to be used for analysis of specific policy alternatives such as alternative perceptions of energy resource availability, introduction of new energy technology, and energy consumption scenarios. The outputs of the model provide information beyond that used for shadow price analysis. As will be shown, the time phased use of fuels, construction of energy capital equipment, requirements for capital financing, electrification trends, and the development of specific energy sectors (such as nuclear) can be depicted from the output of the demonstration application. 
In order to relate the demonstration study to previous energy studies, it has been calibrated to an earlier BNL study (4). In this study two base cases are analyzed by the BNL single time period linear programming model, BESOM. (9). The two base cases are for the years 1985 and 2000. In the multiperiod demonstration run the original energy production capacities are set consistent with those of the 1985 base case. Growth rates between 1985 and 2001 for fusureco and energy production capacities are set consistent with the difference in output between the two base cases. Total resource availability is consistent with resurices available in the two limiting cases. Energy demands begin with thọse in the 1985 case and grow at a constant rate to those in the 2000 case. The objective is not to reproduce the earlier work but to use it to compare a projection over a fifteen year period eiitisodying the judgment of knowledgeable invesligators with the mechanical results from the model. There is no reason to assume a priori correspondence of the lwo analyses. In fact, the soxrespondence is reasonably good. Where the projected energy world of 2000 in the multiperiod model differs from that of the "experts energy world" of 2000, the differences are intuitively reasonable; e.g., the multi-period model produces more electricity from coal. and less from nuclear and also uses coal more extensively to produce synthetic fuel. Both of these differences seem to represent an implicit en- 
vironmental concern on the part of the "experts" with regard to mining and burning of coal. Such concern could be explicitly incorporated in the multiperiod model.

The second reason for choosing baseline static model cases is to illustrate the additional information provided by the multiperiod model with respect to the timing of the use of resources and the creation of new production capacity of energy supply alternatives. This, combined with the pricing information supplied from the shadow prices on constrained variables, comprises the additional information provided by the multiperiod model.

D. Inputs

Table 13 presents the resource supply constraints used in both models. As can be seen, the multiperiod model resource supply constraints are set at approximately 20 years usage at the higher year 2000 rate of the baseline study. In addition, the multiperiod model explicitly incorporates a uranium constraint. The multiperiod run does not exhaust any of the supplies except uranium, although it would like to have more natural gas available in each period but is constrained by the explicitly incorporated growth rate. This growth rate constraint reflects limitations on how quickly the infrastructure to import liquified natural gas can be enlarged. 
Table $1 \cdot 3$

Primary Fuel Supply Constraints $\left(10^{15}\right.$ BTU)

\section{Category}

Coal, Underground

Coal, surface

Oil, Domestic

Oil, 1 mpurled

Oil, Shale

Natural Gas

Uranium
Stalic Study (1 Yr.)

1985

2000

15.3

15.8

29.2

21.2

50.2

2.0

34.0

no explicit constraint
Multiperiod Model $(20 \mathrm{Yr}$.

300

585

424

1000

40

680

$1600\left(10^{3}\right.$ Tons

$\left.\mathrm{U}_{3} \mathrm{O}_{8}\right)$ 
Table 14

Sipply Conversion Device Constraints (Appropriate units/yr)

\section{Category}

Coal Steam Electric

Coal Steam Electric Comb. Cycle

Oil steam Electric

Oil steam Electric Comb. Cyale

Oil Fired Gas Turbine

Gas Steam Electric

Total Energy Systems

Light water Reactor

Fast Breeder Reactor

High Temperature Reactor

Hydroelectric

Geothermal

Solar Energy

Pumped Storage

Fusion

Syn. Gas from oil

Methane from caal

$\mathrm{H}_{2}$ from Electrolysis

$\mathrm{H}_{2}$ from Coal

Methanol from Coal

Coal Liquefaction

Retorting Shale.

Refineries

Enrichment Plants

$\mathrm{H}_{2}$ Fuel Cells

Fossil Fuel cells

Electrolytic Converters
Multiperiod Model

Static Study Initial Value Annual Growth

$\underline{1985} \quad \underline{2000}$

in 1985

open $\quad 269 \quad 134$

$\begin{array}{llrl}0 & 278 & 10 & (1990)\end{array}$

Rate, \%

Units

52

36

10

52
28

28

55

open

46

61

1

215

0

10

83
6

1
75

0

0

17

open

1.5

1.5

0

not explicit

1
805

164

106

113

11

$12 \frac{1}{1}$

125
0

0

56
open

57
61

61

1

23 (1990)

10

60

3

1
84

0

0

19

4

16
16 $\quad 1.5$

.5

1
127

127
3

10

10

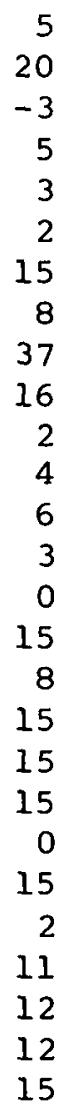

1000NIT (e)

"

"

1

"

1

"1

11

"1

$"$

$"$

"

11

"

$250 \times 10^{6}$ BTU/Day

"

"

$100 \times 10^{3} \mathrm{Bb} 1 / \mathrm{Day}$ $200 \times 10_{6}^{3} \mathrm{Bbl} / \mathrm{Day}$ $8.8 \times 10^{6} \mathrm{Kg} \mathrm{SWU} / \mathrm{Yr}$. $10^{3} \mathrm{MW}$ $10^{3} \mathrm{MW}$ $250 \times 10^{6} \mathrm{BTU} / \mathrm{Day}$ 
Table 14 presents the capacity constraints of supply conversion devices. The general approach has been to set the initial capacity in 1985 for the multiperiod run approximately equal to the constraint in the 1985 static case. ${ }^{18}$ Then a growth rate is assigned for each supply device that sets an upper limit on capacity expansion. Annual demand requirements for five year brackets around 1985 and 2000 in the multperiod model are set. equad to those of the 1985 and 2000 static runs. Annual demands for the five year brackets around 1990 and 1995 are generated by linear interpolation between the end poluls.

E. Outputs

The model produces four types of output. These are:

1) Energy flows including resource consumption and use, the generation of electricity, production of synthetic fuels, production of plutonium, and enriçhment services requirements.

3) Amnints of new production capacity required in each pering and the required flow of capltal investmont over time.

3) Energy sources (fuel or electricity) directed to meeting each type of demand in each period.

4) Shadow prices for resources, capital equipment requirements, demand fulfillment and growth limitations.

Each of these results io presented with emphasis on the interpretation of shadow prices on the constrained

18. The static model does not state the constraints in terms of capacities. The capacities shown are calculated from throughput constraints modified by appropriate load factors. Also, certain capacities are taken from (11), and not from the static model base cases. 
variables.

\section{1) Energy Production and Resource Use}

Figure 7 and Table 15 present the annual resource consumption generated by the multiperiod model. Consumption of all fuels increases, but at very different rates. Output from renewable energy sources and natural gas are almost constant while coal use grows rapidly and nuclear electricity production grows even faster. It is of note that the rate of growth of oil decreases in the third period and increases in the fourth period.

Figure 8 and Table 16 break down the general information on resource use. For each fossil fuel it shows the amount consumed directly, used for generating electricity, and converted into synthetic fuels. For oil and natural gas amounts are shown separately for domestic production and for imports.

The multiperiod model is showing about a third more use of coal by 2000 than the static casc. Mosl of this use is to produce electricity and synthetic fuels. This indicates that with the cost and technology structure of the multiperiod model an optimal energy mix would include more coal and less nuclear than the baseline case. The judgmental coal and nuclear capacities inserted in the static model 


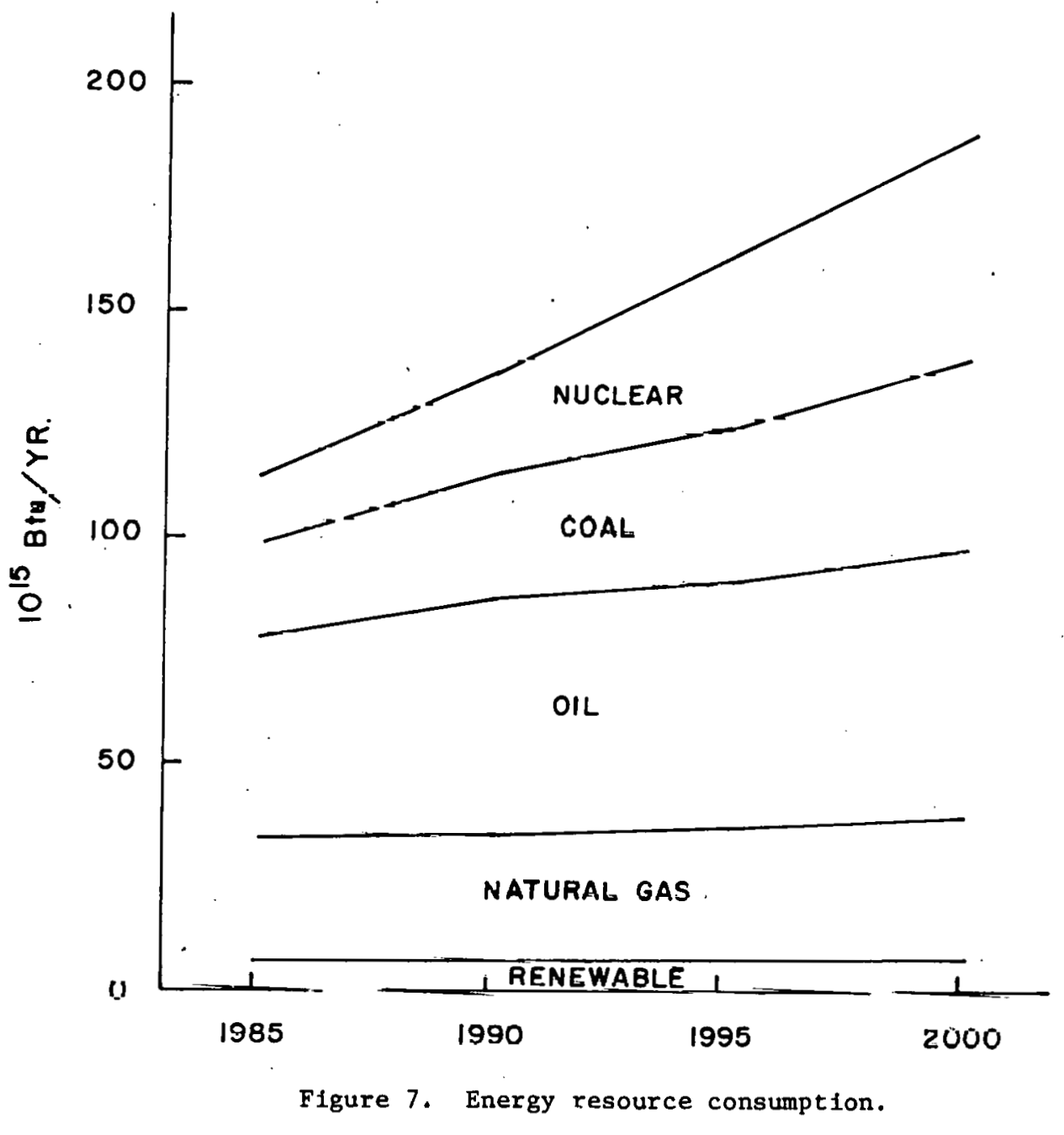


TABLE 15

Total Resource Consumption

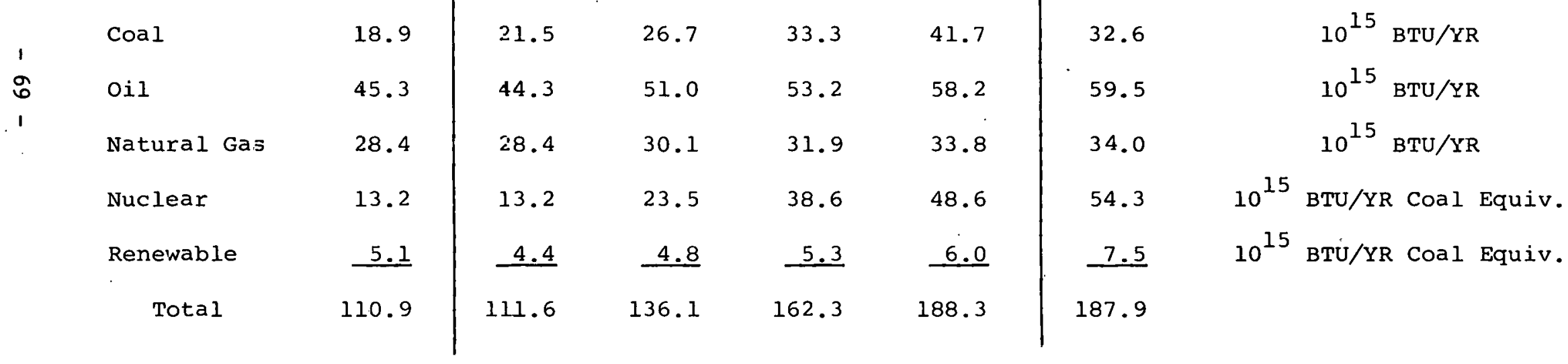




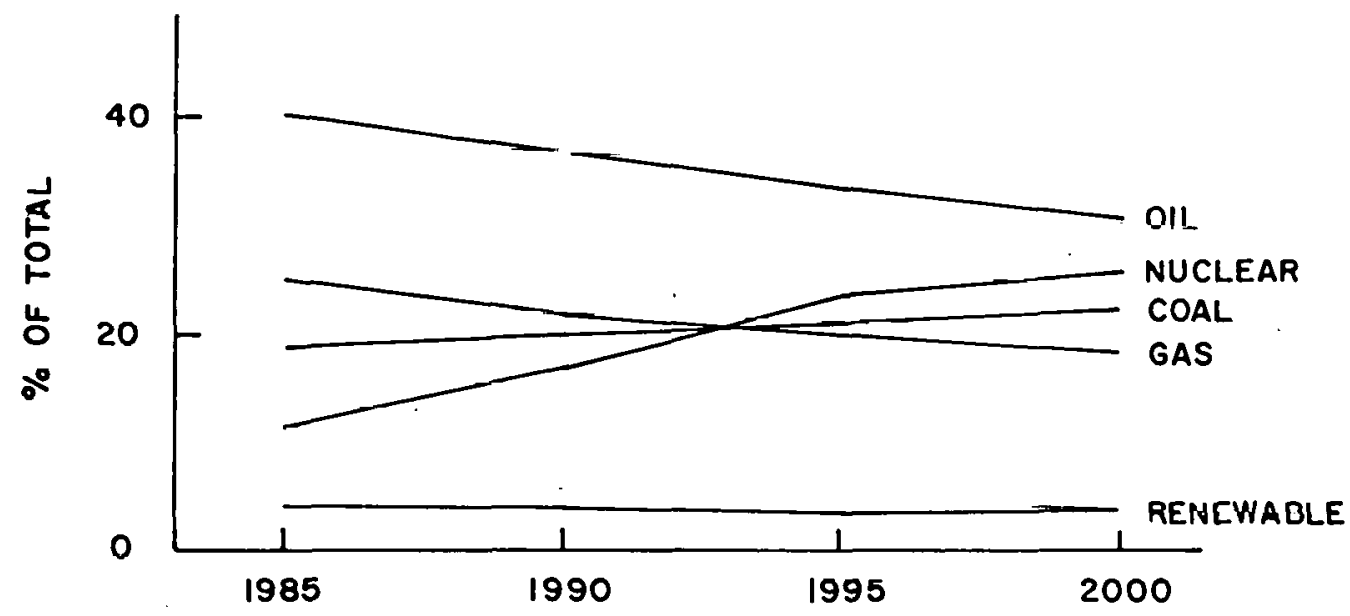

Figure 8. Energy resource consumption. 
TABLE 16

Resource Use

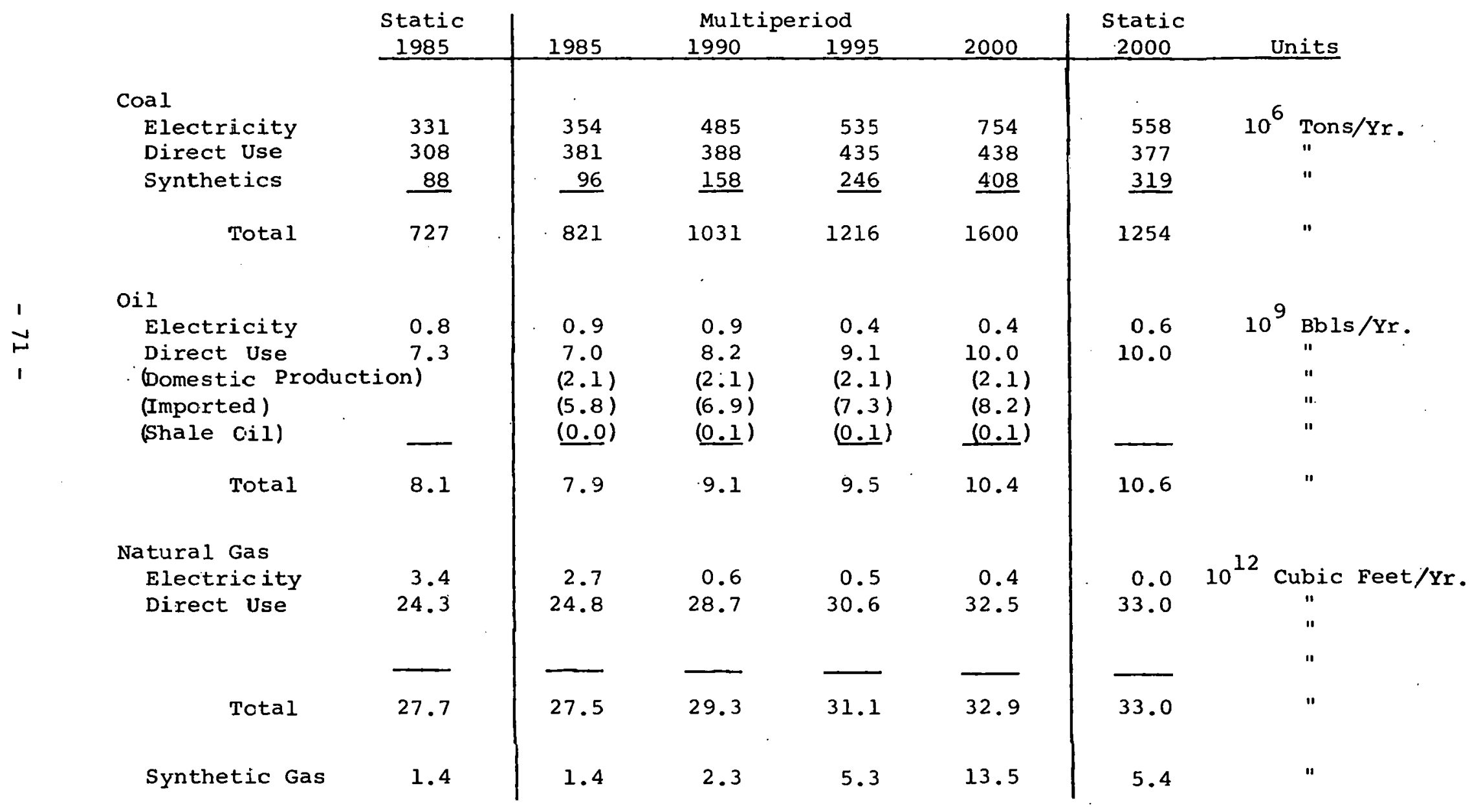


probably reflect an implicit cost assigned to coal because of its environmental effects.

Figure 9 shows fuel use for electricity generation in the multiperiod model, and Table 17 presents comparable results for the static baseline cases and the multiperiod run. Both sets of results are approximately equal in electricity use but the multiperiod results lean to coal rather than nuclear. The hiotorical growth of electrification, shown in Table 17, seems to be similar in the results from the two models. The last line in the table presents the average load factur. The load fastor increases as a result of increased use of off peak capacity to produce pumped storage capacity for peak electrical demands. However, the ovcrall load factor is higher than other historical or experted electric utility load factors. The constraints are being revised to reflect more realistic lodd lactoro. If this had been incorporated in the model, the capacities would have been about $10-15 \%$ larger in each period. Hence, the indicated capital requirements are probably on the low side.

Table 18 indicates the detail that can be developed for fuel production or use. The units are in tonnes of fissile material. The history of the generation and 


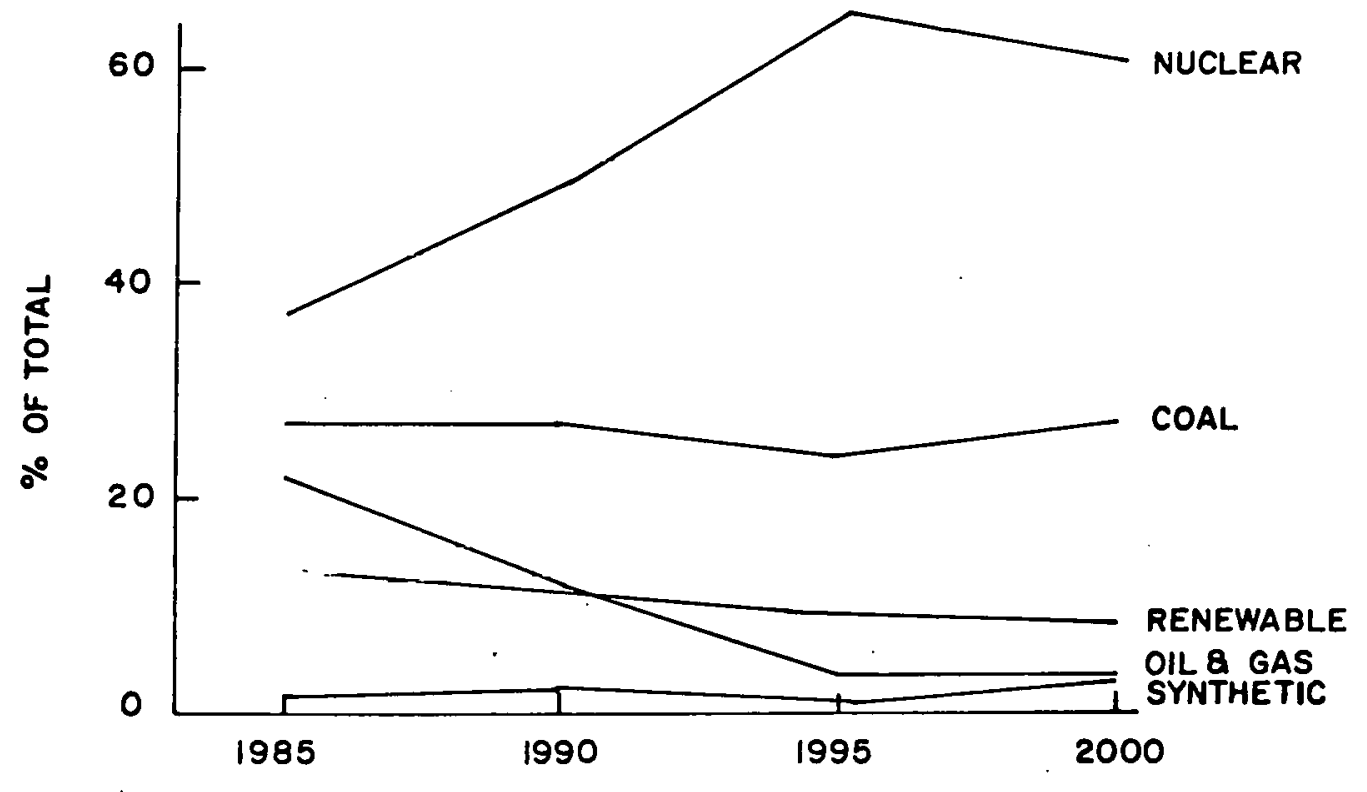

Figure 9. Electricity production by fuel used. 
TABLE 17

Electr:aity Production $\left(10^{\subseteq} \mathrm{KNHr}\right)$

Coal

Other Fossil

Nuclear

Renewable

Synthetic

Total

$\%$ of Fesources

$\%$ of Demand

Average Load Factor \%

\begin{tabular}{|c|c|c|c|c|c|}
\hline \multirow{2}{*}{$\begin{array}{c}\text { Static } \\
1985\end{array}$} & \multicolumn{4}{|c|}{ Multiperiod } & \multirow{2}{*}{$\begin{array}{c}\text { Static } \\
2000 \\
\end{array}$} \\
\hline & 1985 & 1990 & 1995 & 2000 & \\
\hline 878 & 934 & 1268 & 1417 & 1996 & 1531 \\
\hline 740 & 7.73 & 547 & 193 & 193 & 321 \\
\hline 1286 & 1288 & 2318 & 3832 & 4483 & 5402 \\
\hline 524 & 451 & 515 & 547 & 612 & 598 \\
\hline & 26 & 77 & 77 & 155 & \\
\hline 3428 & 3472 & 4725 & 6066 & 7439 & 7852 \\
\hline 31 & 31 & 35 & 38 & 42 & 42 \\
\hline-- & 24 & $2 \varepsilon$ & 32 & 35 & -- \\
\hline-- & 60 & 62 & 62 & 68 & --- \\
\hline
\end{tabular}


TABLE 18

Annual Production And Use of Nuclear Fuels (Tonnes Fissile)

$\begin{array}{llll}1983-87 & 1988-92 & 1993-97 & 1998-2002\end{array}$

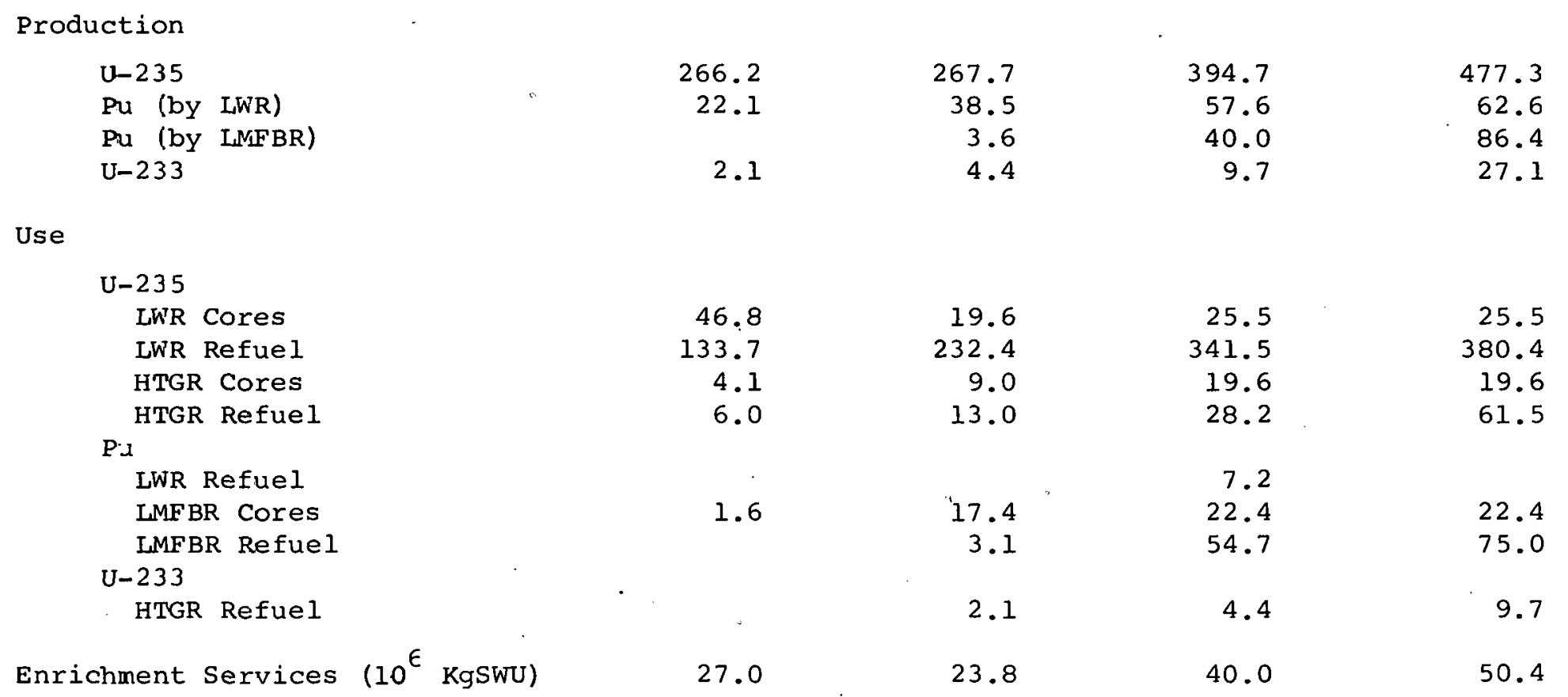


disposition of the four types of nuclear fuel (i.e., U-235 in low enriched uranium, U-235 in high enriched uranium, plutonium including plutonium-uranium mix, and U-233) is clearly presented. From data such as these the requirements for storage, waste disposal, shipments and other activities in the nuclear fuel cycle can be determined. For comparison of the externalities associated with alternative nuclear scenarios or with scenarios substituting other fuels for nuclear, these outputs are most useful. Despite widespread use of the LMFBR by the end of the period, the demand for enrichment services is shown to be increasing.

\section{2) Production Capacity and Capital Requirements}

The model generates the capacity required to produce energy output. Units of capacity are nominal facilities such as a 1000MW(e) power plant or a $250 \times 10^{9}$ BTU per day coal conversion facility. 19 "The moủel is designed so that older nominal facilities are retired and replaced, and additional capacity is added when needed to meet demands. Replacement and increases in capacity are endogenous variables. Retirement of "old" capacity is exogenous.

19. These nominal units are based on typical expected future facilities. The National Science Foundation is sponsoring a study by Bechtel Corp. to generate data on capital and operating costs for nominal facilities (16). If these become standard units, the model inputs will be adjusted to reflect the Bechtel nominal facility definitions anả costs. 
The selection of the type of capacity to build is made from the entire set of available technologies in order to minimize total discounted cost of the system over time.

Tables 19 and 20 show the installed capacity in numbers of nominal facilities at the midpoint of each period. As can be seen, all patterns of capacity development appear. Some facilities such as coal and nuclear electric and most synthetic fuel plants show continuous growth. Others such as gas fired electric facilities increase and then decrease. Still others such as refinery capacity decrease and then increase. Finally, a pattern of constantly decreasing capacity is exhibited by facilities generating electricity from oil. For analytic purposes it is most useful to know the effect that changing the cost or rate of growth of one supply technology will have on the decisions to install capacity of another one. Sensitivity analyses and exercise of the model across alternative scenarios will clearly illustrate the points as which the model chooses to change from one supply technology to another.

Figure 10 shows the history of electrical generating capacity including the phaseout of inherited capacity at the beginning of the period and the installation of new 


\section{TABLE 19}

Installed Ẽlectriclty Generating Caparity (Nominal 1000MW(e) plants)

\begin{tabular}{|c|c|c|c|c|}
\hline & 1985 & 1990 & 1995 & 2000 \\
\hline Cดล 1 & 134 & 174 & 214 & 261 \\
\hline Oil & 80 & 80 & $7 n$ & 60 \\
\hline Gas & 60 & 63 & 54 & 37 \\
\hline LWR & 201 & 302 & 452 & 492 \\
\hline HTGR & 10 & 23 & .47 & 104 \\
\hline IMFBR & 0 & 3 & 50 & 111 \\
\hline Renewable & 64 & 70 & 77 & 90 \\
\hline Peaking & 117 & 160 & 134 & 103 \\
\hline Total & 666 & 875 & 1098 & 1258 \\
\hline
\end{tabular}


TABLE 20

\section{Installed Production Capacity for selected \\ Non Electrical Supply Technology \\ (No. of nominal plants)}

\section{$1985 \underline{1990} 1995 \quad 2000$ Nominal Plant Description}

Synthetic Fuels

Methane

Methanol

$\mathrm{H}_{2}$ (Coal)

$\mathrm{H}_{2}^{2}$ (Electrolysis)

Syncrude from Shale

Refineries

Enrichment

Fuel Cells

$\begin{array}{rrrrlll}17 & 26 & 38 & 56 & 250 \times 10^{9} & \mathrm{BTU} / \mathrm{Day} \\ 1 & 2 & 5 & 12 & 250 \times 10_{9} & \mathrm{BTU} / \mathrm{Day} \\ 1 & 3 & 7 & 14 & 250 \times 10_{9} \mathrm{BTU} / \mathrm{Day} \\ 3 & 3 & 3 & 3 & 250 \times 10^{3} & \mathrm{BTU} / \mathrm{Day} \\ 1 & 2 & 2 & 2 & 100 \times 10^{3} \mathrm{Bbl} / \mathrm{Day} \\ 127 & 115 & 118 & 127 & 200 \times 10^{6} \mathrm{Bbl} / \mathrm{Day} \\ 3 & 3 & 5 & 6 & 8.8 \times 10^{6} \mathrm{KgSWU} / \mathrm{Yr} \\ 20 & 27 & 40 & 64 & 10^{3} \mathrm{MW}(\mathrm{e}) & \end{array}$




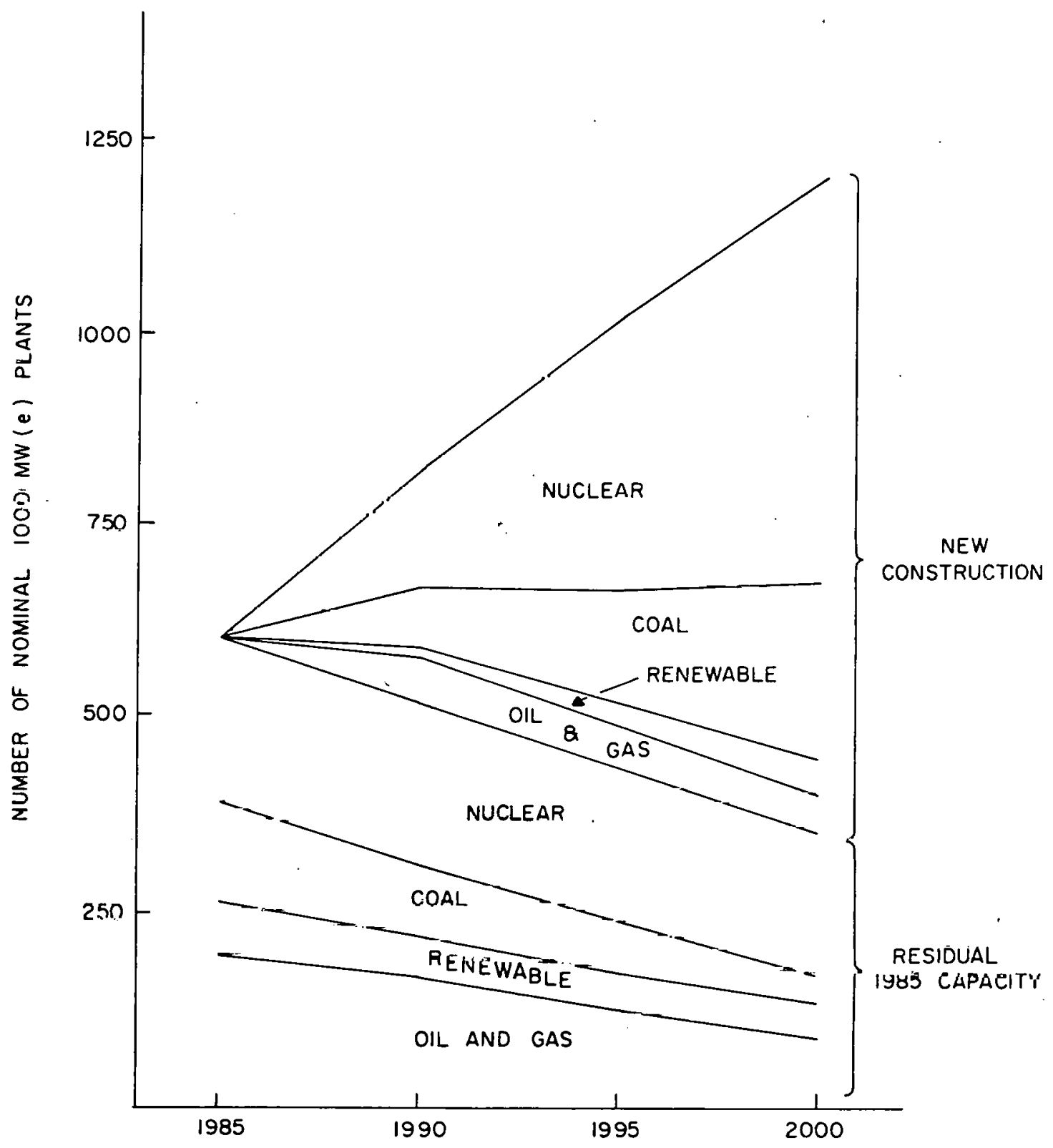

Figure 10. Electricity generating capacity. 
capacity. The generating capacity is shown in cumulative nominal 1000MW(e) generating facility units. As can be seen, after 1990 virtually no new oil and gas generating capacity is added. The fraction of capacity provided by nuclear plants grows faster than the new nuclear installations since much of the existing nuclear capacity in 1985 is new whereas the fossil capacity is older and requires replacement sooner.

Table 21 presents the capital requirements to provide the new capacity. The requirements are stated in terms of billions of 1970 dollars per year. Most of the capital requirements are internally generated by the model using cost inputs from earlier Brookhaven studies (12). However, the synthetic fuel and shale oil retorting costs are based on the MIT energy policy group costs (17). These costs are comparable to those used in previous BNL studies. Enrichment plant costs are based on reference (18, p. 52). The costs for the rest of the fuel cycle and for uranium and rnal mines have been generated using information developed by Bechtel under a National Science Foundation grant (16). All of the costs in the multiperiod model will be updated to 1974 dollars upon completion of this report. 
TABLE 21

Capital Investment Requirements

(Billions of 1970 dollars per year)

\begin{tabular}{|c|c|c|c|}
\hline & \multicolumn{3}{|c|}{ Period } \\
\hline & $1985-89$ & $1990-94$ & $1995-99$ \\
\hline \multicolumn{4}{|l|}{ Elestricity Generation } \\
\hline Cual & 40.3 & 40.1 & 44.8 \\
\hline other Fossil & 20.4 & 0.6 & 0.6 \\
\hline LWR & 36.5 & 59.1 & 20.0 \\
\hline HTGR & 8.1 & 16.4 & 42.2 \\
\hline LMF BR & 2.4 & 34.3 & 44.7 \\
\hline Renewable & 6.1 & 6.4 & 8.1 \\
\hline Storage & 9.7 & --- & --- \\
\hline \multicolumn{4}{|l|}{ Oil Processing } \\
\hline Refineries & 7.1 & 12.8 & 13.2 \\
\hline Retorting Shale & 0.9 & --- & $-\infty$ \\
\hline \multicolumn{4}{|l|}{ Synthetic Fuels } \\
\hline Methane & 2.7 & 3.7 & 7.3 \\
\hline Methanol & 0.4 & 1.1 & 2.1 \\
\hline $\mathrm{H}_{2}$ from Coal & 0.5 & 0.8 & 1.8 \\
\hline \multicolumn{4}{|l|}{ Mines 2} \\
\hline $\operatorname{Coal}^{\star}$ & 2.5 & 3.1 & 3.8 \\
\hline Uranium* & --- & 0.5 & 0.3 \\
\hline \multicolumn{4}{|l|}{ Nuclear Fucl Cycle } \\
\hline Conversinn* & ---- & 0.2 & 0.1 \\
\hline Enrichment & 0.3 & 3.2 & 1.6 \\
\hline Fabrication * & 1.5 & 1.6 & 0.9 \\
\hline Reprocessing* & 0.2 & 0.3 & 0.2 \\
\hline Fuel Cells & 2.1 & 4.3 & 7.4 \\
\hline
\end{tabular}

*These costs are not ondonennisly developed in the model. They have been derived from reference(16). They are expressed in 1 y/3 dollass. $n l 1$ other costs are in 1970 dollars. The Bechtel costs are those that wmild be pain to the architect engineer. They do not include owner incurred costs, e.g. interest on funds invectud, lnnd costs, rost. of licensing, taxes, etc. 
Although costs based upon the Bechtel inputs were generated manually, the approach used lends itself to a simple program for computerized computation. This demonstrates that one can insert a scenario into the multiperiod model, generate for that scenario the flow of capital requirements associated with an optimum mix of energy supply technologies, fully accounting for interfuel substitution, and then calculate through the medium of the Bechtel costs the time phased level of investment associated with the scenario. Effort devoted to fully exploiting this coupling should enhance the value of both the BNL and the Bechtel studies.

Although a substantial fraction of direct capital costs for energy is shown in Table 21 , there are other costs associated with any given pattern of energy growth. For example, investment in pipelines, ships, port and storage facilities for LNG is not shown. Transportation and storage costs for Western coal are not included and land rehabilitation costs may be understated. Costs for nuclear waste disposal are not shown. An alternative and complementary technique for arriving at these costs is through use of an inputoutput model with an associated capital matrix. This capacity will soon be developed by the Economic Analysis 
Group at Brookhaven.

The total investment shown is about 200 billion dollars per year in 1970 prices. This would be about $10 \%$ of the 1990-95 GNP given a growth, rate of about $3 \%$ per year. Since gross investment seldom exceeds $16-18 \%$ of GNP and since the total energy investments will exceed those shown here, one begins to get a quantitative feeling for often expressed concerns about the interaction between huge demands for capital by energy producing industries and the economic system's capability to supply the capital requirements. 


\section{3) Energy Demands}

The fuel mix directed to meeting energy demands is a third type of output generated by the multiperiod model. Table 22 presents this kind of output. The results are intuitively satisfying since they show a gradual substitution over time of one energy source for another. A concern that exists with solutions to linear programming problems is the possibility of making very large shifts as a result of small changes in parameters and prices at the margin. For the cases studied this does not happen. A feature of the dynamic model over the single-period model which helps to prevent such radical shifts is that initial capital stock for the first period are explicit inputs. The result is gradual rather than dramatic fuel substitution.

Figure 11 portrays the shifting of the fuel mix over time for the automobile (1la) and water heat (11b) demand requirements. This demonstrates another application of the model. The shift to other fuels for the automobile was limited by constraints that were supplied to the model as inputs. For example, one can examine the substitution of alternative fuel, the rate at which end usc conversion devices (batteries and IC engines) coul, bo replaced and alternative assumptions as to the flexibility or inflexibility 
TABLE 22

Fuel Mix to Meet Energy Demands $10^{15} \mathrm{BTU} / \mathrm{Yr}$

$\underline{1983-87} \quad \underline{1988-92} \quad \underline{1993-97} \quad \underline{1998-2000}$

Petrochemicals

Oil

Gas

Coal

water Heat

Electricity

Solar

Oil

Space and Process Heat

Electricity

Oil

Gas

Coal

Automobile

Electricity

Oil

Hydrocen

Enrichment (Electricity)

Air (Oil)

Truck, Bus, Fail (Oil)

Electric Rail (Electricity)

Iron Feeds=ocks :Coal)

fir Conditioning (Electricity:

5.0

1.2

0.7

7.7

1.4

0.5

0.3

0.4

1.4

1.6

7.5

8.6

1.6

1.5

0.8

1.0

1.7

1.3

18.8

3.5

20.5

3.7

0.7

0.4

0.9

1.8

0.4

0.1

2.3

0.2

2.4

2.3

2.9

3.8

5.8

26.7

24.1
3.4

4.2

0.3

2.1

1.5

0.2

2.3

2.0

0.3

0.4

2.4

2.4

0.2

0.6

0.3

2.4

1.7

0.2

2.5

0.1

0.5

2.9

2.0

1.8

0.3

0.3

2.9

3.0

*less than .05 


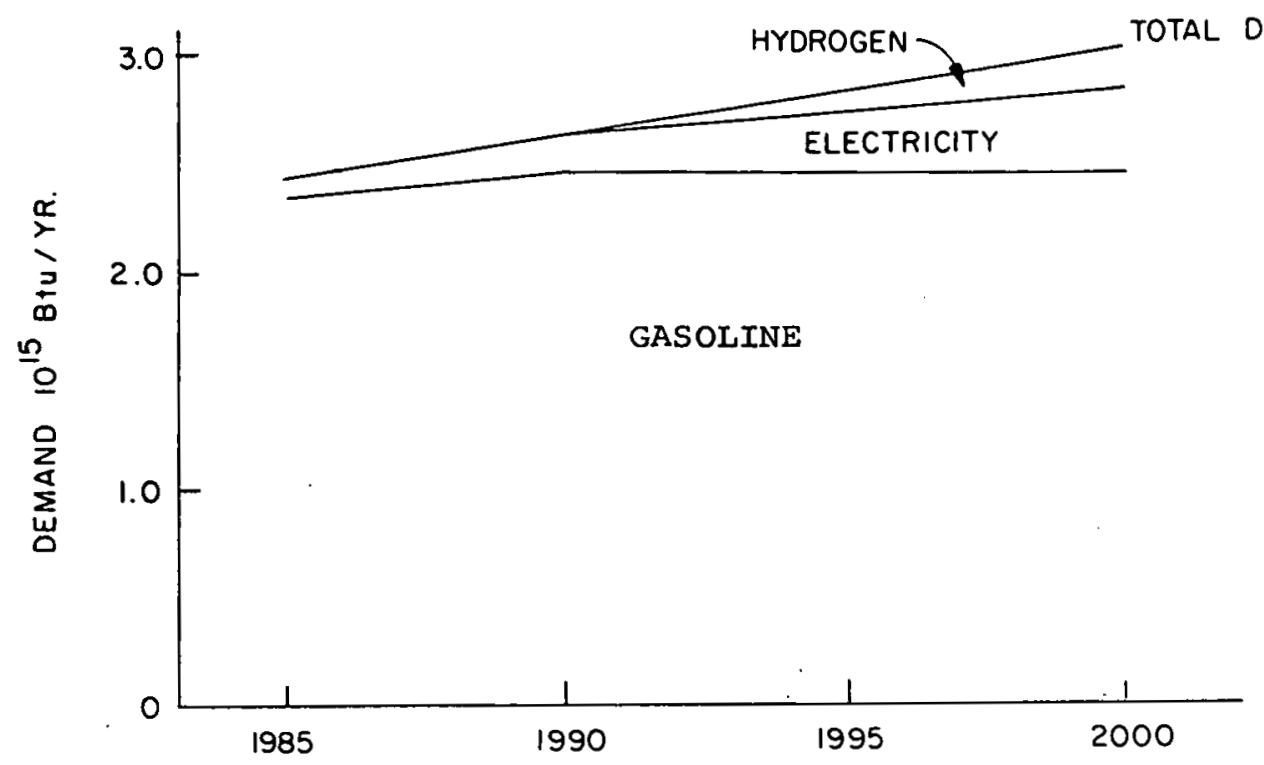

ANNUAL FUEL USE TO MEET AUTO DEMAND

(a)

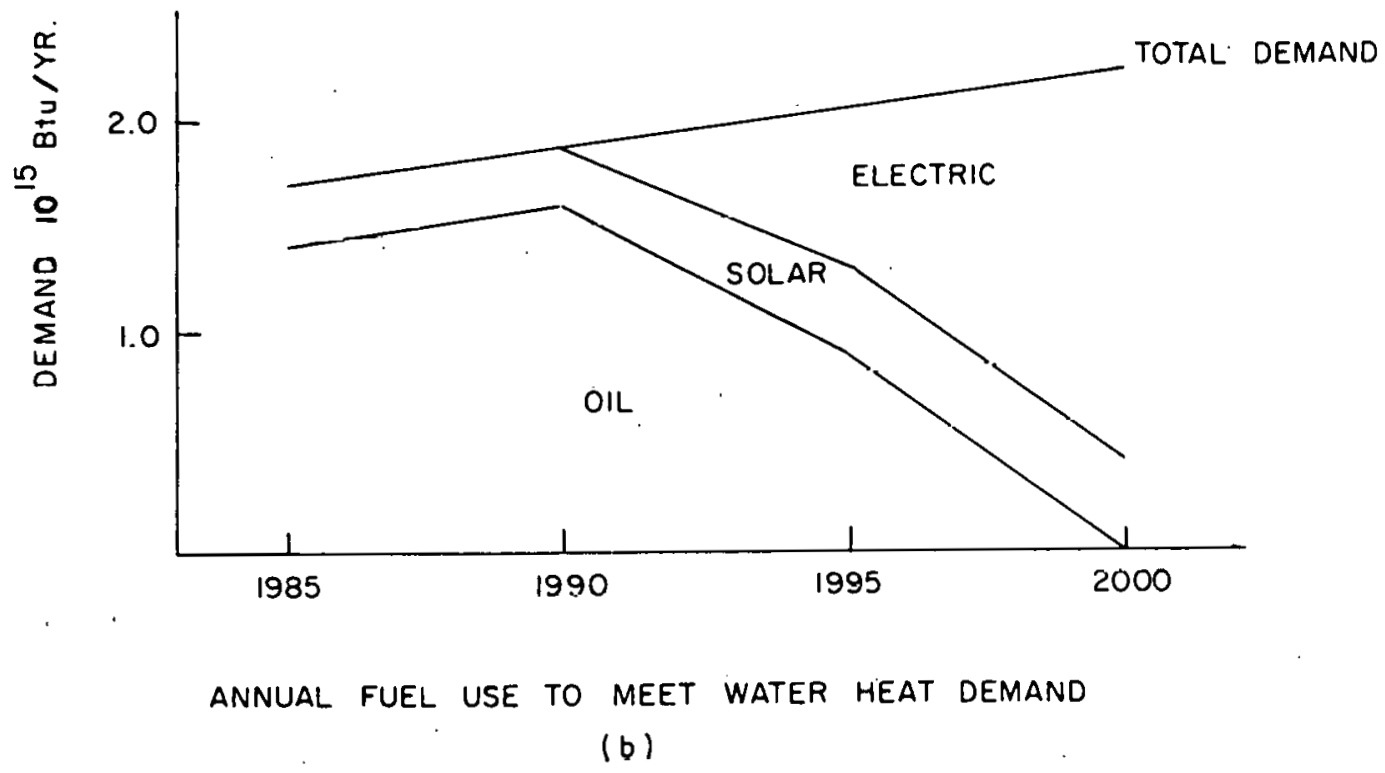

Figure 11. Annual Fuel Use to Meet Auto and Water Heat Demands. 
of the current Iuel delivery infrastructure. Alternatively, one could examine the impact on the fuel mix of conservation strategies that would effectively reduce demand growth.

On the other hand, no constraints were placed on water heat, and the model solution indicates a dramatic shift away from oil and to electricity toward the end of the century. If this shift is too extreme, constraints can be imposed that would indicate for the later years either the installed end use devices using oil for heat and therefore also likely to use it for hot water, or regional patterns such that some regions would not heat hot water electrically. In any case these two examples demonstrate the tailoring that can be done to (1) provide for some regional characteristics in a national model and (2) more realistically describe inertia in the systein caucad by inherited conversion devices, government policies, vi thạ twin human behavioral charactcristics of fear of the untried and reluctance to alter established behavior patterns.

\section{4) Slaadow Price Tnterpretations}

The research proposal that initiated the grant for this study was directed to generating and Inlerprcting ghadow prices with the Brookhaven Energy System Optimization Model 
(BESOM). Two shadow price applications are described in Chapters III and $V$ of this report. The third proposed application was to interpret shadow prices associated with energy resources. The original research plan called for a decision to be made during the first year as to whether BESOM would be modified or an alternative model developed under the second year of research. It became obvious at an early date that a multiperiod model would enhance the resource shadow price analysis. Therefore a decision was made to develop this new model (DESOM) which is both a modification and extension of BESOM. This portion of the report discusses this model. The discussion that follows is the heart of the first year findings. In a sense, the previous discussion of the model's outputs and uses is a byproduct of the research goal. Before continuing, let us define shadow price. A shadow price on a resource arises when its supply is constrained to some maximum value in the linear program and the solution bumps against the constraint. It is defined as the decrease in total system cost if one more unit of a constrained supply is available. Energy demand requirements are specified in the linear program as equality 
constraints, and shadow prices also arise for each of these constraints. In the first case, the shadow price represents the upper limit of monetary outlay (cost) one would make to acquire an additional supply unit. Conversely, in the second case, it is an upper limit on the savings (benefit) that would accrue if one demand unit less had to be met. In models where prices are not explioit, these represent the upper bound on the prices (market clearing prices) that a knowledgeable and efficient seller of the supply or demand units could extract in a perfectly competitive market. In our model the demand price is not explicit and hence the shadow price signifies the upper limit on its market price. On the supply side costs (prices) are assigned to resources and energy supply production equipment., For these cases where costs are explicitly introduced, the shadow price is a differential price, and it represents the increment that can be added to the exogenously specified cost. This increment, is, in fact, the premium or "économic rent" that can be extralled bcoause the resource is scarce.

Our model generates no less than four different kinds of shadow prices. One of these is unlquely relatud to energy resources, one is uniquely related to energy capacity, one is related to both energy capacity and energy resources, and one is related to energy demands. These can be enumerated 
Shadow Price 1 - Upper bound on resource availability;

Shadow Price 2 - Upper bound on capacity;

Shadow Price 3 - Growth limitation;

Shadow Price 4 - Demand requirement.

Each of these will be examined.

Shadow Price 1 - Resource availability

This shadow price can arise from either of two factors. First there may not be enough of a resource in terms of the total quantity available over all periods. In the demonstration run this constraint is binding only for uranium. The available amount of all other resources is in excess of the requirement to meet the energy demands.

The second constraint on resource availability is the quantity available in each period. This constraint arises from the incorporation of a limit on the amount that can be produced in period $t+1$ based upon the pronlustion level in period $t$. The limit is representative of the condition that output is a function of the number of producing wells or mines and that an increase in production can only take place by drilling new wells or opening new mines. Moreover some of this new capacity is needed to replace holes that 
run dry or mines that become exhausted. This constraint is manifested by a shadow price that applies to an additional unit of the resource in each period. The value associated with this constraint can be called the "market clearing price" if perfect competition and a perfect futures market is assumed. It is the price (or cost) that could be assigned to the resource in the period without changing the allocation of resources in the optimal solution of the LP. It should not be confused with the shadow price assigned to the growth constraint, which will be discussed later. This is the most interesting shaduw prico with respect to resource allocation.

The third kind of shadow price associated with resources is that associated with the growth constraint. Producing an additional unit of a resource in period $t-1$ permits additinnal production of that resource in perion t.. If additional period $t$ output could be obtained without increasing period $t-1$ output, then a possible savings might exist. In other words, less of the resource in period $t-3$ might have been used to support period $t$ output require- . ments before bumpiny up agdinst the growth limitation. This is a value that can be attributed to relaxing the growth conslraint. The interpretation of this is that it is the 
value of drilling more wells or opening more mines than allowed by the growth parameter put into the model.

As discussed above, only. uranium availability is

limited by a total resource constraint. This run of the model values this limit at slightly over $\$ l$ per pound of $\mathrm{U}_{3} \mathrm{O}_{8}$. This might be interpreted as stating that in a world of perfect future markets the owner of uranium mines could extract an economic rent (premium of price over cost) of about $\$ 1.00$ per pound. This would be reflected as a capitalized cost in the market price of uranium ore reserves. The second type of demand price information is the "market clearing price". in each period for each resource. These are presented in Figures 12-15. for coal, oil, gas, and uranium. These figures can be interpreted as follows. A price in 1970 dollars for a unit of each resource is provided as an input to the model. The "market clearing price" is defined as the price (cost) that could have been assigned to the supply without changing the solution to the linear program. The difference between the "market clearing price" and the cost is a return that accrues because the growth is limited. If the market price were to rise toward the "market clearing price" an incentive would be created for further exploration and development and the exploitation 
of less richly endowed resources.

The discussion that follows deals with the "market clearing price" for each resource. Two warnings are in order. First, this value for each resource is related to the associated growth rate for the resource and in general would be lower if the permissable growth rate were larger. Second, the "market clearing price" in any period for any resource is relaled to all other periods and prices. Therefore changes in other prices can affect any given "market clearing price." Changes in growth rates will affect the "market clearing price" in all future periods. Analysis of "llarket clearing prise" for coal Figure 12 presents the supply price for coal that was input to the model. The "market clearing price" exceeds the supply price in each period. This result is misleading if it is interpreted as reflecting future shurlages of coal as a resource. The result arises from the growth rate constraint and implies that the coal capacity constraints should be relaxed. The modelmaker is alerted to examine the growth constraint to make sure he has not underestimated it. Alternativaly, the policymaker is alerted to the possible need for policies that will permit accelerated 
FIGURES IN PARENTHESES ARE \$/TON IN 1970 PRICES

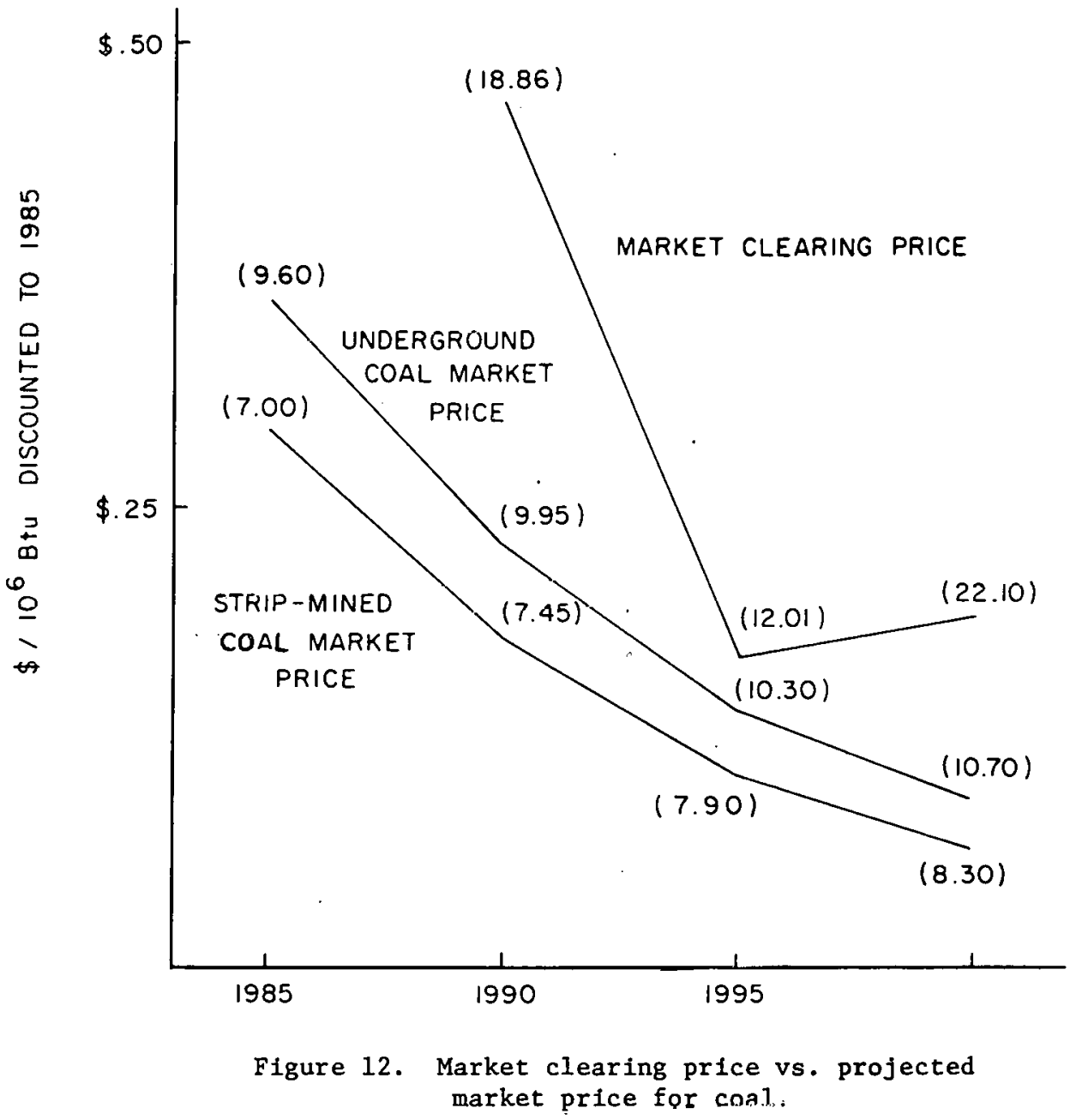


growth in coal extraction capacity.

If coal growth is limited because of environmental considerations, the difference between the "market clearing price" and the cost of coal is indicative of the incremental cost to society for less environmental degradation.

\section{Analysis of "market clearing price". for oil}

The 1990 "market clearing price" for oil shown in Figure 13 is very similar to that for coal. The interpretation is the same. The high price may result from an underestimate of the growth rate for oil. Alternatively, it may imply that the o1l pliced that are put into the model are toolow. The "market clearing price" for oil is exactly equal to the market price for oil for 1995 and 2000. This rosult nocurs because the total supply of oil ic sufficient to meet requirements and it can expand at a rate that i.s consistent with increasiny demand. Analysis of "market clearing price" for gas

The natural gas market clearing price shown in Figure 14 ic vory much larger than the projected market price. This differential is partly due to regulation on the price of gas although the price includes more and more deregulated gas each year. Of greater importance is the fact that natural 
FIGURES IN PARENTHESES ARE IN \$/BOI IN 1970 PRICES

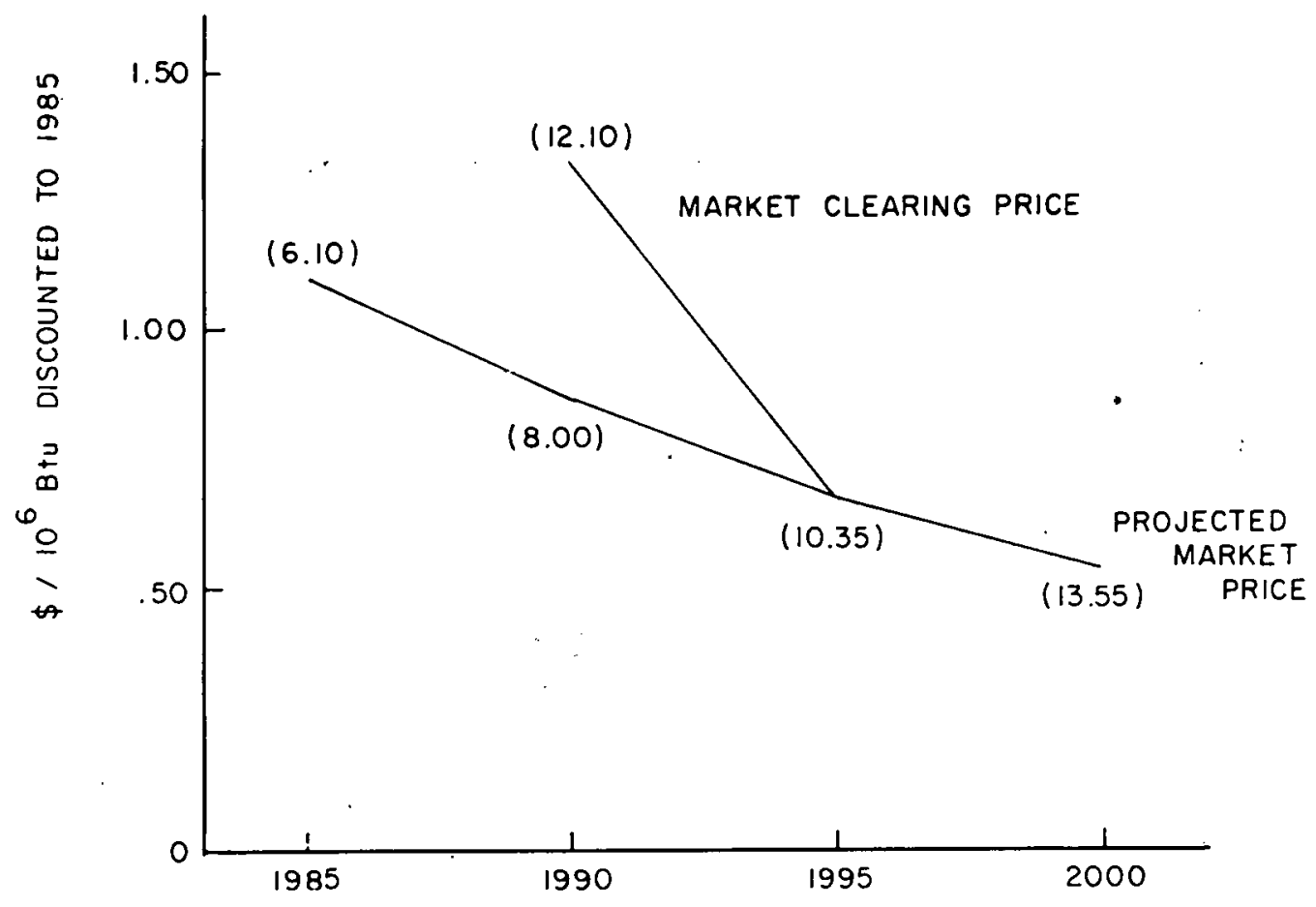

Figure 13. Market clearing price vs. projected market price for oil. 
FIGURES IN PARENTHESES ARE \$/ 1000 CUBIC FEET IN 1970 DOLLARS

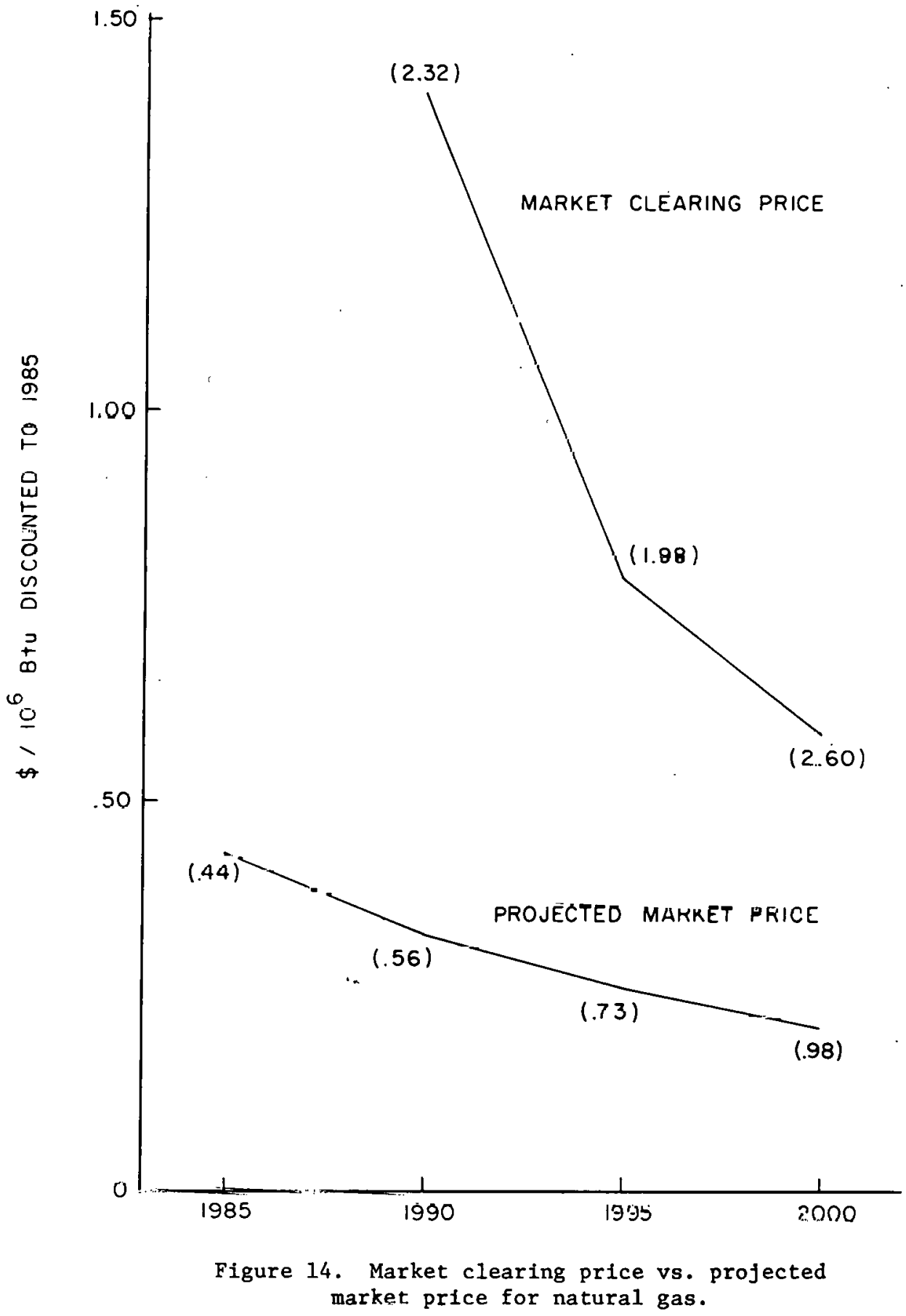


gas production and imports are limited and hence growth is limited. The level of the "market clearing price" approaches the market price at which synthetic gas can be profitably produced.

Analysis of "market clearing price" for natural uranium

The uranium case, Figure 15, is interesting because 1) it is the only supply that was exhausted and 2) it has a negative "market clearing price" in the second period. Since the total quantity of uranium must be spread over all periods and actual production of uranium falls off between the first and second period, the model wants to use the uranium toward the end of the century. However, the rules are that the amount mined in period $t+1$ is dependent upon the amount mined at time $t$. Uranium must be produced in the second period in order to keep the mines open so that the maximum amount can be produced in the last two periods. The one dollar per pound shadow price on uranium discussed earlier would be additive to the "market clearing price."

The optimal solution also generates the imputed market clearing prices of plutonium and uranium 233. These are presented in Figure 16. The plutonium price of $\$ 8.02$ per yram in 1970 prices compares well with direct 
NUMBERS IN PARENTHESES ARE IN \$/Lb. IN 1970 PRICES

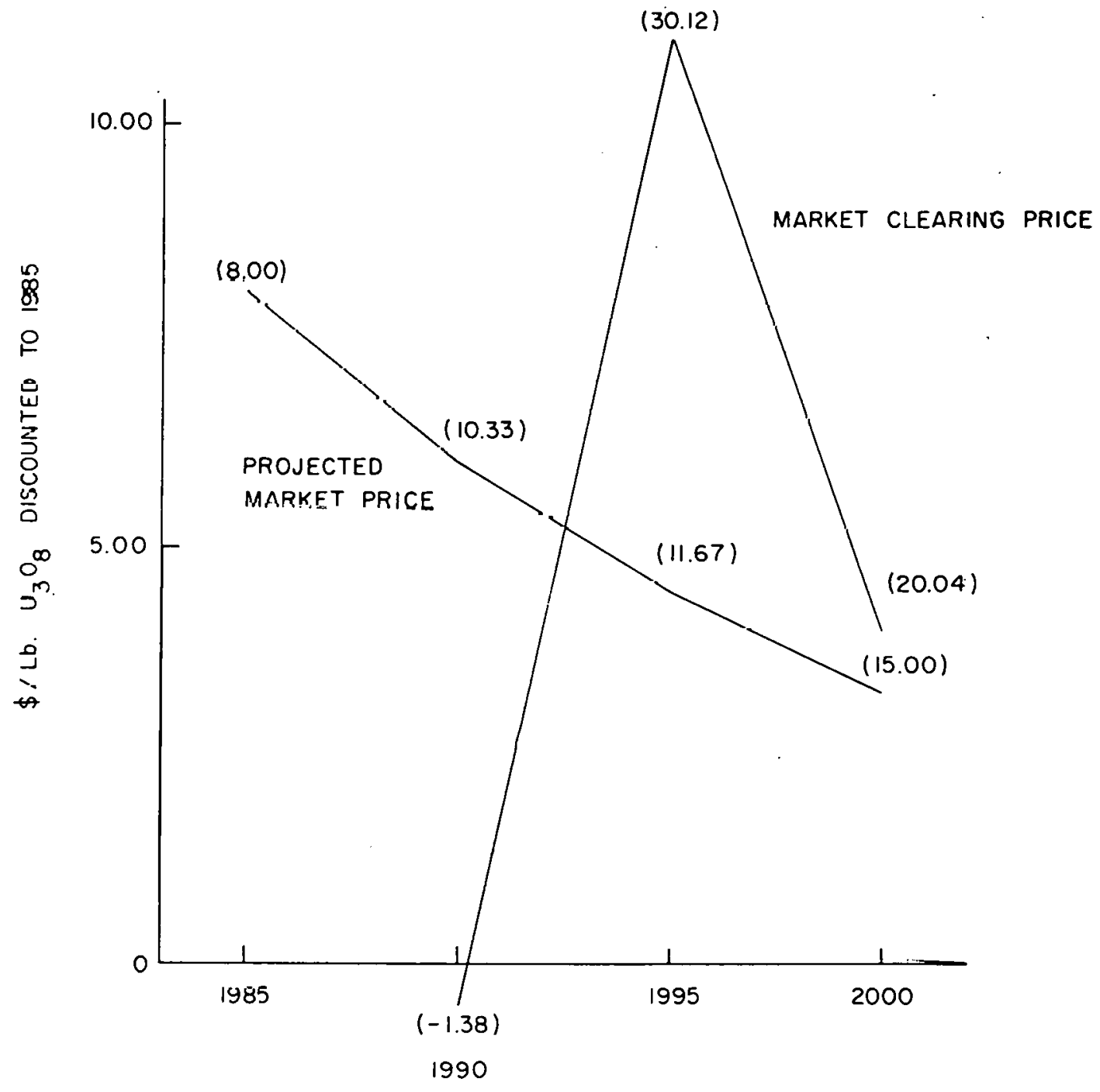

Figure 15. Market clearing price vs. projected price for uranium. 
NUMBERS IN PARENTHESES ARE IN \$/GRAM. IN I970 PRICES

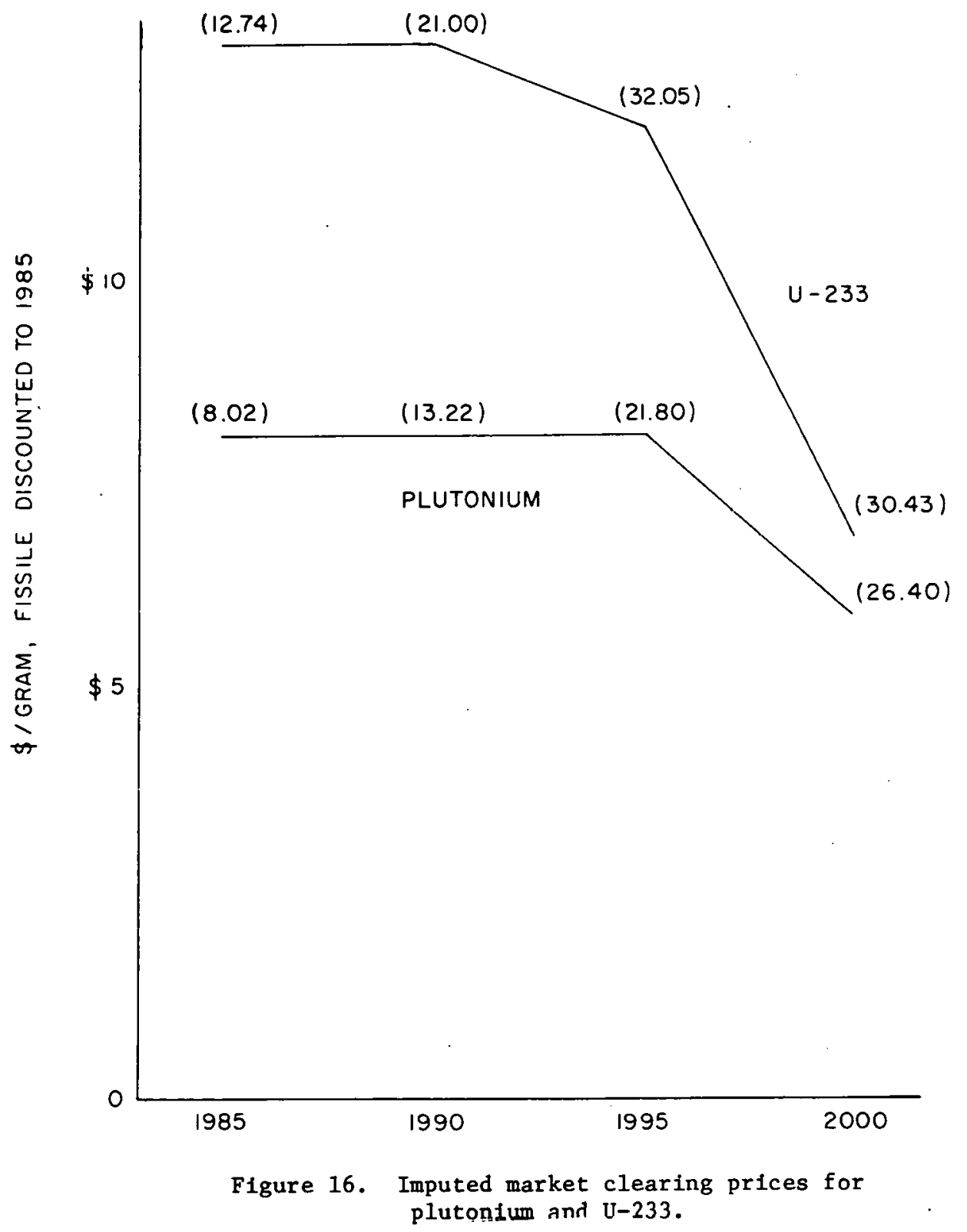


calculations of the value of plutonium. These generally impute a value of about $\$ 9$ per gram in 1970 prices. The fall in imputed price in the fourth period results from the truncation of the model. If the time horizon of the model run included the requirement to fuel nuclear reactors after the uranium has been exhausted, plutonium and U-233 prices would rise in the fourth period.

\section{Shadow Price 2- Capacities}

Capacity is added in each time period in order to satisfy increasing demands. Retired capacity must be replaced and incremental capacity must be constructed. The value of a unit of new capacity is its incremental value in meeting demands in the period in which it comes into being and in each successive period until it is retired. Unless it alas valuo (decreases total system cost) equal to or in excess of what it costs, additions to existing capacity will not appear in the optimal solution. The measure of incremental value added for a unit of capacity that initially contributes to output in time is its shadow price: Bchavoir of these shadow prices exhibit several different patterns. For one 
group of supply categories, shadow prices in all three periods exceed the 1970 costs. The higher shadow price indicates that production capacity has been emplaced in the previous time period and is available in the current period. It also shows that the new capacity emplaced was limited. Had this limitation not existed, more capacity would have been built. The difference between the shadow price and the market price is a measure of how much the new capacity is desired.

\section{Very Desirable Supply Technologies}

Ten supply technologies having very desirable characteristics are shown in Figure 17. Note that this group includes all of the nuclear and renewable central electric generating stations and the conversion of coal to synthetic fuels. Also included are total energy systems which use oil. They are constrained to produce a small fraction of the electrical energy produced. The renewable resource growth rates are limited by the avdilability of hydroelectric and geothermal sites. Available growth is fully exploited. The nuclear sector was allowed to expand quite rapidly but it eventually bumps into a fuel availability constraint. The synthetic fuels are 

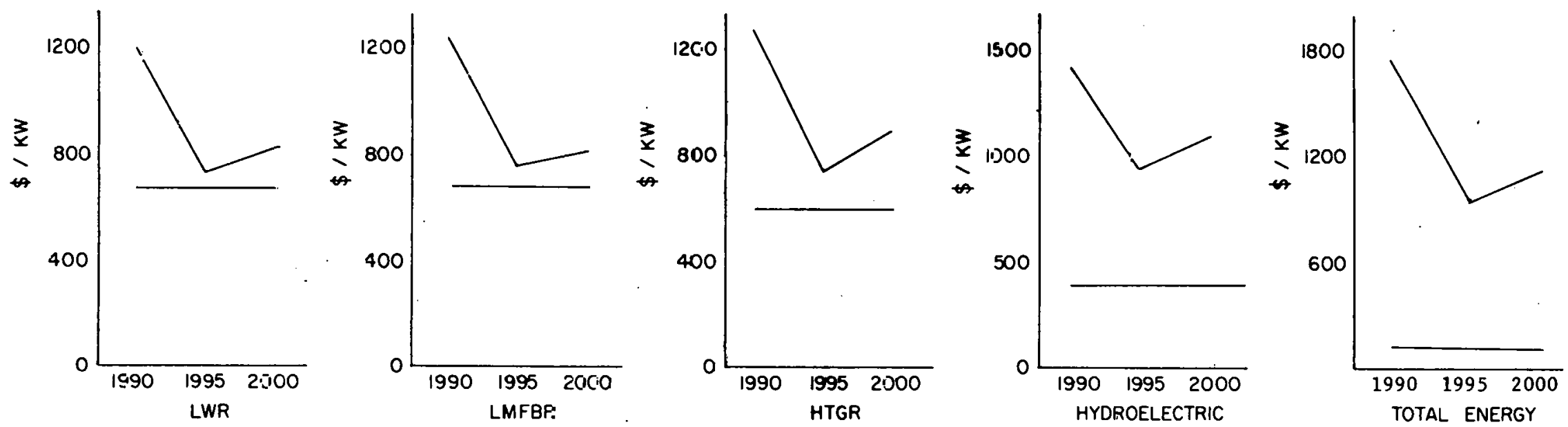

1
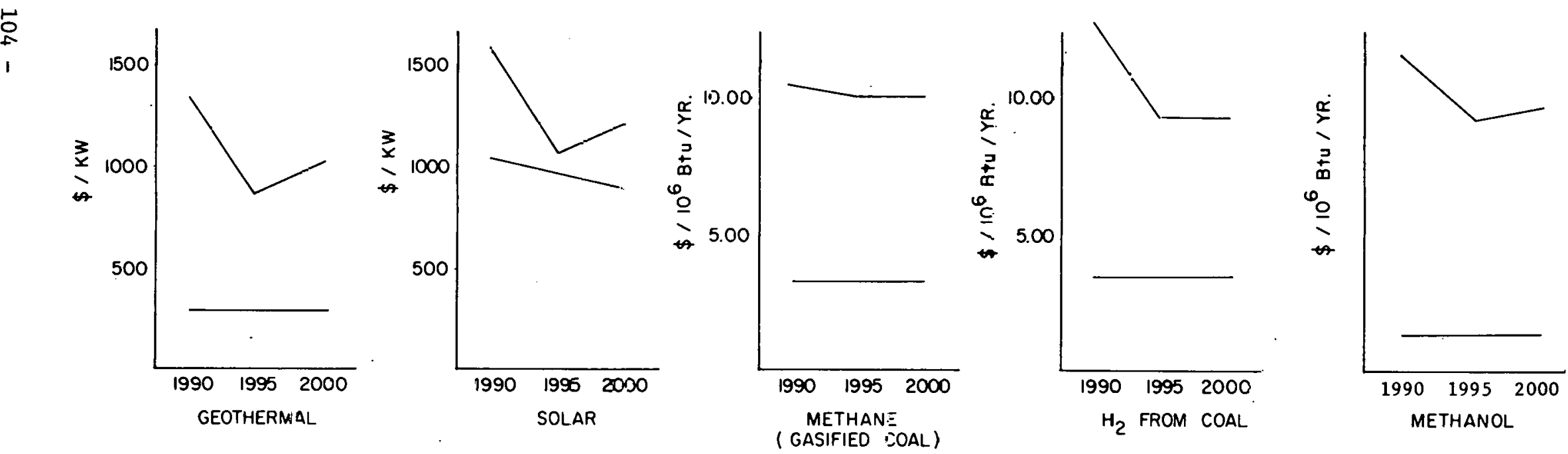

Figuze 17. Supply technologies in short supply

- shadow prices (upper curve) vs. cost (lower

clrve). 
permitted to grow very fast and the model run would like even faster growth. The desirability of the synthetic fuels is also evident from the large margins by which their shadow prices exceed their cost. This indicates that the cost estimates could be too small by a factor of two or more (factor of fifteen to twenty for methanol). It also implies that the cost inputs to the model may need careful examination.

\section{Desirable Supply Technologies}

The next set of supply technologies are those whose shadow prices indicate that they were desirable (new facilities were emplaced) in at least two time periods and those that, although desirable, would just recover their cost. The shadow price information is shown in Figure 18. New coal generating capacity was added in each period. In the third period even more new coal electric stations would be built if the growth limitation were relaxed, but total system cost will barcly be affected. In the final period the constraint is no longer binding and the building of new or replacement coal steam electric capacity does not affect total energy cost.

Both oil refining and enrichment are supply technologies where the shadow price equals the cost. In both cases new 

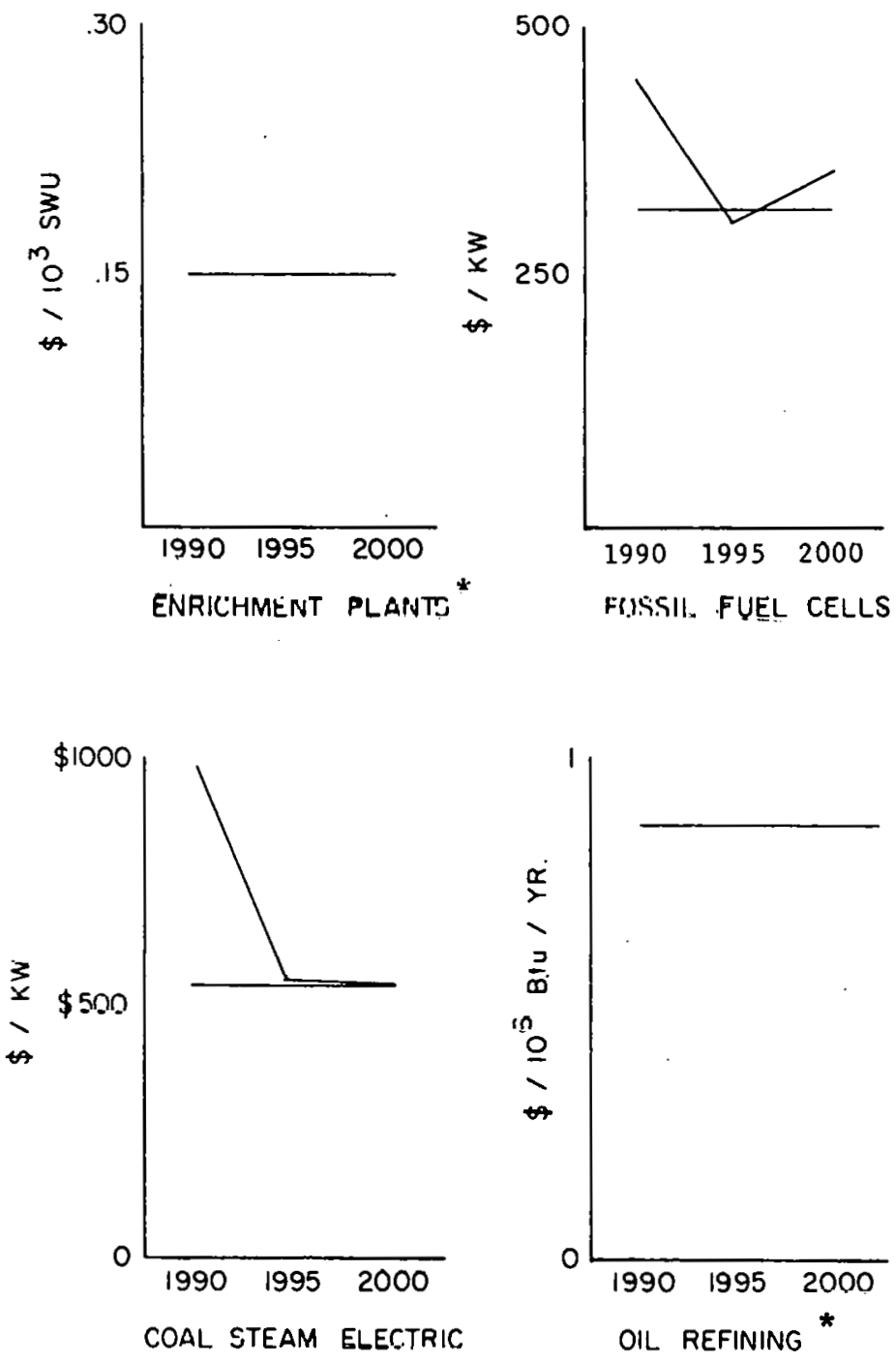

*Shadow price and cost curves coincide.

Figure 18. Desirable supply technologies - shadow prioes (upper curve) vs. cost (lower curve). 
and replacement facilities are constructed to meet refining and enrichment demands. The level of this construction is low enough so that the growth constraint is not exceeded. Finally the use of fuel cells as an electric storage system proves worthwhile in the first and third periods when shadow prices exceed costs. None are built in the second period when cost exceeds the shadow price.

\section{Marginal Supply Technologies}

The set of supply technologies depicted in Figure 19 are those that are attractive (shadow price exceeds cost) in only one of the three periods. For seven of the eight supply technologies shadow price exceeds or equals cost only in the first period. This means that these fossil fueled capacities are desirable until nuclear and synthetic fuel substitutes are available in large enough amounts to supplant further introduction of new fossil fuel capacity. The exception is gas from oil which is a technology that has not been allower to entcr inlu the solution but which is incorporated in the data set. The model results: tell us that if this technology were available at the costs provided to the model, some capacity would be built in the second period for introduction in the third. 

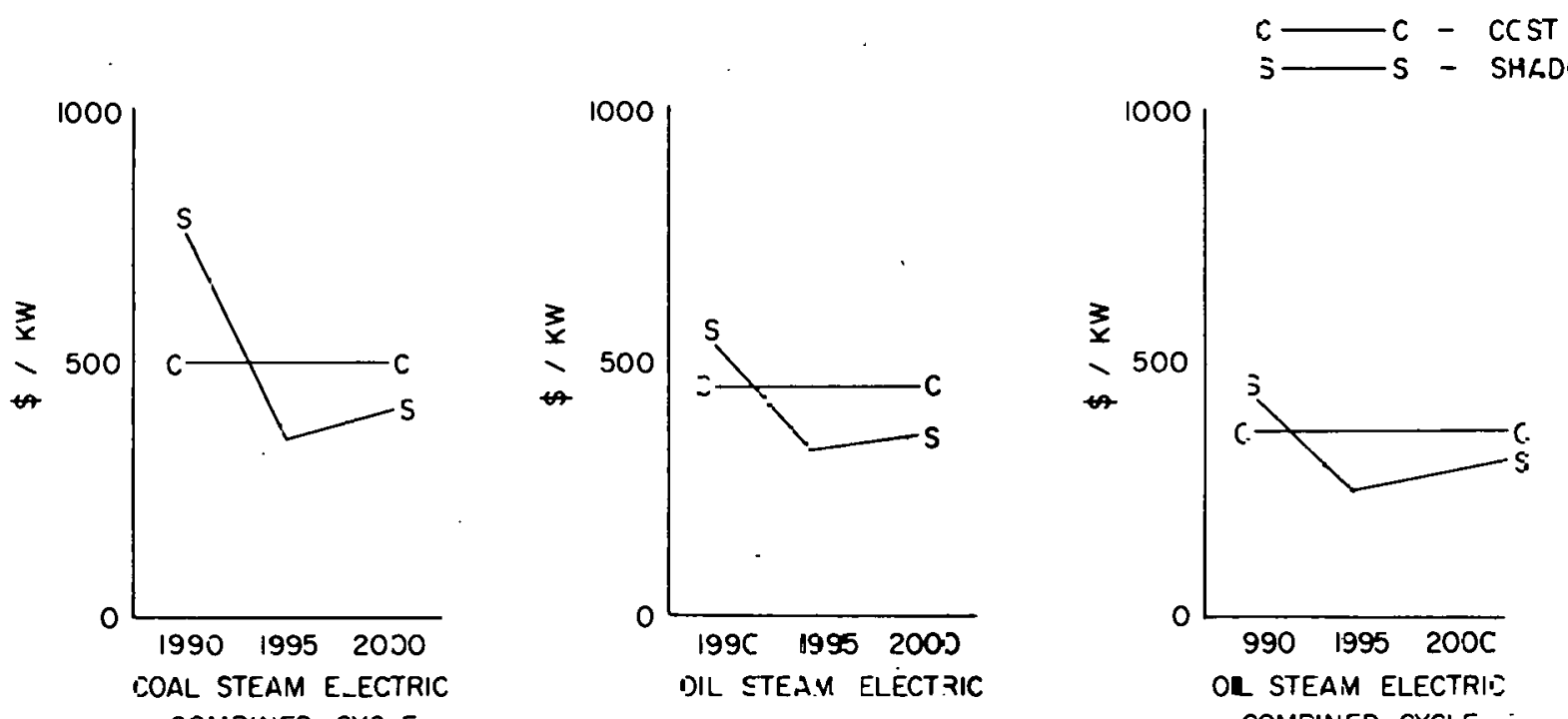

$\stackrel{\circ}{\circ}$ COMBINED CYC.
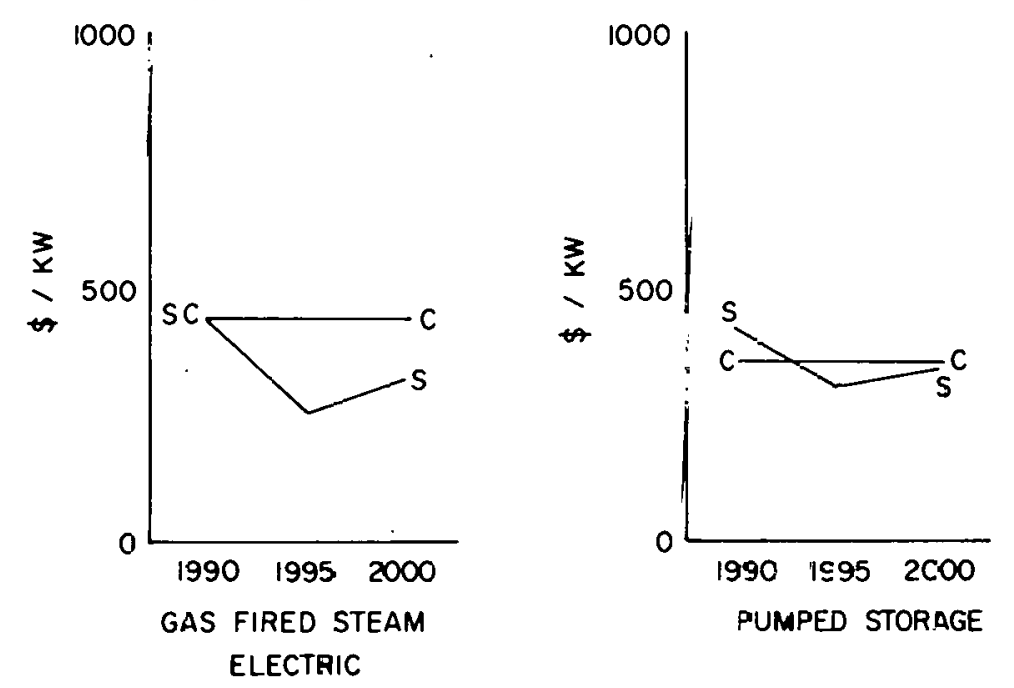

OL STEAM ELECTRIS COMBINED CYCLE
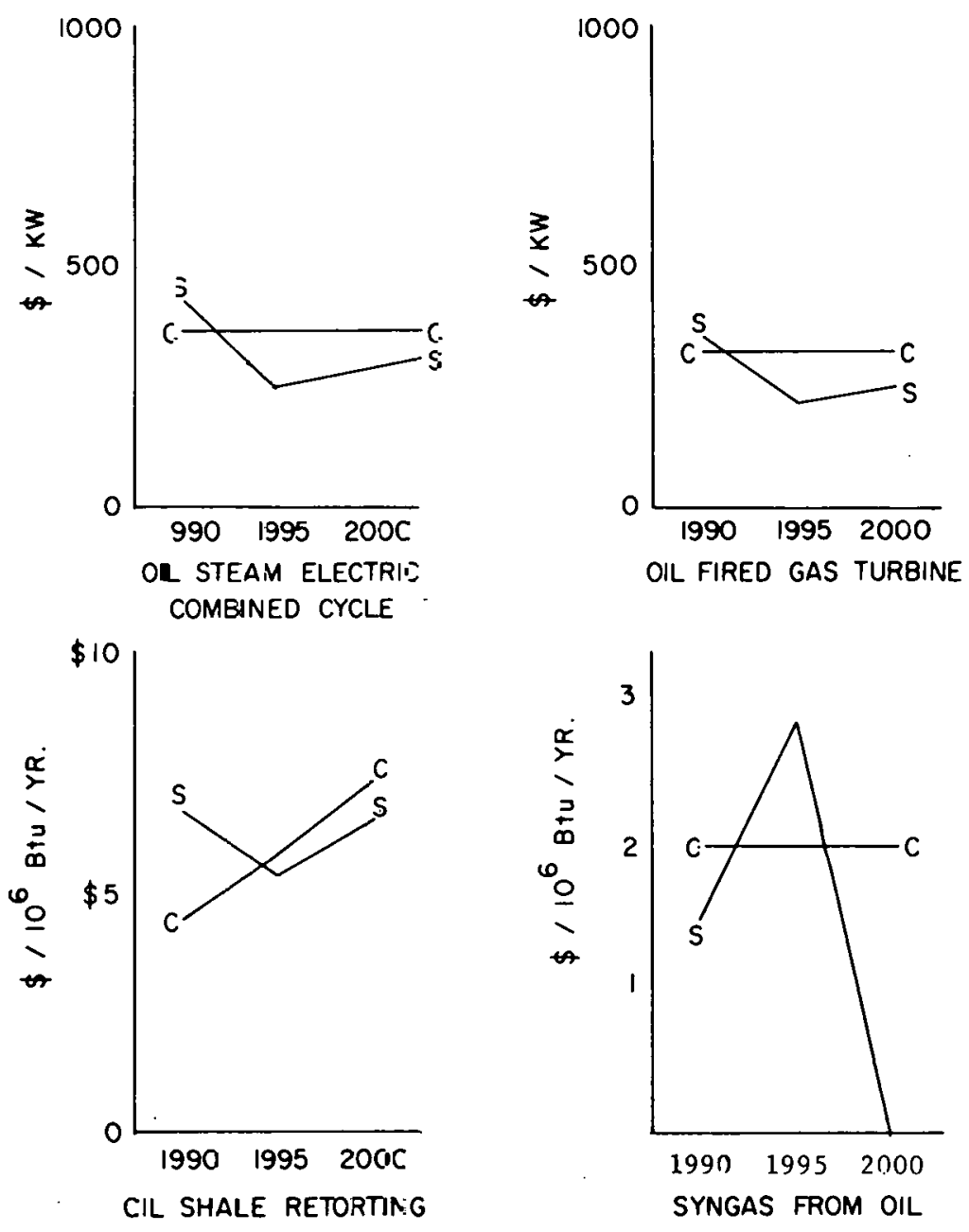

Eigure 19. Marginal supply technologies - shadow price vs. cost. 


\section{Undesirable Supply Technologies}

The remaining supply technologies are those whose shadow prices are lower than their costs in all periods. No new construction, even for replacement, is undertaken. These technologies are the related ones of electrolytic production of hydrogen with off peak electricity and fuel cells fueled by hydrogen. Shadow prices and costs for these technical options are shown in Figure 20. These shadow prices are of interest because they indicate the cost at which it will be desirable to build such capacity. Apparently, with the current set of inputs into the model, electrolysis is never attractive. Hydrogen fuel cells that are inherited are used for generating electricity, and they use hydrogen produced from coal. If some small amount of capacity built prior to 1985 had not been provided as inherited capacity, this technical alternative would not have been utilized.

Shadow Price 3 - Growth Limitations

These shadow prices are closely related to the "market clearing prices" for resources and the shadow prices for supply conversion technology capacity. The growth equations 

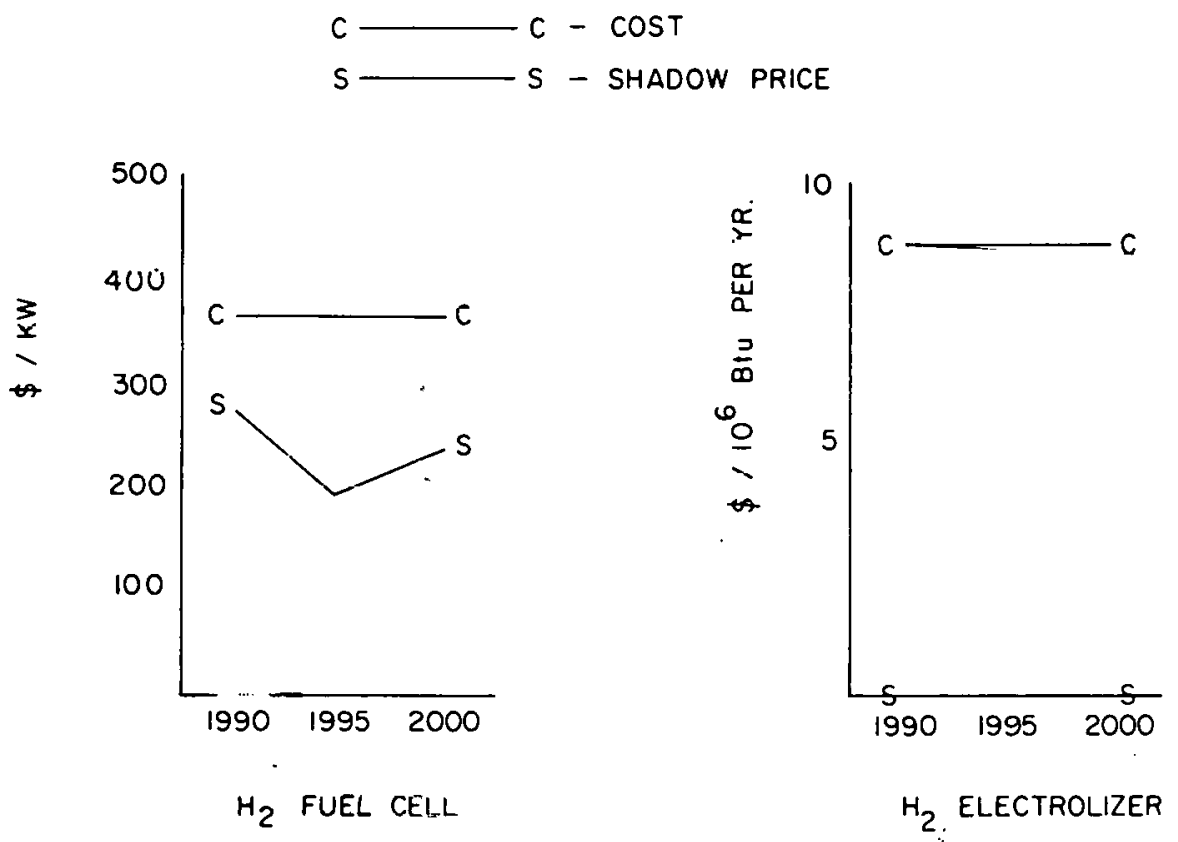

Figure 20. Unattractive supply technologies (shadow price vs. $\cos t$ ). 
are of the form:

$$
\begin{aligned}
& \text { Capacity } \\
& \text { in } t+1
\end{aligned}-\begin{aligned}
& \text { Capacity in } t \\
& \text { multiplied by } \\
& \text { Growth Factor }
\end{aligned} \leq 0
$$

Since the shadow price is the partial derivative of total cost with respect to the right hand side of the equation, this shadow price is very hard to interpret. If this constraint is binding and the associated dual

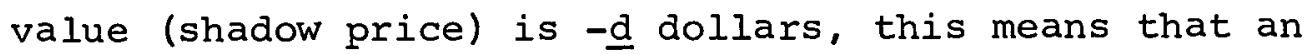
increase in the right hand side from 0 to 1 would decrease total system costs by d dollars. That increase might be accompanied by an increase in capacity in $t+1$, which would permit substitution of this resource or capacity for more expensive ones or by a decrease in the required resource or capacity in time to to support the $t+1$ level. A better interpretation is that the shadow price is indicative of the value of increasing the growth factor so that the capacity in $t+l$ can increase by one unit. I'nis interpretation relates shadow price to growth. The larger the shadow price, the more an increase in the growth rate will reduce system cost. Hence, examination of the shadow prices of growth provide indicators of energy technologies 
that might be considered as candidates for government support in order to accelerate their introduction. Growth shadow prices are presented in Table 23 .

\section{Resource Growth Limitations}

An examination of the growth shadow prices shows their close connection with the "market clearing price" for the resources and the shadow prices for supply capacities. For the resources, the high "markel clearing price" for gas is directly related to a high shadow price on the low growth rate specified for gas. Policy changes cannot increase this rate very much. The moderate shadow price on coal growth is reflected by moderate "market clearing prices." This is an area where the fairly low growth rates could be expanded if snriety is willing to suffer the environmental impact of increased coal use. The oil growth rate contributes a shadow price only in llie firet perino. Tlie uranium growth rate has a minor impact in only one period. Apparently the growth rate specified in the model is consistent with using up the total available uranium. Supply Technology Growth Limitations

The same pattern prevails as with the resources. The fossil electric and the peak electric sectors would like 
TABLE 23

SHADOW PRICES ON GROWTH

Upper Bound On

Growth Rate

$\% / 5$ Yrs.

Resources

Underground Coal

Surface Coal

Domestic Oil

Imported oil

siale Oil

Natural Gas

Uranium

Supply Technologies

Coal Stear Electric

CsE Combined Cycle

Oil Steam Electric

OSE Combined Cycle

Oil Fired Gas Turbine

Gas Steam Electric

Total Energy

LWR

LMFBR

HTGR

Hydroelectric

Geothermal

Solar

Pumped Storage

Refineries

Shale Oil Retorting Plant

SNG From Oil

SNG From coal

Hydzogen (Electrolysis)

MethanoI

Hydrogen (Coal)

Electrolytic Converters

Enrichment Plants

Fossil Fuel Cells

$\mathrm{H}_{2}$ Fuel Cells
11

28

0

115

6

50

22

173

$-12$

26

15

10

25

50

540

118

10

25

35

17

12

115

48

80

115

115

80

70

80

80
Shadow Price, $\$ / 10^{6} \mathrm{BTU}$

$1985-89$

$\underline{1990-94}$

$1995-99$

\section{.60}

.53

.50

.44$$
2.00
$$

9.84

5.57

1.68

.95

.82

$59 . \overline{9}$

13.13

12.75

15.60

24.94

26.26

13.51

1.13

1. 55

-

6.85

3.20

11.94

-
3.08
-
$.29 \quad .17$

.22 . 12

$.04 \quad .02$

-

.87

.01

-

.38

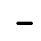

.04

-

$-$

$-$

94

.42

.05

1.18

7.02

7.38

1.98

-

$-$

.31

2. 90

-

18.23

3.62

-

$-$
4.45

-

.14

3.17

3.14

1.40

-

.95

-

5.26

.96

$-$

.16 
to grow more during the first period and fall off after that. Only coal electric seems to call for a possible policy change to increase the growth rate: The nuclear technologies are desired early but fall off rapidly. Total energy systems and renewable energy sources carry high shadow prices on their limited growth. Hydroelectricity Eannot grow much more rapidly although total energy systems and geuthermal steam could be speeded up. Faster solar growth, while desirable, is less attractive than geothermal or total energy systems.

The synthetic fuels produced from coal (methane, methanol, hydrogen) would like to grow much faster as evidenced by high shadow prices. Growth rates do not affect refineries, enrichment plants, electrolytic converters, or hydrogen fuel cells. Growth limitations have a minor impact upon the remaining technolugies.

\section{Shadow Price 4 - Demands}

This shadow price is the easiast to interpret and is directly related to the value of conservation measures. Since demand equatiuns àre cuuality constraints, all demand specifications are binding. A shadow price exists for 
each demand in each period. These are shown in Table 24. The demand equations are of the form

$\begin{aligned} & \text { Sum of outputs of all supply } \\ & \text { technologies } j \text { in time } \\ & \text { period } t \text { directed to } \\ & \text { demand } i\end{aligned}=\begin{aligned} & \text { Demand } \\ & \text { requirement } i \\ & \text { in period } t\end{aligned}$

The shadow price can be interpreted as the savings in system cost if the demand requirement in period $t$ is reduced by one unit. The shadow prices give a rough indication of the areas in which conservation activities will have the greatest payoff. However, they do not differentiate between fuels and are not helpful in identifying conservation measures that decrease dependence on insecure or scarce sources by substituting secure or abundant ones (e.g., electricity from coal as a gasoline substitute for ground transportation).

It is possible to generate the implied prices that users would pay for fuel for final demand from these numbers. Such calculations are presented in Table 25 for selected energy purchases. The prices are in current, not discounted, dollars at 1970 prices. 


\section{SHADOW PRICES OF DEMANDS} $\$ / 10^{6}$. BTUS

\begin{tabular}{|c|c|c|c|c|}
\hline Demand & 1985 & 1990 & 1995 & 2000 \\
\hline Process Heat & .46 & 7.10 & 1.10 & .86 \\
\hline Space Heat & 1.22 & 2.57 & 1.38 & 1.02 \\
\hline Water Heat - Cooking & 1.55 & 2.57 & 1.38 & 1.03 \\
\hline Air Conditioning & .82 & 3.74 & .90 & .72 \\
\hline Iron & .46 & .70 & .29 & .31 \\
\hline Fetrochemicals & .59 & 1.48 & .77 & .61 \\
\hline Air & 4.47 & 8.28 & 4.32 & 3.31 \\
\hline Truck, Bus, Rail & 7.08 & 9.48 & 4.82 & 3.46 \\
\hline Electrio Rajil. & 2.65 & 9.75 & 3.10 & 2.42 \\
\hline Auto & $\% .36$ & 0.19 & 5.00 & 3.63 \\
\hline Base Load Electric & 2.09 & 7.00 & 2.25 & 1.74 \\
\hline Intermediate Load Electric & 2.41 & 8.86 & 2.82 & 2.20 \\
\hline
\end{tabular}

IMDIII:I'L' PRICES FOR EMTRGY LURCHABES

\begin{tabular}{|c|c|c|c|c|}
\hline & 1990 & 1995 & $2 \underline{000}$ & $\underline{U H \perp L}$ \\
\hline Base Load Electric & 39 & 21 & 27 & mills/Kwhr \\
\hline Intermediate Load Electric & 50 & 26 & 43 & $"$ \\
\hline Electricity for Air conditioning & 63 & 25 & 33 & $"$ \\
\hline Eloctririty for space Heat & 23 & 20 & 24 & $"$ \\
\hline \#2 Fuel oil for space Heat & 41 & 36 & 44 & cents/gal \\
\hline Gas for Space Heat & 349 & 309 & 381 & cents/loujer ${ }^{3}$ \\
\hline Gasoline & 38 & 34 & 41 & cents/gal \\
\hline Jet Fuel & .37 & 32 & $4 \overline{2}$ & cents/gal \\
\hline
\end{tabular}


APPENDIX A

\author{
Analytical Methodology for Evaluating R\&D \\ in New Energy Tëchnologies
}

In order to evaluate an $R \& D$ funding proposal, it is necessary to explicitly state $R \& D$ expenditures, expected results, and the probability of achieving the desired results. Annual R\&D funding levels based on informed engineering and economic information for this strategy constitute the research cost.

Expected results from the R\&D are stated in terms of feasible annual capacity or output and cost of production for the new technology in future years. It is presumed that production costs include an adequate return on private capital invested in the new technology.' Because of the uncertainty involved in predicting production costs and/or output it is common for forccasters to present a range for their estimates. This uncertainty can be accommodated by postulating more than one possible result, each having its own output and cost estimates plus a probability of achieving that result.

Although estimates of production cost and capacity describe expected R\&D results, they do not say whether or not these results can be economically incorporated into the nation's energy 
system. It is here that a quantitative model of the national energy supply and utilization system, such as BESOM, becomes useful. Shadow prices generated from such a model can quickly indicate whether or not incorporation of each R\&D outcome into the energy system can be economically justified. The model also generates the dollar savings resulting from the new technology--the research benefit. Comparison of this benefit with research cost determines the economic.return expected from thc funding strategy. Additional benefits or costs may accrue that cannot be accounted for in dollars (e.g. extermalities).

BESOM is a linear programming model in which the total cost of satisfying a given set of national energy product requirements is minimized. Given a set of energy requirements defined by end use (i.e., motive power, space hoat, electricity) and a set of avạilable energy resources and conversion technologies, the model determines the minimum coct allocation of energy supplies to meet energy demands. For instance, it generates the annual coal and oil required by electric generating plants, the quantities of oil and electricity direster to space heat, and the refined oil/ electricity mix to mcet the demand for motive power.

Because of limited energy resources the model fruguently indicates that total system cost could be reduced if the supply of 
a certain resource was increased. In this instance a shadow price is generated for the constrained resource. This shadow price is the total cost reduction that would result from a unit increase in that resource's supply.

A shadow price can indicate whether or not a new technology can reduce total energy system cost in some future year. It is found by:

1) estimating the unit costs of energy supply/conversion activities for the new technology and inserting these costs into the objective function;

2) estimating alternative conversion parameters for the new technology and inserting these supply activities into the BESOM model technology matrix; and

3) inserting a capacity value equal to zero. If solution of the model results in a shadow price greater than zero for the new technology supply equation, introduction would be economically feasible. That is, it will pay to introduce new capacity because total. coot of meeting specified energy demands, including production costs of the new technology, will be reduced. 
Additional information can be extracted from the model. If one specifies the actual capacity of the new technology expected in a future year, total system cost reduction due to the new technology can be determined.

Annual reductions in total energy system cost (TC) from the introduction of a new technology are depicted in Figure A-l. Results' 1 and 2 indicate total system costs with the new technology assuming R\&D outcomes $\perp$ and 2 respectively. Result 3 shows total system cost without the technology, the base case. Because savings are spread over time they must be discounted to one point in time. Expected lenefit is ralculated by multiplying energy system savings under case 1 and rase 2 by the estimated probability of achieving each result, adding them together, and discounting to one point in time:

Eq. 1 Discounțed Expected Research Benefit,

$$
\begin{aligned}
& B_{t_{0}}= \sum_{t} \frac{\left[\left(T C_{3_{t}}-T C_{2}\right) \cdot p_{2}+\left(T C_{3}-T C_{1_{t}}\right) \cdot p_{1}\right]}{(1+r)^{t-t_{0}}} \\
& r=\text { discount rate } \\
& p_{1}+p_{2}+p_{3}=1.0
\end{aligned}
$$




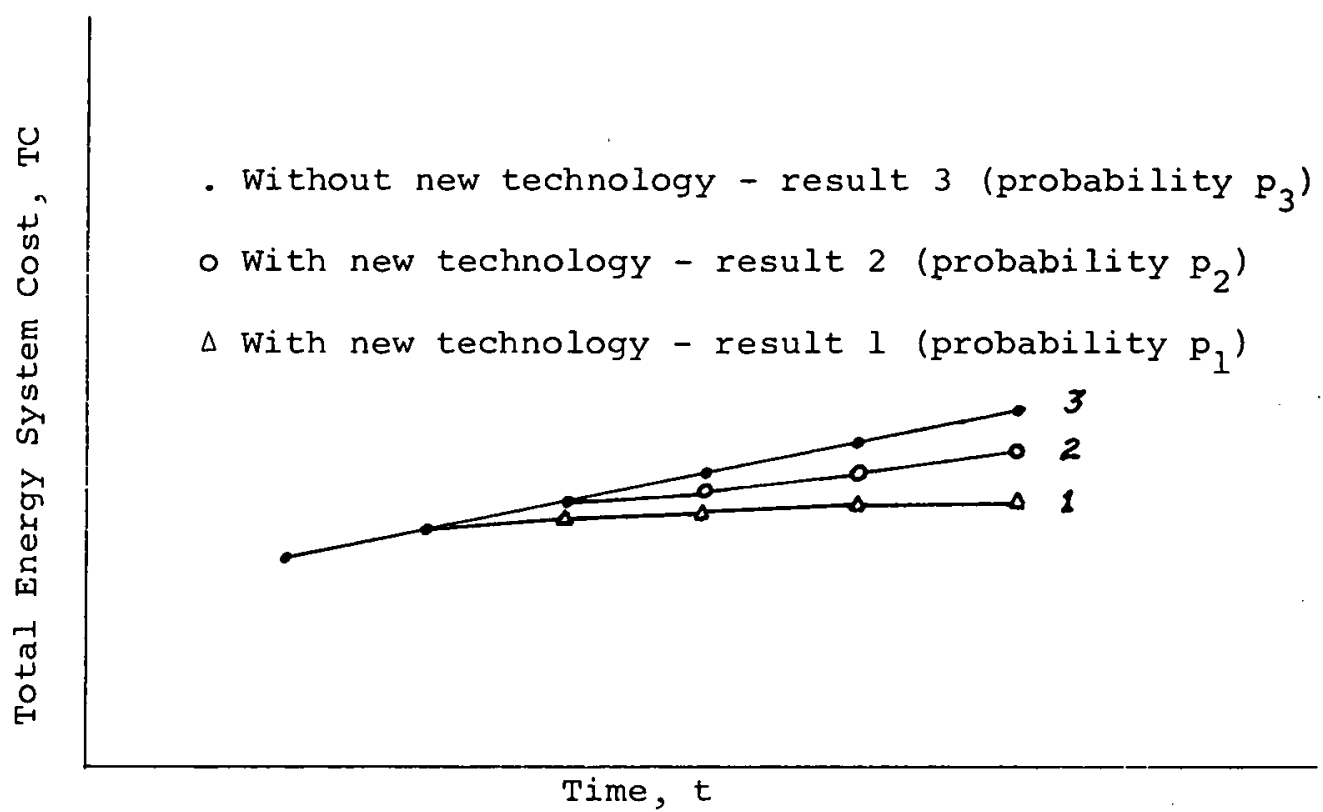

Figure A-1. Energy system benefit from a new technology. 
Optimization runs with BESOM are made for two future years, 1985 and 2000. Calculated annual savings for the technology analyzed in this report are listed in Table 2, Chapter III E for the years 1985 and 2000. They correspond to the numerator of equation 1 for these two years. Savings listed for other years between 1980 and 2000 have been estimated under the assumption that savings are exponentially distributed over time. Since production cosls under cases 1 and 2 include an adequate return on private investment in the new technology, expected benefit can be viewed as a return on the federal R\&D investment that produced the successful technology.

R\&D expenditures can also be discounted to the same point in time to facilitate comparison with expected benefits:

Eq. 2. Discounted Research rost, $E_{t_{0}}=\sum_{t} \frac{t}{(1+r)^{t-t_{0}}}$

If discounted benefit is greater than discounted expenditure, R\&D investment in the new technology can be justified on the basis of total energy system cost reduction. This is the general methodnlogy used in this report to evaluate an $R \& D$ funding strategy. 
Base cases for 1985 and 2000 are the same as those

utilized in Brookhaven's recent electrification study (4)

with the exception that available coal gas capacity is set

at zero. As such the base cases represent BNL's most probable estimates of the national energy system configuration for the years 1985 and 2000. Unlimited use of imported oil at a price of $\$ 6.17 /$ barrel in 1985 and $\$ 13.50 /$ barrel in $2000,^{1}$ is assumed in these estimates, and final demand projections have been appropriately reduced to reflect reasonable levels of conservation in response to recent energy price changes. When high Btu coal gas is introduced, the model is structured so as to allow its use in seven final demand categories: miscellaneous industrial thermal use, the petrochemical industry, space heat, water heat, air transport, truck and bus transport, and automobiles. Alternative fuels for these demands include imported and domestic oil and natural gas. Use of high Btu coal gas in electric power stations is not permitted in the model. A separate artivity, the combined cycle, is incorporated which uses low Btu coal gas in gas turbines with turbine exhaust fed through a waste heat recovery steam generator.

1. In constant 1970 dollars. 
THIS PAGE

\section{WAS INTENTIONALLY LEFT BLANK}




\section{APPENDIX B \\ Description of the Dynamic Energy system Optimization Model (DESOM)}

\section{Introduction}

This model is an extension of the Brookhaven Energy System Optimization Model (BESOM). BESOM is a static single period model that optimally (under minimum cost) meets a set of 22 postulated energy demands under 27 supply constraints upon available fuel supplies and electrical generating capabilities. BESOM has the capability of generating a vector of twenty two environmental emissions. Alternatively, total permissible emission levels can be imposed as constraints.

Each possible supply demand relationship is representative of an energy technology. Hence, the model is capable of representing virtually all existing, under development, and potential . energy technologies. Because BESOM is static, it is directed toward generating oplimal fuel mixes within single period constraints on supplies and capital availability. The dynamic version extends this capability of optimizing single period fuel mixes to optimizing multiperiod mixeo. This leads to time phased flows of resource use and of the creation and phasing out of energy capital. The shadow prices associated with scarce resources and capital availability in each period are useful indicators of 
preferred rates of resource use, rate of introduction of new technologies, and the timing of capital investment. These indicators can be useful to policy makers who can affect the prices or the availabilities of resources or capital.

\section{Model Description}

\section{Reference Energy System}

The model is based upon a representation of the energy system developed at Brookliaven National luaburatery, dalled tho Reference Energy system (REs).* This is basically a flow chart that traces all of the possible paths through which a BTU, as an energy source, can find its waỳ to an encrgy demand. Figure B-l is a typical energy reference system. Each possible path is called a trajectory. An example of such a trajectory would be strip mined coal to a coal gasification plant to a pipeline to residential dcmand' for space heat. For each trajectory an intermedlate tiuergy roum is definer. This establishes the point in the trajectory at which energy flow is measured. The intermediate energy form is generally defined as a BTU of ellergy input into a

* Reference Energy Systems are described in "Refereluce Encrgy Systems and Resource Data for Use in the Assessment of Energy Technologios," Aasociated Universities, Inc. report No. AET-8 (April 1974 rev.). 
demand conversion device. Hence, energy flow though each trajectory has associated with it a demand efficiency and a supply efficiency. The demand efficiency depicts energy loss in the demand conversion device (e.g. air conditioner, automobile). The supply efficiency depicts energy loss from the point of extraction to the point where the intermediate energy form is defined.

\section{BESOM - Intermediate Energy Flow.S}

Figure $\mathrm{B}-2$ is a matrix representation of the supply and demand categories used in the current version of BESOM. The column headings identify the demand categories that are also seen in Figure B-1. There are 22 identifiable demand categories. The row headings consist of 27 supply categories, comparable to but arranged somewhat differently than those in the RES. Intersections in the matrix represent intermediate energy flows. Each is a variable in both the static and dynamic models, and will henceforth be referred to as $X(J, L, T)$, where $J$ is the supply category, $I$ is the demand categnry, and $T$ is the time period. A new index can be defined, $f=22(\mathrm{~J}-1)+L$, in which $f$ is the number of the cell in Figure B-2. Examples of $X^{\prime}$ 's are oil products to space heat, gas to space heat and nuclear electricity to space heat. 
Other examples of X's are oil generated electricity to process heat, and electricity from fuel cells fueled by methane made from coal to peak electricity demand. The static model has a single cost assigned to each intermediate energy flow, $x$, representing annualized capital costs, fuel costs, operating costs and other costs including distribution and transportation. In the dynamic model the cost assigned to each $\mathrm{x}$ is exclusive of capital and fuel custs. The onst associated with the X's are in 1970 dollars in both models but in the dynamic version the cost in each time period may be different.

\section{Resource Variables}

Figures $B-3$ to $B .-8$ give another representation of the reference energy system and the paths that energy can take from the basic resources to final demand. Each box in this figure is reprceanter by variables in the model. At the extreme left in these figures are the basic resources - coal, oil, yas and nuclear = that arise in the extractive industries. These are the $\mathrm{Z}$ (I, T) variables, where I denotes the resourco and $T$ the time period. Unlike the $\mathrm{x}$ variables which are intratemporal, the $\mathrm{z}$ variables also have intertemporal relationships associated with them. For example, the use of oil over all perfods must be less than some constraint. Further, the amount that can be extracted in any 
period is a function of the amount extracted in the previous period. A basic fuel cost is associated with each $Z(I, T)$. This fuel cost can vary for each time period.

\section{Capacity Variables}

The boxes that remain in Figures $B-3$ to $B-8$ after removing the resource supply and final demand categories represent chemical or electrical conversion processes. Each of these consists of a conversion process or device requiring capital investment. The capacity of these conversion processes is characterized in the model by a third set of variables, $Y(K, T)$ where $\mathrm{K}$ denotes the conversion process and $\mathrm{T}$ the time period. These are defined in most cases in terms of BTUs of output per year. Like the resource supply variables these are intertemporal. For each conversion process we assume that we start with a given stock of capital (capacity). Over time, some of this capacity is retired and new capacity is installed to meet the energy requirements for each period. Hence, the new capacity installed in a given period is a function of thc values taken on by the intermediate energy flows in the period. On the other hand, the total amount of capacity that can be installed is limited to some constant multiple (generally $>1$ ) of the capacity in place in 
the previous period. A cost in 1970 dollars is associated with each unit of capacity and may vary with the time period. Inputs

The inputs necessary to drive the model are closely related to the policy variables to be studied. Energy demand requirements for each demand category in each future time period are reyuired. These can be used to reflect alternative conservation policies or assumptions concerning life style changes. Total resource availability by supply category for the entire period also must be stated. These values reflect assessments of the available supply of scaree fuels at given supply prices. These inputs can also be used to simulate policies affecting fuel supplies, e.g. limitations on the amount of oil imported, expanston of the Alaskan pipeline, or nuclear stimulation of natural gaэ.

Another set of inputs is the current eapaoities (existing capital) for the energy conversion processes. The rate at which they wear out, their permissible upper limit on growth and the Lust of the new capacity are also stated. The capital stock and its depreciation rate are historical givens but the permissible growth rate can be used to represent puliaiea that may encourage 
or restrict capacity growth for specific energy products, e.g. shale oil, gas from coal. Growth rates are also supplied for the extraction and supply of the basic fuels.* Capital constraints can be introduced for any time period, directly limiting additional capacity expansion in particular sectors or across all investment possibilities.

Another set of inputs are the supply efficiencies, demand efficiencies, and costs associated with each intermediate energy flow. These inputs define the detailed technology based structure which is unique to the Brookhaven energy models. These inputs describing current and potential energy conversion technology are the means by which the timing and impact of the introduction of new technology is incorporated in the model framework. By simulating technological development in terms of what conversion technology may become available at different points in time, how efficient the process will be and how much it will cost, the overall optimization model can evaluate the impact of the introduction upon the entire energy structure.

* In the current version of the model the upper bound on output of the extractive sectors is based upon the previous periods output and not upon new capital investment. The cost is an average cost that includes an annualized return on capital. An improved version of the model could break out the capital investment in extractive industries and make output a function of investment. 
Another set of inputs necessary only if environmental

questions are to be studied consists of the emission coefficients associated with each conversion process for each fuel.

\section{Objective coefficients}

The coefficients of the objective function are the costs associated with the variables. Cost assigned to the basic fuel variables are the cost in $\$ / 10^{6}$ BTU extracted from the ground.* In the present version of the model this coet in 1970 dollars is increased in later time periods to reflect increasing extraction costs as more accessible resources are depleted. In later versions several supply quantities will bo represented, each providing additional units of the scarce resource at a higher cost. This is a better representation of increasing supply price. costs assiyned to the rapacity variables are in $\$ / 10^{6}$ BTU per year of output.** The actual capacity emplaced exceeds the diliunt produch by a load factor that alluws for downtime. These costs are accrued in the time period in which the capacity is emplaced.

\footnotetext{
* For Uranium the costs are in $\$ 10^{9} / 10^{3}$ sliut tonc of $\pi_{3} \Omega_{8}$.

* * For enrichment plants they arc in $\$ 10^{9} / 10^{6} \mathrm{~kg} \mathrm{swU}$. For retineries and sylusure conversion they are for BTUs of input, not output.
} 
Costs assigned to the intermediate energy forms are in $\$ / 10^{6}$ BTU of flow. These costs include operating costs for the conversion facilities plus transportation and distribution costs.

All costs are in 1970 dollars. The costs are discounted back to the mid-point of the first period. The discount factor is applied to the total cost for any subsequent period and applied at the mid-point of that period. The model is initially being run with a discount rate of $10 \%$ per year. However, this is one of the parameters that may be varied as a policy parameter. 


\section{Model Structure}

In this section, we shall describe in detail the eight classes of general constraints which we use in the model. Additionally, a brief description of the other constraints in the model and the structure of the linear program are presented. The variables in this model can be broken down into the following three groups:

- $\dot{x}(j, l, t)=$ anomnt of energy flow in time period

$t$ from supply category $j$ to meet energy demand $\ell$.

- $y(k, t)=$ capacity/year to be built in time period $t$ for conversion process $k$.

- $z(i, t)=$ amount of resource $i$ to be used in time period $t$.

The inputs to the model are:

- $D(\psi, t)=$ demand requirements for category $\ell$ in time period $t$ in $1015 \mathrm{BTU}$.

- $R(i)=$ total available stock of resource $i$ in 1015 BTU : *

- $s(k, t) .=$ the inherited capacity (capital stock) for conversion process $k$ in time period $t$ measured in $10^{15}$ BuU uf rnpacity/year.**

- $E(m, t)=$ maximum permissible quantity of emissions of type $m$ in time period $t$.

* Except for uranium which is measured in $10^{3}$ tons $\mathrm{U}_{3} \mathrm{O}_{8}$.

**Except for uranium enrichment which is measured in $10^{6} \mathrm{~kg} \mathrm{sWU} / \mathrm{y}$ 
- $s(i, j, l)=$ supply coefficients representing the technical efficiency of a conversion technology for some intermediate energy flow of resource $i$ from supply category $j$ to demand category $\ell$.

- $e(j, l, m)=$ amount of emission of type $m$ for intermediate energy flow from supply category $j$ to demand category $\ell$.

- $\mathrm{d}(j, l)=$ demand coefficients representing the technical efficiency of a conversion technology for some intermediate energy flow from supply category $j$ to meet energy demand $\ell$.

- $C_{X}(j, l, t)=\cos t / 10^{15}$ BTU for the intermediate energy flow $x(j, l, t)$.

- $C_{y}(k, t)=\cos t / 10^{15}$ BTU per year of capacity to be built in time period $t$ for conversion process $\mathrm{k}$.

- $C_{z}(i, t)=\cos t / 10^{15} \mathrm{BTU}$ for resource $i$ in time period $t$.

- $\mathrm{p}(\mathrm{k})=$ lifetime of conversion process $\mathrm{k}$.

- $r(j, l)=$ load factor for intermediate energy flow from supply category $j$ to demand category $\ell$.

- $\mathrm{g}(\mathrm{k})=$ proportion of time a unit of capacity of type $k$ can be operated during the year. 
As can be noted from the above notation, the subscripts mean the following.

- $i$ = basic fuel supply or resource type

- $j=$ supply category (row heading, Fig. B-2)

- $\mathrm{k}=$ energy conversion process

- $\ell=$ demand category (column heading, Fig. B-2)

- $m=$ emission type

- $\mathrm{n}=$ length of the time period

- $t=$ time period index

- $\rho=$ discount rate

The objective of this linear program is to minimize total cost; i.e.,

$$
\begin{aligned}
\operatorname{Min} T & =\sum_{j, l, t} c_{X}(j, l, t) x(j, l, t) /(1+p)^{t} \\
& +\sum_{k, t} c_{y}(k, t) Y(k, t) /(1+p)^{t} \\
& +\sum_{i, t} c_{z}(i, t) z(i, t) /(1+p)^{t}
\end{aligned}
$$

'the yeneral constraints in our model carl be broken down into two groups - the interperiod constraints which join together the time periods and the intraperiod constraints which represent conditions within a time period. The interperind constraints are 
the following:

$$
\sum_{g=t-p}^{t} Y(k, g)+s(k, t)
$$

This equation says that the new capacity of type $k$ to be emplaced in time period $t$ plus the inherited capacity from previous time periods (left hand side of equation (2) must not exceed the total capacity available in time period $t-1$ times a growth factor $\alpha$ (generally $\alpha$ is greater than 1 which implies that installed capacity may expand in time period $t$. If $\alpha<1$, the installed capacity will decrease in time period t.)

$$
\frac{1}{n} \cdot \sum_{j, l} \frac{1}{r(j, l)} x(j, l, t) \leq s(k, t)+\sum_{g=t-p}^{t} Y(k, g)
$$

The right hand side of (3) is the amount of installed capacity in time period $t$. The left hand side determines the amount of installed capacity required in time period $t$ to deliver $x(j, l, t)$. Thus (3) says that the amount of installed capacity to be available in time period $t$ must be sufficient to produce the

* $\mathrm{X}(j, 1, t)$ variables representing off peak usage do not appear in this equation. 
intermediate energy forms utilizing capacity for this conversion process in time period $t$. Capacity is required to meet both base and peak demands in the electrical sectors. Off-peak electrical intermediate energy flows that use capacity installed for peak requirements are not included in this constraint. This is a very important consideration if storage technologies using peak capacity off-peak for storage batteries or producing hydrogen are to be included as potential energy strategies.

$$
\frac{1}{n} \sum_{j, l} x(j, l, t) \leq q(k)\left[s(k, t)+\sum_{g=t-p} Y(k, g)\right]
$$

In (4) the total amount of sapacity available in time period $t$ must be sufficient to produce the intermediate energy flows for base load, peak, and storage demands. $q(k)$ is an overall load factor applied to all electrical capacity saying that a conversion facility of type $k$ can only operate $q(k)$ proportion of the time. Equation set (4) applies only to electricity conversion processes.

$$
\underline{R}_{i} \leq \sum_{t} \eta_{i}(i, t) \leq \bar{R}_{j}
$$

For resource $i$, the total amount to he extracted over the time horizon of the model must lie between lower and upper limits. The lower limit assures some minimum consumption. The upper limit is representative of real world resource capacity.

$$
z(i, t) \leq B(i, t) \quad Z(i, t-1)
$$


The amount of resource $i$ to be extracted in time period $t$ is no greater than a constant $B(i, t)$ : times the amount of resource $i$ to be extracted in time period $t-1$. Generally $B(i, t)$ is greater than 1. To phase out a resource over time, however, we can set $B(i, t) \leq 1$ for $t$ in the later time periods.

The intraperiod constraints are equations 7,8 , and 9. These constraints are, for the most part, extracted from the BESOM model.

$$
\sum_{j} d(j, l) x(j, l, t)=D(l, t)
$$

(7) says that the amount of energy from intermediate energy flows $x(j, l, t)$ must be sufficient to meet demands $D(l, t)$ for each demand category in time period $t$.

$$
\sum_{j, l} s(i, j, l) \quad x(j, l, t)=z(i, t)
$$

Constraint ( 8 ) says that the intermediate energy flows $x(i, l, t)$ in time period $t$ give rise to a demand for resource $i$ which must be met.

$$
\sum_{j, l} e(j, l, m) x(j, l, t) \leq E(m, t)
$$

for all $\mathrm{m}$ and $t$. The intermediate energy flows $x(j, l, t)$. give rise to emissions of type $\mathrm{m}$. This constraint says the total emissions of each type cannot exceed some upper bound in each time period. 
In addition to the eight classes of constraints above a number of other. less general constraints are incorporated in the model. For brevity these are not included here in equation form. Among these are two sets of equations that model the electric power load duration curves. One of these addresses daily peaks and the other seasonal patterns. Other equations are used to provide constraints that take into account inherited stocks of cnd use conversion devices. Still other sets of equatluns model the nuclcar sector which generates some of its swn fuel (Pu and $\mathrm{U}-233$ ) as a joint product and alsu generates an endogenous demand for eleclricity fui enrishment.

The model without the environmental constraints has about 130 rows (constraint) and 750 variables per time period. It takes about one half hour on the IBM 370-155 to solve a four period problem. However, once a basic solution has been found it can be stored and subsequent runs with different data can be started by entering the stored basic solution. This reduces running time in many rascc and permite one to perform parametric studies at little cost.

\section{Model Application}

A standard base case is being developed. This case will cover the 100 year period from 1973 to 2073. It will consist of six rive-year periods providing considerable detail to the turn of the century; three ten-year periods to permit large scale introduction of fusion and solar technologies and two twenty-year periods to minimize problems caused by truncation. 
The base case will include the introduction in the late 70 's and early 80's of various coal conversion processes and oil from shale. Realistic upper bounds will be placed on total supply from these sources. Total oil imports will be limited to some maximum amount in any time period. Total available uranium, domestic oil, and domestic gas will be specified at each of several rising supply prices. Geothermal and hydroelectric will be allowed to grow but only to realistic upper bounds. Fusion and solar technologies will become available late in the 20 th century and the breeder introduced in the late 1980's will be replaced with an advanced breeder at about the turn of the century. Technological alternatives will be specified that will allow ground transportation to be supplied by hydrogen and electric alternatives. Both of these would be fueled by storing electricity produced with off peak capacity. Given this base case, we will be able to examine virtually any energy policy scenario. If an R\&D policy maker wishes to know the impact of increased R\&D funding leading to earlier introduction, greater technical efficiency or lower cost, the model can supply an answer.

A policy that would call for reduced inputs can be examined. Estimates could be made of the cost of such a program. Changes in fuel $\mathrm{mix}$, rate of growth of alternative energy sources and time phased substitution of fuels would be generated for comparison of alternative scenarios. 
Other scenarios can be studied. In fact, any change in energy conversion, efficiencies, costs, rate of introduction of new capital or interest rates would lend itself to analysis. Finally, the way the system is being implemented, alternate base cases can be created which would allow for different numbers of periods to be run, periods of shorter and/or longer duration and aggregation of resource and/or intermediate energy forms. Tlus, finer analyses in early time periods can be attempted ur grossly agyregated runs can be made. Approximately 60 time periods can be run without exceeding the problem size which the computer algorithm can handle. 


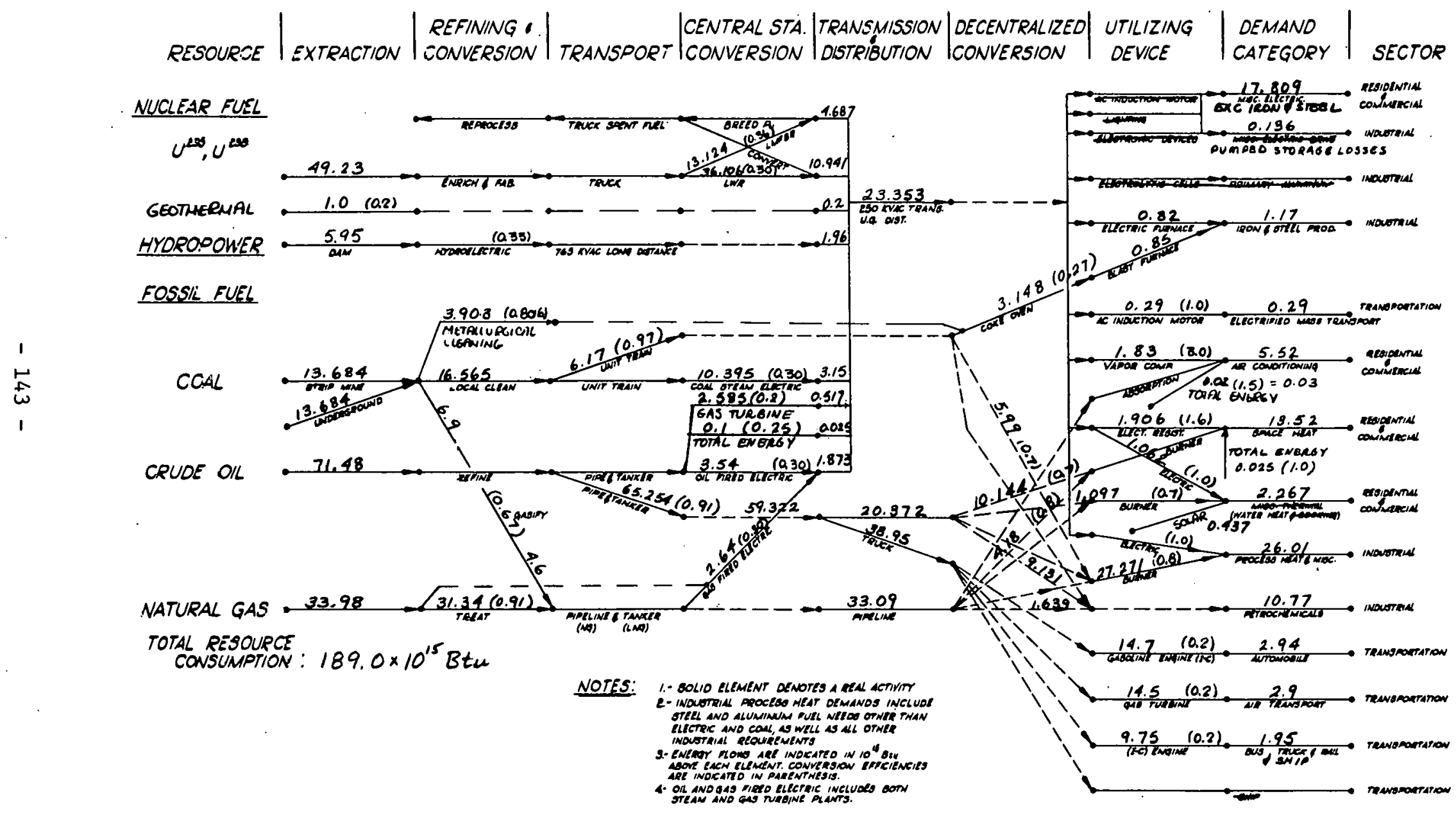

Figure B-1. Reference energy system, year 2000. 


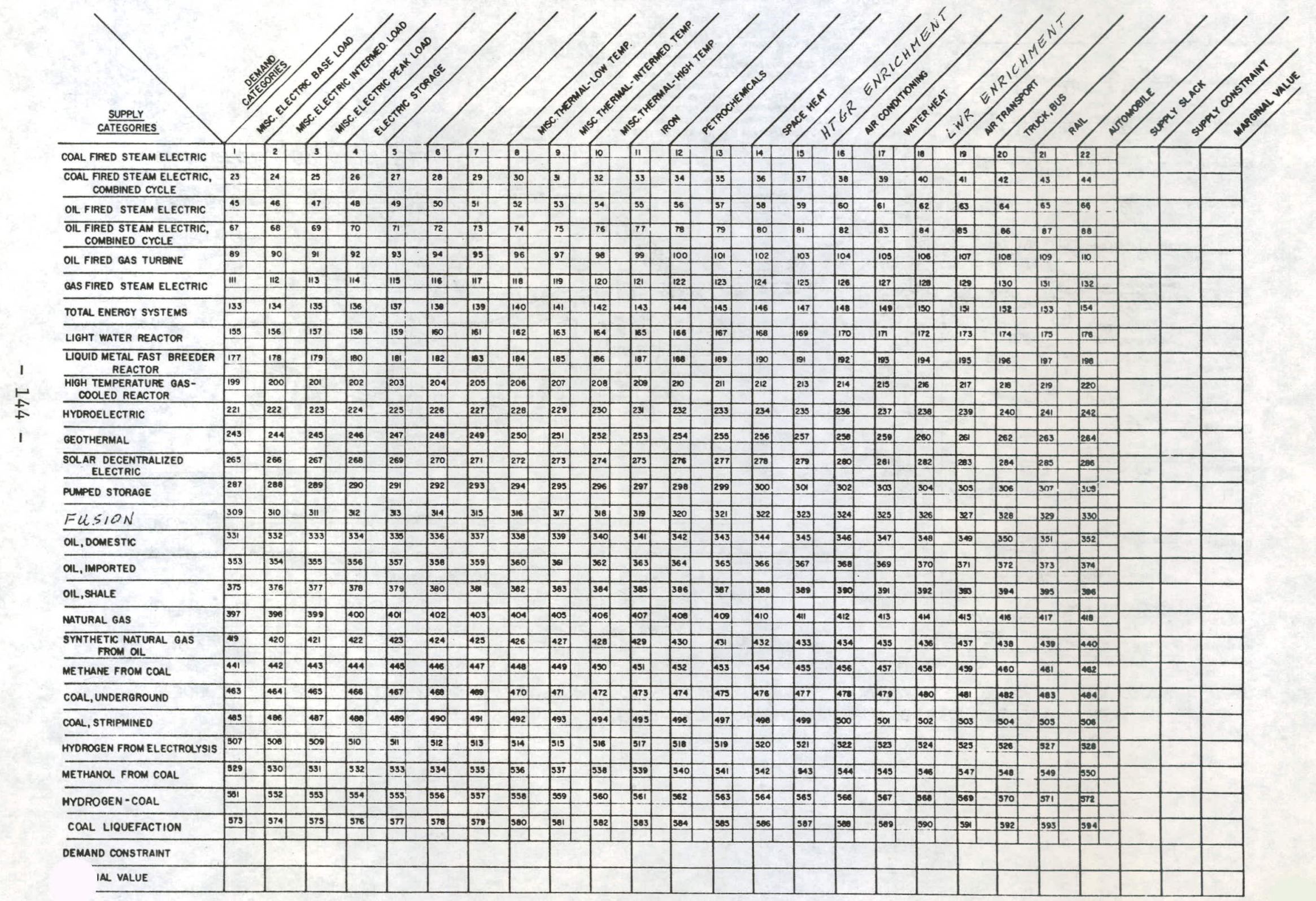

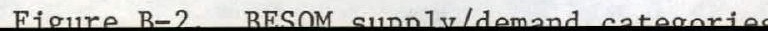




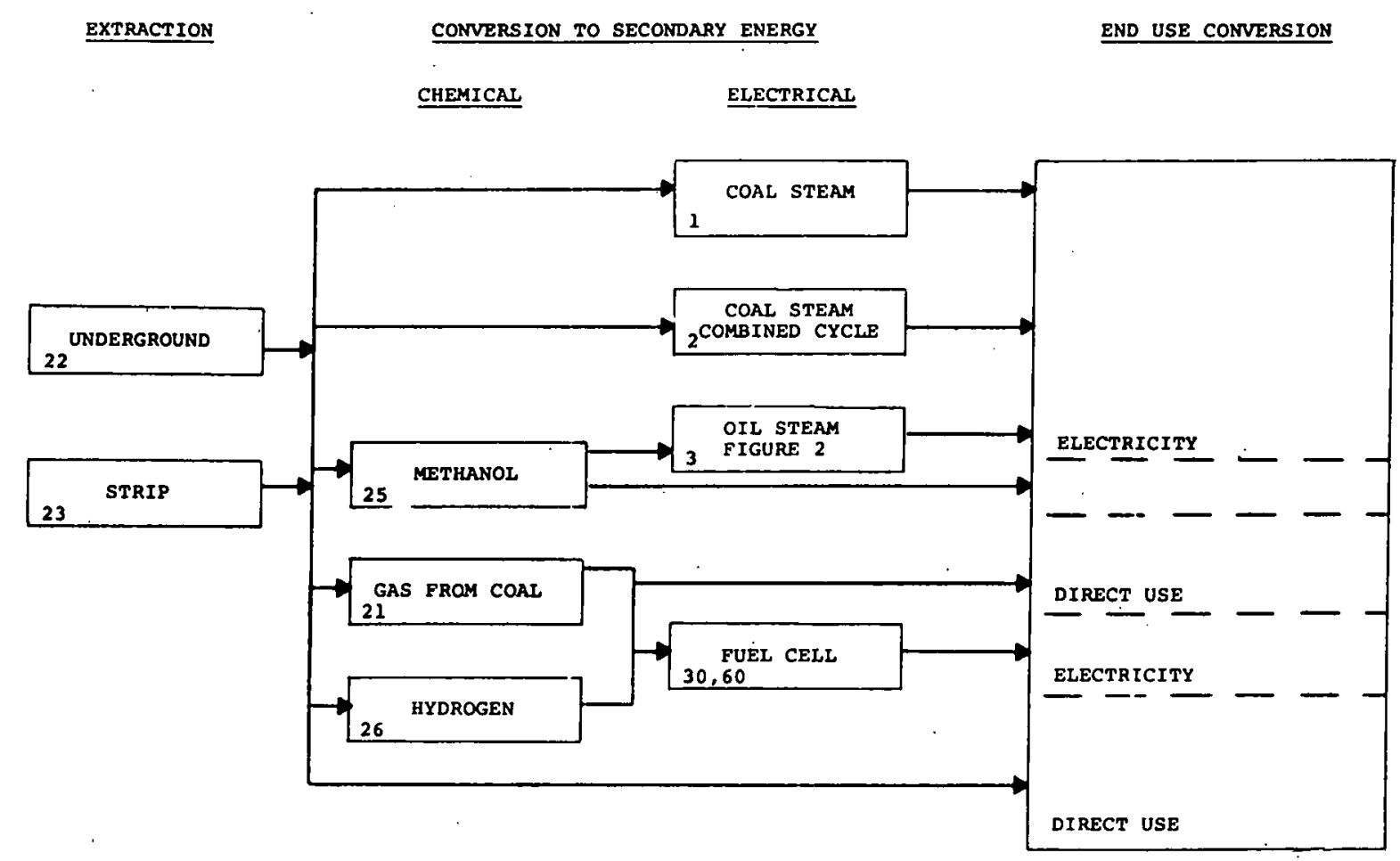

Figure B-3. Coal Sector.

\section{EXTRACTION}

CONVERSION TO SECONDARY ENERGY

END USE DEVICES CHEMICAL

ELECTRICAL

METHANOL

FROM FIG. 1
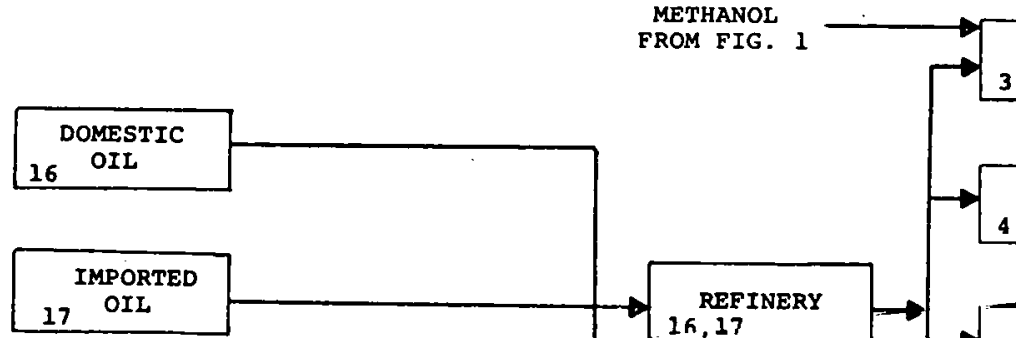

\section{OTI STEAM}

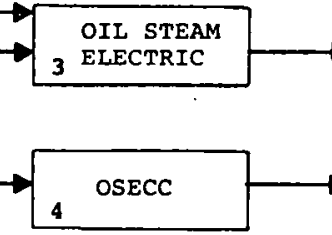

17 OIL

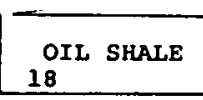

18

SYNCRUDE
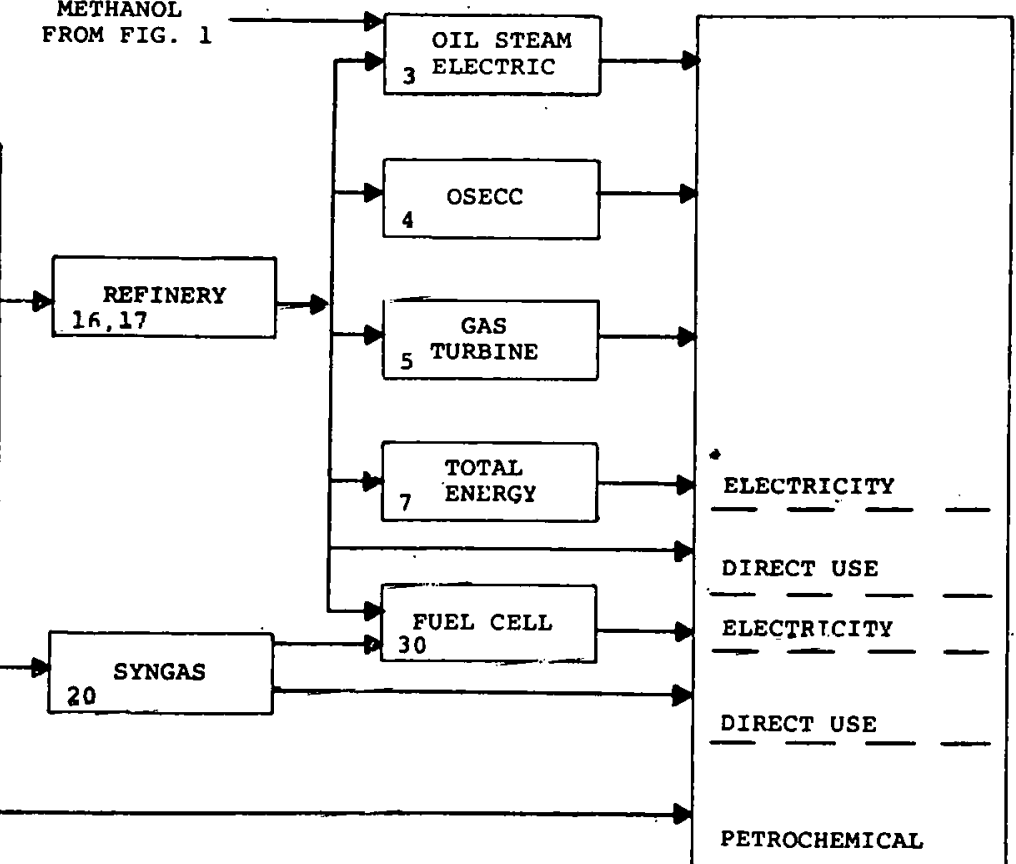

Figure B-4. $0 i l$ sector. 


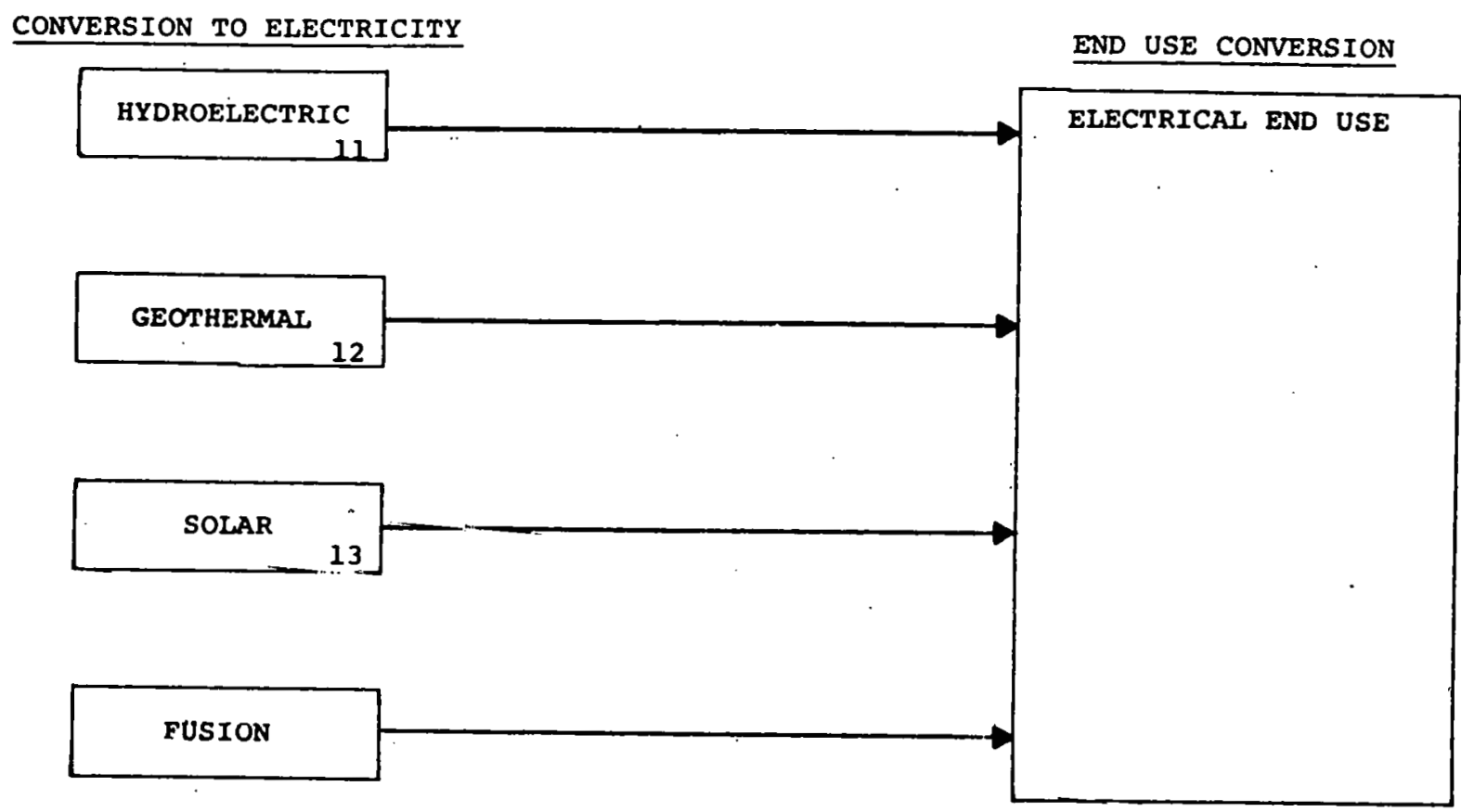

Figure B-5. Renowable energy sector.

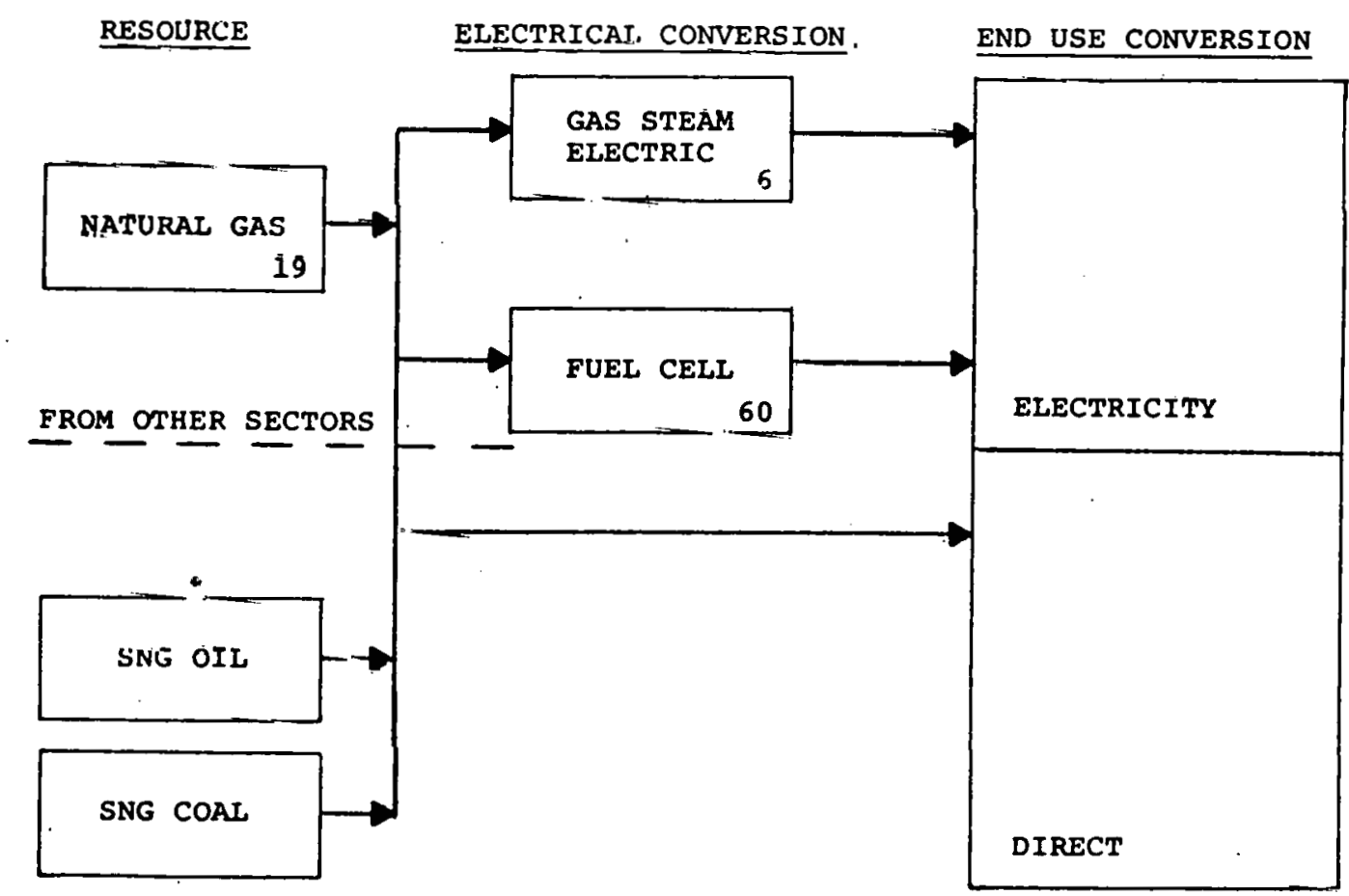

Figure B-6. Natural gas sector. 
STORAGE SOURCE

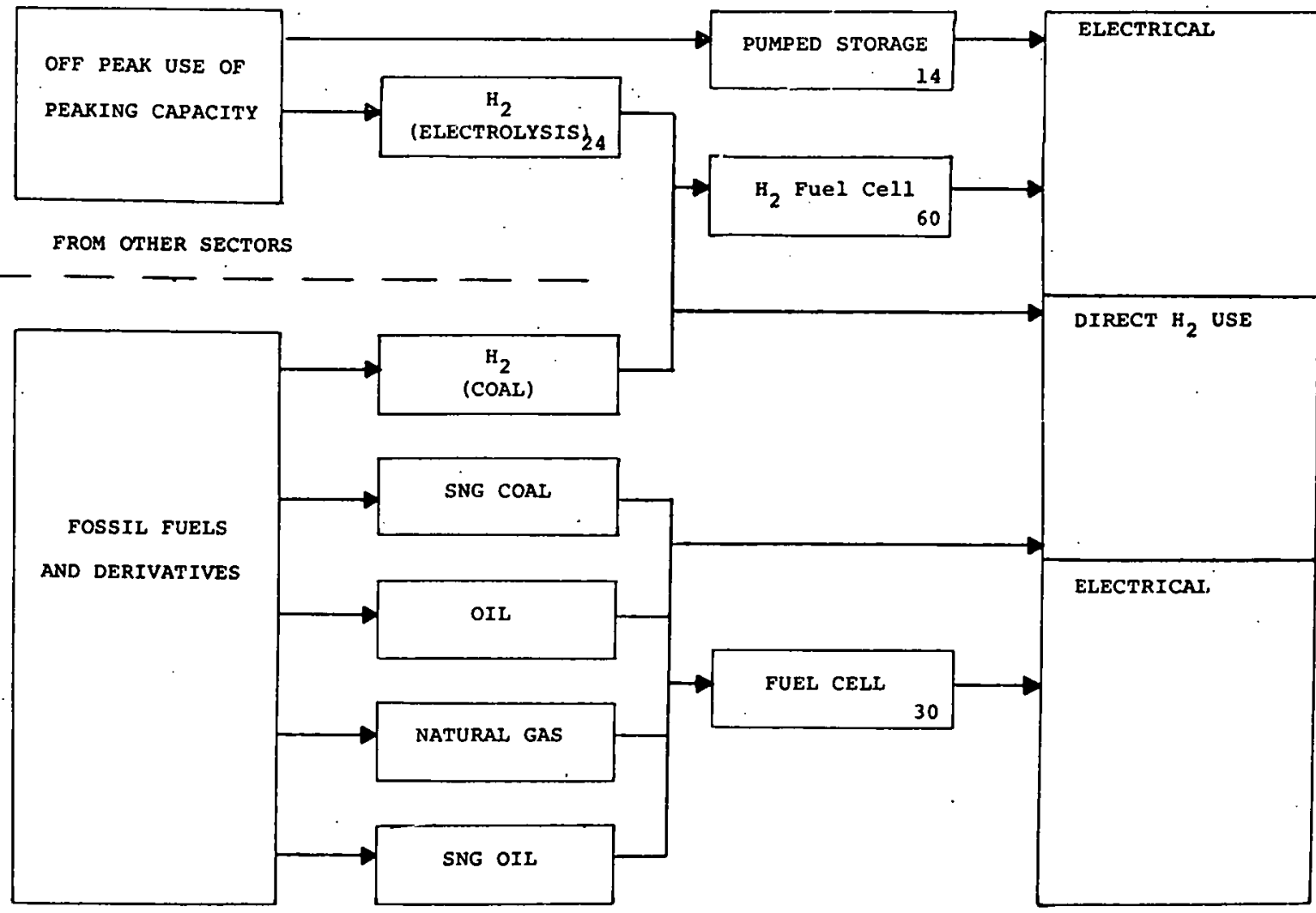

Figure B-7. Electrical storage sector.

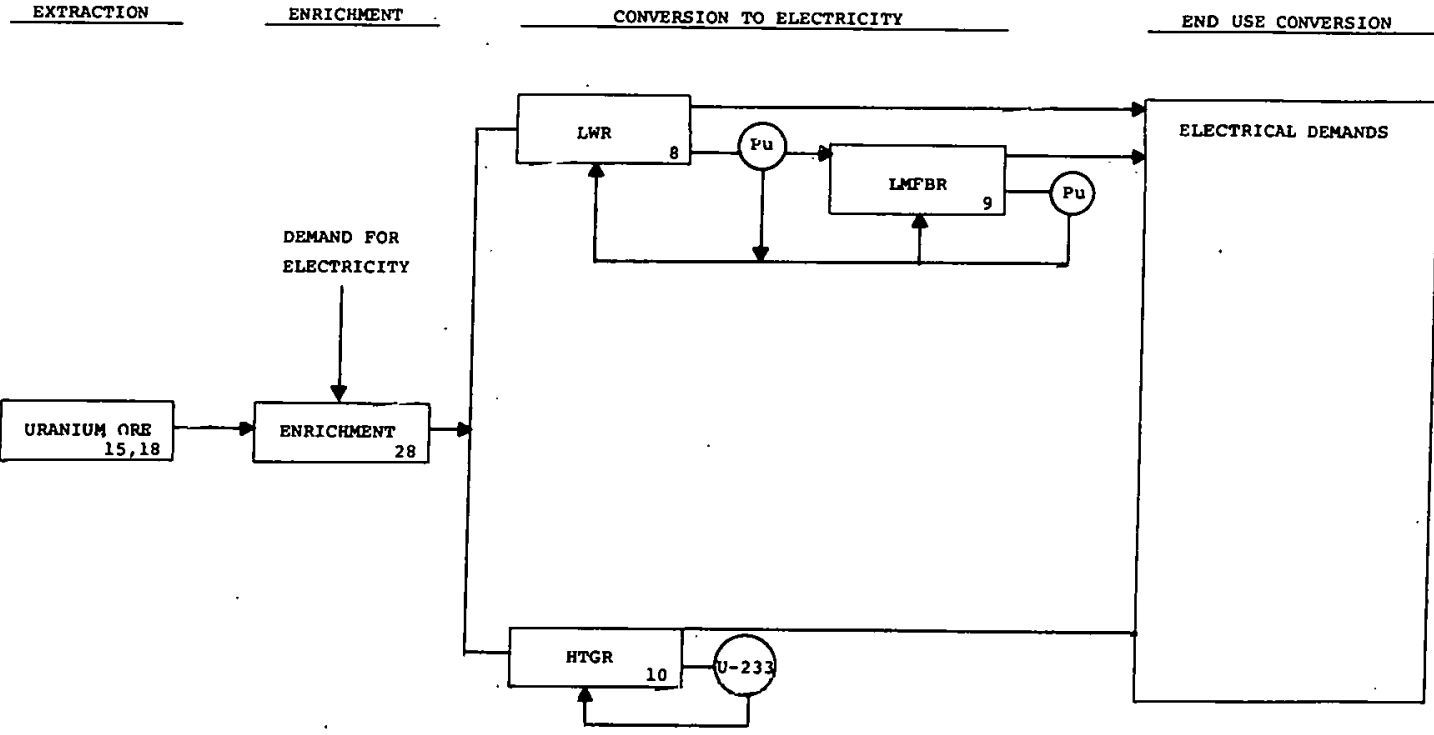

Figure B-8. Nuclear sector. 


\section{REFERENCES}

1. Nordhaus, William D., "The 1974 Report of the President's Council of Economic Advisers: Energy in the Economic Report," American Economic Review (Sept. 1974).

2. "A Study to Assess the Application of Shadow Pricing Techniques to National Energy Resource Planning," Research Proposal Submitted to NSF-RANN by Brookhaven National Laboratory and State University of New York at Stony Brook (Nov. 1973).

3. "A. Guide to Optimal. Energy Resource Development - Second Year Activity, NSF Grant AG-501," Research Proposal SubmitteA to NSF-RANN by Brookhaven National Laboratory and State University of bew York at Stony Brook (Mar. 1975).

4. BotlHL, M., E.A. Cherniavsky, K.C. Hoffman, and R.H. Williamson, "Interfuel Substitution Study - The Role of Electrification," Brooklavon National Laboratory Peport \#BNL 19522 (ESAG-17), (Nov. 1974).

5. "The Nation's. Energy Future," U.S. Atomic Energy Commission, WASH-1281, (Dec. 1, 1973).

6. Statistical Abstract of the United States, 1974, U.S. Departement. of Commerce.

7. Perry, H., "Coal Conversion Technology," Shemical Fuginefing (july 22, 1974).

8. U.S. Energy Outlouk, a Report of lho Nitional Petrolem Council's Committee on U.S. Energy Outinok (DeC. 1972).

9. Cherniavsky, E1lon A., "Brookhaven Energy System Optimization Model," Brookhaveir National Laboratory Report HBNL 19569.

10. Report of the Hearing Panel, National Public Hearings on Power Plant Compliance with Sulfur Oxide Air Pollution Regulations, U.S. Environmental Protection Agency, Washington, D.C. (January 1974).

1.1. Reference Energy Systems and Resource Data for Use in the Assessment of Energy Technologies, AET-8, Brookhaven National Laboratory, Associated Universities, Inc., (April 1974 (rev)). 
12. Undated Cost Tables for Expanded LP Mode1, ESAG-16, Brookhaven National Laboratory, Associated Universities, Inc., (April 1974).

13. Mudge, L.K., et al., The Gasification of Coal, Pacific Northwest Laboratories; (July 1974).

14. Just, James E., Impacts of New Energy Technology Using Generalized Input-Output Analysis, Massachusetts Institute of Technology Doctoral Dissertation, (January 1973, p. 205-211).

15. U.S. Energy Outlook, Vol. II, National Petroleum Council, (November 1971, p. 165).

16. Bechtel Corp., path to Self-Sufficiency: Directions and Constraints, Final Report-Phase $I$, Appendices, (August 1974).

17. The Policy Study Group of the MIT Energy Laboratory, "Energy Self-Sufficiency: An Economic Evaluation," Technology Review (May 1974).

18. Golan, Simcha, and R。 Salmon, "Nuclear Fuel Logistics," Nuclear News (February 1973).

19. Solow, Robert M., "The Economics of Resources or the Resources of Economics," American Economic Review

(May 1974). 